\title{
DOE/ID/13230-T.T3
}

\section{ADVANCED LOST FOAM CASTING TECHNOLOGY}

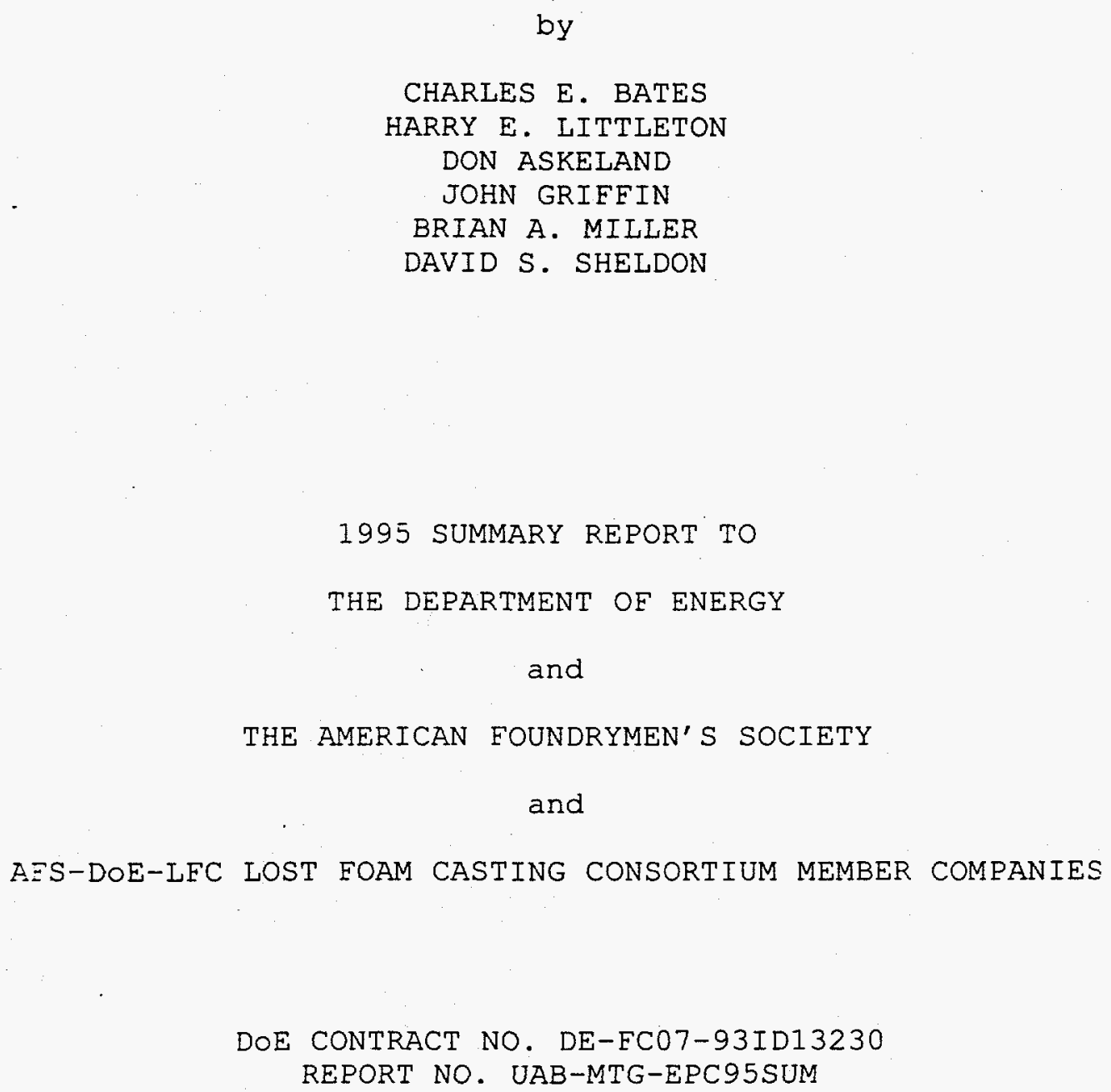




\section{DISCLAIMER}

This report was prepared as an account of work sponsored by an agency. of the United States Government. Neither the United States Government nor any agency thereof, nor any of their eraployees, makes any warranty, express or implied, or assumes any legal liability or responsibility for the accuracy, completeness, or usefulness of any information, apparatus, product, or process disclosed, or represents that its use would not infringe privately owned rights. Reference herein to any specific commercial product, process, or service by trade name, trademark, manufacturer, or otherwise does not necessarily constitute or imply its endorsement, recommendation, or favoring by the United States Government or any agency thereof. The views and opinions of authors expressed herein do not necessarily state or reflect those of the United States Government or-any agency thereof. 


\section{DISCLAIMER}

Portions of this document may be illegible electronic image products. Images are produced from the best available original document. 


\section{ADVANCED LOST FOAM CASTING TECHNOLOGY}

Table of Contents

ACKNOWLEDGMENTS . . . . . . . . . . . . . . . . . . . . . iV

EXECUTIVE SUMMARY \& CONCLUSIONS . . . . . . . . . . . . . . . . . 1

Precision Pattern Production and Gauging . . . . . . . . . . 1

Pattern Coating Control . . . . . . . . . . . . . . . . 2

Sand Fill and Compaction Effects . . . . . . . . . . . . 4

Metal flow and Gating . . . . . . . . . . . . . . . . . 5

Mechanical Properties of Castings . . . . . . . . . . . . . . 7

1.0 PRECISION PATTERN PRODUCTION AND GAUGING . . . . . . . . . . 10

1.1 Experimental Materials and Procedures . . . . . . . . 10

1.1.1. Dimensional Changes During Aging. . . . . . 10

1.1.2. Dimensional Measurements. . . . . . . . . . 10

1.1.3. Air Gauge Calibration on Commercial

Shaped Parts. . . . . . . . . . . . 11

1.1.4. Test Patterns. . . . . . . . . . . . . . 12

1.1.5. Pattern Density Measurements. . . . . . . . 12

1.2 Flange Pattern Production and Aging . . . . . . . . . 15

1.2.1. Natural and Artificial Aging of EPS and Copolymer

Flange Patterns. ............ 15

1.2.2. Air Gauge $R$ \& $R$ on the Flange Pattern. . . . . . 15

1.2.3. Flange Pattern Processing. . . . . . . . . 15

1.2.4. O.D. Shrinkage Summary on EPS and

Copolymer Flanges. . . . . . . . . . . 16

1.2.5. Density Variations in Copolymer Patterns. . . . 17

1.2.6. Molding Variable Effects on Pattern Density Gradients. . . . . . . . . . . . 17

1.3. Intercooler Pattern Production and Aging. . . . . . . . 19

1.3.1. Intercooler Pattern Aging. . . . . . . . . . . . 22

1.3.2. Intercooler Length Changes. . . . . . . . . . 22

1.4. Conclusions - Foam Stabililzation . . . . . . . . . . 23

2.0. PATTERN COATING CONTROL . . . . . . . . . . . . . . . . . 25

2.1. Casting Fill Model . . . . . . . . . . . . . . 27 
TABLE OF CONTENTS (CONTINUED)

2.2 Air Flow Apparatus . . . . . . . . . . . . . . 30

2.3 Liquid Flow Apparatus . . . . . . . . . . . . 30

2.4 Summary and Conclusions - Coating Control . . . . . . 34

3.0 SAND AND COMPACTION EEFECTS . . . . . . . . . . . . . . . . . 36

3.1. Introduction . . . . . . . . . . . . . . 36

3.2. Basic Fill and Compaction Parameters . . . . . . . . . 38

3.2.1. Clamped and Unclamped Flasks. . . . . . . . 38

3.2.2. Horizontal and Vertical Compactors. . . . . . . 42

3.3. Guidelines for Fill and Compaction . . . . . . . . . . 46

3.4 Summary and Conclusions from Compaction Studies . . . . 48

4.0 MEtAl FLOW AND GATING . . . . . . . . . . . . . . . . . . 51

4.1 Introduction. . . . . . . . . . . . . . . . . . 51

4.2 Definition of Gating. . . . . . . . . . . . . . . 51

4.3 Reconsideration of Previous Data. . . . . . . . . . 52

4.4 Current Research on Gating and Filling . . . . . . . . . 52

4.4.1. Task 1: Pouring Temperature and Fill Rate. . . 53

4.4.2. Task 2: Effect of Gate Size and Other Process
Parameters on Fill in Cast Iron. . . . . 53

4.4.3. Task 3: Effects of Gating and Other Process
Parameters on Fill in Aluminum . . . . . . 53

4.4.4. Task 4: Making the Gating System the Choke. . . 54

4.5 Summary and Conclusions - Metal Flow and Gating . . . . 54

5.0 MECHANICAL PROPERTIES OF CASTINGS . . . . . . . . . . . . . 55

5.1 Experimental Procedures for Tensile Properties . . . . . 55

5.1.1. Tensile Bar Production. . . . . . . . . . . 55

5.1.2. Hardness Measurements . . . . . . . . . . . 55

5.1.3. Nondestructive Characterization Density. . . . . 55

5.1.4. Ultrasonic Longitudinal Velocity . . . . . . . . 55

5.1.5. Tensile Property Measurement . . . . . . . 57 


\section{TABLE OF CONTENTS (CONTINUED)}

5.2. Tensile Property Results and Discussion . . . . . . . 57

5.2.1. Class 30 Gray Iron. . . . . . . . . . . . 57

5.2.2. Tensile and Fatigue Properties of Class
30 Gray Iron and 100-70-03 Ductile Iron. . . . . 66

5.3. Fatigue Bar Production . . . . . . . . . . . . . 70

5.3.1. As-Cast No-Bake Specimens. . . . . . . . . 70

5.3.2. As-Cast Lost Foam Specimens. . . . . . . . . 72

5.3.3. Machined Specimens. . . . . . . . . . . 72

5.4. Fatigue Test and Analysis Procedures . . . . . . . . 72

5.4.1. Monotonic Tensile Tests... . . . . . . . 72

5.4.2. Analysis of Tensile Data. . . . . . . . . . . 72

5.4.3. Fatigue Test Procedure. . . . . . . . . . 75

5.4.4. Analysis of Fatigue Data. . . . . . . . . 75

5.5. Test Specimen Microstructure . . . . . . . . . . . . 76

5.5.1. As-Cast No-Bake Specimens. . . . . . . . . . 76

5.5.2. Lost Foam Casting Specimens. . . . . . . . . 81

5.5.3. Lost Foam Cast and Machined Specimens. . . . . 89

5.6. Tensile and Fatigue Test Results . . . . . . . . . . . 94

5.6.1. Class 30 Gray Iron . . . . . . . . . . . . 94

5.6.2. 100-70-03 Ductile Cast Iron. . . . . . . 102

5.7. Summary and Conclusions-Gray and Ductile Iron Properties 102

6.0 CONCLUSIONS

6.1. Pattern Dimensional Analysis . . . . . . . . . . . . 104

6.2 Pattern Coating Control. . . . . . . . . . . . . 104

6.3 Sand Fill and Compaction Effects . . . . . . . . . . 105

6.4 Metal Flow and Gating. . . . . . . . . . . . . 107

6.5 Mechanical Properties of Castings. . . . . . . . . . 108

7.0 FUTURE RESEARCH . . . . . . . . . . . . . . . . . . . . . 109

8.0 REEERENCES. . . . . . . . . . . . . . . . . . . . . 110 
ADVANCED LOST FOAM CASTING TECHNOLOGY

EXECUTIVE SUMMARY \& CONCLUSIONS

Previous research, conducted under DOE Contract \#DE-FC0789ID12869, made significant advances in understanding the Lost Foam Casting (LFC) Process and clearly identified areas where additional research was needed to improve the process and make it more functional in an industrial environment. The current project focused on five areas listed as follows:

$\begin{array}{ll}\text { Task 1: } & \text { Precision Pattern Production } \\ \text { Task 2: } & \text { Pattern Coating Consistency } \\ \text { Task 3: } & \text { Sand Fill and Compaction Effects } \\ \text { Task 4: } & \text { Pattern Gating } \\ \text { Task 5: } & \text { Mechanical Properties of Castings }\end{array}$

This report summarizes the work done under the current contract in all five areas in the period of Oct 1, 1994 through December 31, 1995.

Twenty-eight (28) companies jointly participate in the project. These companies represent a variety of disciplines, including pattern designers, pattern producers, coating manufacturers, plant design companies, compaction equipment manufacturers, casting producers, and casting buyers.

This section of the report summarizes the work done in the past two years and the conclusions drawn from the work.

Precision Pattern Production and Gauging

The objective of the precision pattern production task was to determine the parameters that control the precision of foam patterns used in the lost foam process. Casting accuracy is dependent on producing dimensionally accurate patterns and maintaining consistent shrinkage during the aging period.

Pattern dimensional precision is directly related to the bead blowing and curing techniques. Although there appears to be some advantage in initial dimensional stability of patterns produced from copolymer beads over expanded polystyrene beads, the long-term stability of patterns from all bead types was similar.

The discovery of large density variations within patterns is significant. "At least two casting defects in sponsor foundries were 
caused by extremes in pattern density. In both cases, density gradients were minimized by changing the foam blowing variables, and the casting defects were eliminated.

Density gradients were also found to cause pattern warpage. The effects of pattern blowing variables on density gradients and warpage was examined in several carefully conducted experiments. The results are summarized as follows.

- For dimensional consistency, it is imperative that consistent and reproducible foams and blowing conditions be used.

- Variations in blowing cycle can substantially alter pattern dimensions.

- Demolding after short cooling cycle can produce

a. O.D. growth above tool dimensions

b. I.D. growth below tool dimensions

c. Both O.D. and I.D. growth.

- Density variations were found to be a function of the tool temperature variations.

- It is recommended that patterns from each batch be dimensionally analyzed using a calibrated coordinate measuring machine (CMM) or air gauging system to assure dimensional consistency. Only dimensional checks will assure that repeatable dimensions are being achieved.

- A dimensionally accurate "HARD" standard is needed for each pattern to maintain air gauge calibration.

Details of the experimental procedures used and a more complete description of the observations made regarding the pattern stabilization and distortion are presented in the report section entitled "Precision Pattern Production and Gauging."

Pattern Coating Control

Several conclusions have been drawn concerning coating properties that control the metal/pattern exchange during pouring. These effects are summarized as follows.

- The coating permeability for gas, especially air, is the primary factor controlling the rate of pattern replacement by molten metal. 
- Air and gas removal from the mold cavity must occur prior to the time that the Iiquid pyrolysis products wet the coating. Wetting by the liquid pyrolysis products occurs at about $250^{\circ} \mathrm{C}\left(480^{\circ} \mathrm{F}\right)$ and closes the coating pores so that no more gas can pass through the coating.

- Room temperature permeability measurements of coatings are reasonably good measures of permeability during pouring. The pores are open until pyrolysis products soak into and close the pores.

- Liquid pyrolysis products must be removed at a rate equal to their rate of generation to prevent accumulation at the metal/pattern interface.

The flow rate of both air from the bead pores and gaseous pyrolysis products from the foam through the coating control the metal fill rate. Incomplete casting fill is almost always caused by low fill rates. Iiquid pyrolysis product absorption largely controls carbonaceous residue and lap defects in castings. These factors dominate the coating performance and must be monitored and controlled in the foundry operation.

Based on the understanding of the events occurring during pattern replacement, two apparatuses were developed to measure appropriate coating properties. These are referred to as the "air flow apparatus" and the "liquid flow apparatus". The air flow apparatus measures the flow of air through a coating of known thickness under a known pressure to determine the characteristic gas flow properties. Similarly, the liquid flow apparatus measures properties related to the ability of the coating to absorb liquid pyrolysis products produced during pattern decomposition. The use of these two apparatuses resulted in the following:

- A correlation was found between coating properties and causes of casting scrap in one aluminum foundry. Excessively high gas permeability was associated with short pour times and porosity in the aluminum castings. Low permeability was associated with long pouring times and laps and misruns in the castings.

- Careful quality control to maintain consistency in the coating resulted in a scrap reduction in one aluminum foundry from seven percent to under one percent.

Details of the experimental procedures and results are presented in the section entitled "Pattern Coating Control." 
Sand Fill and Compaction Effects

Both sand fill and compaction in pattern cavities must be accomplished without pattern distortion. Improper equipment or equipment use can result in pattern distortion and/or poorly compacted areas (areas of low sand density) that result in metal penetration during pouring. Understanding, controlling, and maintaining reproducible sand fill and compaction is essential if dimensionally accurate castings with a good surface finish are to be produced. The significant results obtained in this area of study are summarized as follows:

- The flask serves as the energy transfer medium between the compactor table to the sand. Even though the drive table may have principally a horizontal or vertical direction of motion, other vibrational modes are introduced into the sand because of flask wall movement.

- Flasks that are vibrated principally by vertical forces have both horizontal and vertical components introduced by flask wall movement. The ratio of horizontal to vertical accelerations depends on the ratio of vertical to horizontal flask stiffness, sand density, and the amount of off-axis loading.

- Horizontally vibrated flasks similarly develop vertical vibrational components because of off-axis loading and flask movement.

- Horizontal vibration moves sand into cavities more quickly than vertical vibration in flasks at equivalent vibrational amplitudes with accelerators above one $G$.

- Certain operational features are required of both vertical and horizontal compactors employing either clamped or unclamped flasks. Sand densification in the flask and pattern cavities must progress in a systematic manner beginning toward the bottom of the flask and moving toward the top. It is generally desirable to have a 50 to $75 \mathrm{~mm}$ (2 to 3 in.) thick layer of fluidized sand at the top sand surface with densified sand below the fluidized layer. Cavity filling should occur from within the fluidized layer. Densification occurs below the fluidized layer as sand moves downward to reduce the sand fraction.

- Achieving the proper pattern position and orientation can provide generous rewards in compaction time savings. Since each compactor/flask/sand combination is somewhat different, 
acceleration maps within representative flasks should be developed.

- Procedures have been developed to map accelerations that cause sand flow in flasks. The mapping procedure provides options for pattern placement within flasks to maximize the fill rate of pattern cavities.

- There are two basic modes of sand vibration within flasks. The first consists of sand fluidization accompanied by the formation of a ridge or mound of sand toward the center of the flask. The mound in cylindrical flasks is produced as sand flows upward along the centerline, outward on the free surface, and downward along the flask wall. In square flasks, the mounding occurs on a line across the flask perpendicular to the direction of forced vibration.

- A second vibrational mode is associated with extremely rigid flasks and has significantly less sand fluidization associated with it. This condition has been found in both round and square flasks at vibrational forces equal to those in flasks where total fluidization occurred. Flasks with a low stiffness produced more fluidization at a given vibrational amplitude. Flasks with high stiffness produced more rapid sand densification.

- Filling of pattern cavities and densification of sand within the cavities must occur simultaneously to prevent sand collapse defects at the top cavity surface during pouring. Sand collapse can be minimized or avoided by filling the flask slowly to allow complete sand migration and compaction before the depth of sand above the cavity becomes too great.

- The discovery of casting distortion caused by sand expansion is significant. Sand expansion not only distorts castings but is thought to be the root cause of most metal penetration defects. Alternate low expansion materials are currently being evaluated for physical and thermal properties which will yield dimensionally accurate castings.

More details of the compaction research are presented in the report section entitled, "Sand Fill and Compaction."

\section{Metal Flow and Gating}

In conventional casting processes, the gating system is designed to control liquid metal flow, and the principles of fluid dynamics are employed to control the metal velocity, mold filling time, and the path taken by the molten metal. By careful engineering of the 
- Fully machined lost foam cast 100-70-03 fatigue specimens exhibited better fatigue life compared to lost foam and sand cast specimens tested with as-cast surfaces.

- Failures on as-cast lost foam cast 100-70-03 ductile iron fatigue specimens began at bead triple points where coating penetrated to produce a pit on the cast surface. Smoother patterns are required to improve the fatigue properties of as-cast parts in lost foam castings.

Details of the experimental procedures employed and the results obtained are described in the section entitled, "Mechanical Properties of Castings." 


\subsection{PRECISION PATTERN PRODUCTION AND GAUGING}

The first objective of the precision pattern production task was to determine the parameters that control the precision of foam patterns used in the lost foam process. Casting accuracy is dependent on producing dimensionally accurate patterns and maintaining consistent shrinkage during the aging period.

The second objective of this task was to determine the precision of the casting process by measuring the dimensions of castings made from the patterns on various molding systems.

\subsection{Experimental Materials and Procedures}

1.1.1. Dimensional Changes During Aging. Polystyrene beads contain many small individual cells, and each cell in the raw bead stock contains both liquid and gaseous pentane. During preexpansion, the liquid pentane is flashed to a vapor, and the polymer membranes are heated above the glass transition temperature, softened, and plasticized by the heat. The conversion of liquid pentane to gas causes pentane expansion which causes beads to enlarge. After a short stabilization period, the beads are blown into a tool and reheated with steam. The beads again soften, the gases expand, the liquid pentane present flashes back to a gas, and the beads fuse together. The tool is then flushed with cold water, and the part is cooled prior to ejection from the molding machine.

Foam patterns are almost always "aged" for a period after molding. Parts change dimensions rapidly after removal from the molding tool, and aging which may range from a few hours to several weeks, allows some dimensional stabilization to occur.

Two theories have been proposed to explain dimensional changes occurring in parts during aging. The first theory is that equalization of gas pressure in the beads causes pattern expansion and contraction. The second theory attributes some of the shrinkage to stress relaxation in the polymer cell structure. Stress relaxation in the cell walls occurs during aging and is accelerated by artificially aging patterns at slightly elevated temperatures.

In addition to pattern deformation associated with molding, ejection, and pattern aging, patterns sometimes warp during and after ejection from the tool. Warpage has been studied in the past year, and results are described in subsequent sections of this report.

1.1.2. Dimensional Measurements. Making systematic foam pattern processing variations and tracking part dimensions was difficult prior to the development of air gauging systems. Freshly blown foams are soft and easily deformed by the stylus on coordinate measuring 
machines. Coordinate measuring machines are also relatively slow and require substantial amounts of time to make multiple measurements on multiple foams.

All dimension measurements made on foam patterns in the current project were made with an air gauge system marketed by Matrix Technologies. The Matrix Technologies system incorporates primary and secondary air chambers and two critical flow orifices to make dimensional measurements. The primary pressure chamber, referred to as the manifold, is the larger of the two chambers and is located before the first orifice. The primary chamber pressure is controlled by an external regulator set to a predetermined pressure. This chamber pressure stays relatively constant ( $\pm 0.34 \mathrm{kPa}$ or $0.05 \mathrm{psi})$ during operation.

The secondary pressure chamber is created by the gas volume in the air line between the first and second orifice. The secondary chamber pressure varies according to the amount of air leaving the second orifice.

When the gap between the second orifice and a part is zero, the air flow is shut off. This makes the pressure in the secondary chamber equal the pressure in the primary chamber. When the gap is opened, air flow begins and the pressure in the secondary chamber drops to produce a pressure ratio greater than one.

The system is calibrated by measuring pressure ratios as a function of gap opening. A computer is used to curve fit the data with up to a tenth order polynomial expression. Lower order polynomial expressions are used if the fit to the data is high enough. The calibration curve is then divided into segments, and a "look-up" data table prepared that relates gap opening to the measured pressure ratio. The "look-up" table allows quick determinations of the gap opening from the pressure ratio.

Two opposing sensors can be placed a known distance apart to allow a part thickness or length to be measured. When a pattern is placed between the sensors, two gaps are measured. The formula (part thickness $=\mathrm{X}-\mathrm{A}-\mathrm{B}$ ) applies where $\mathrm{X}$ is the total distance between the two sensors, $A$ is the gap between the part and first sensor gap, and $B$ is the second sensor gap. The total distance between the sensors, $X$, is usually measured during setup with a coordinate measuring machine. If the part moves toward the first sensor, that gap becomes smaller but the second gap becomes larger by the exact amount. This allows part thickness measurements to be made using two transducers independent of the position of the pattern between the transducers.

1.1.3. Air Gauge Calibration on Commercial Shaped Parts. The calibration process used to develop the polynomial that relates the pressure ratio to the gap width is usually developed by mounting a 
flat smooth plate on a stand in front of an orifice. The plate is backed away from the orifice with a micrometer in carefully measured steps to develop a series of pressure ratios as a function of known gap width.

In practice, foam patterns are usually smooth but the dimensions of interest on parts may not be flat or on surfaces that are perpendicular to an orifice. The lack of flatness may allow air from an orifice to flow past the part surface with less resistance than provided by a flat plate, and this can cause some deviation in the pressure ratio from the calibration curve. The variance can make it more difficult to establish true part dimensions from the pressure ratios. For this reason it is necessary to make a final calibration check using a "hard" copy of the part.

In the current study, precise "standards" with known dimensions having the pattern shape and contours were machined from graphite. Graphite was chosen as the standard material since it has a low coefficient of thermal expansion and is unaffected by normal variations in atmospheric humidity. Calibration curves for the curved patterns were developed using same procedures described above for flat plates, but in this case, the machined standard was used. These curves were then verified and the calibration adjusted if necessary by making measurements on precisely machined graphite standards.

1.1.4. Test Patterns. Two foam patterns were used in the current study. These patterns are referred to as the flange pattern and the intercooler pattern and are illustrated in Figure 1.1 and 1.2, respectively.

1.1.5. Pattern Density Measurements. During the course of the study, density differences were found within foam parts, and pattern distortion was found to be associated with the differences. In order to study the distortion phenomena, techniques were developed to make accurate density measurements on cut pattern sections.

Density determinations involve measuring the weight and volume of an object. In the current program, all weight measurements were made with a Mettler AE200 analytical balance. When placed on a stable surface in a temperature controlled room, the Mettler has a repeatability of 0.0001 grams and is self-calibrating to ASTM class 1 standards.

Since obtaining uniformly shaped sections of a foam pattern with smooth surfaces is difficult, an immersion technique was needed for determining the volume. The liquid used in the immersion test should be stable, have minimum volumetric expansion as a function of temperature, and have a sufficiently high contact angle that the liquid does not wet and run into small pores on the cut pattern surface. The specimen volume is determined by dividing the buoyant 


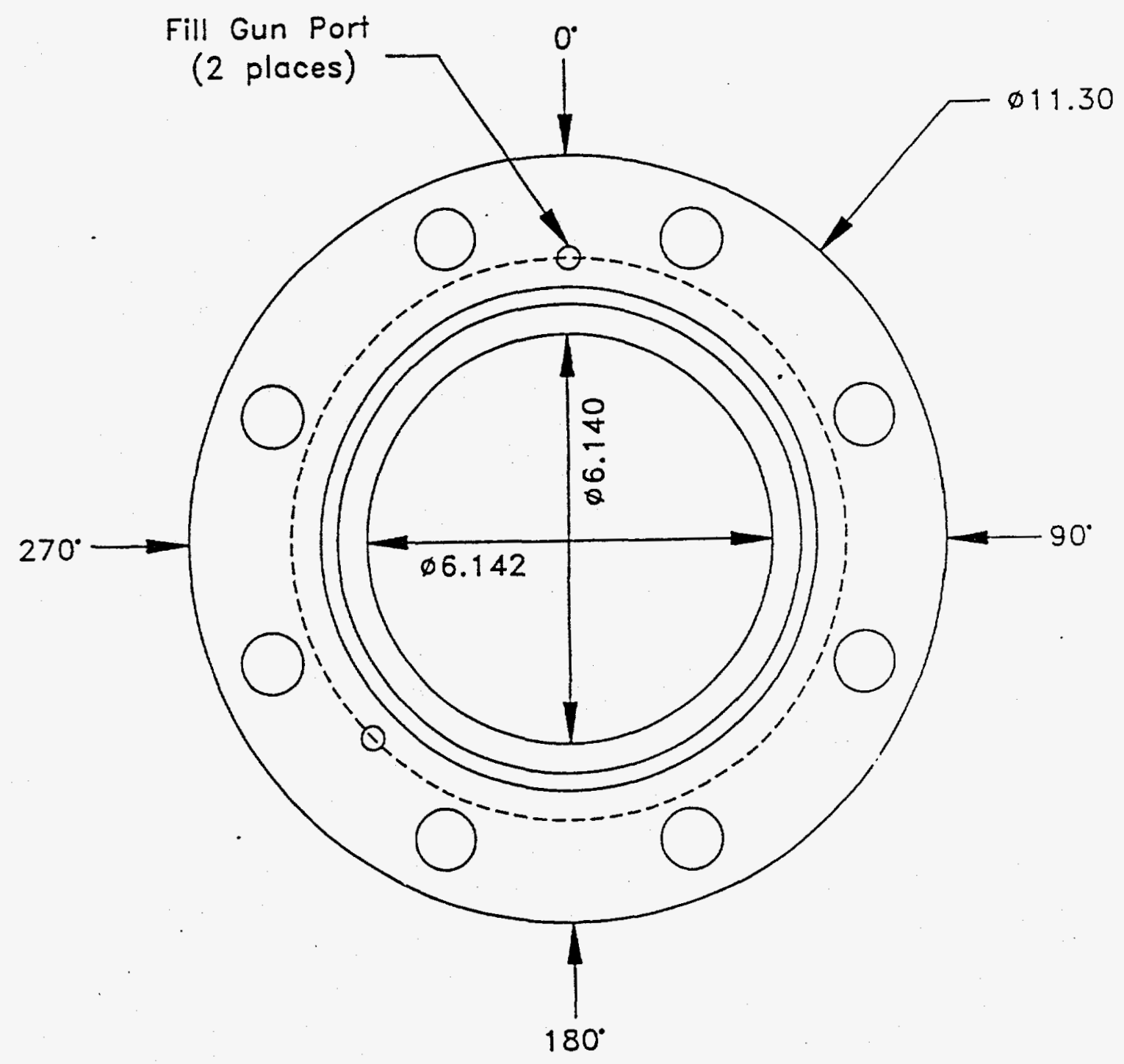

Figure 1.1. Flange Tooling Dimension at $36^{\circ} \mathrm{C}\left(97^{\circ} \mathrm{F}\right)$. 


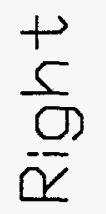

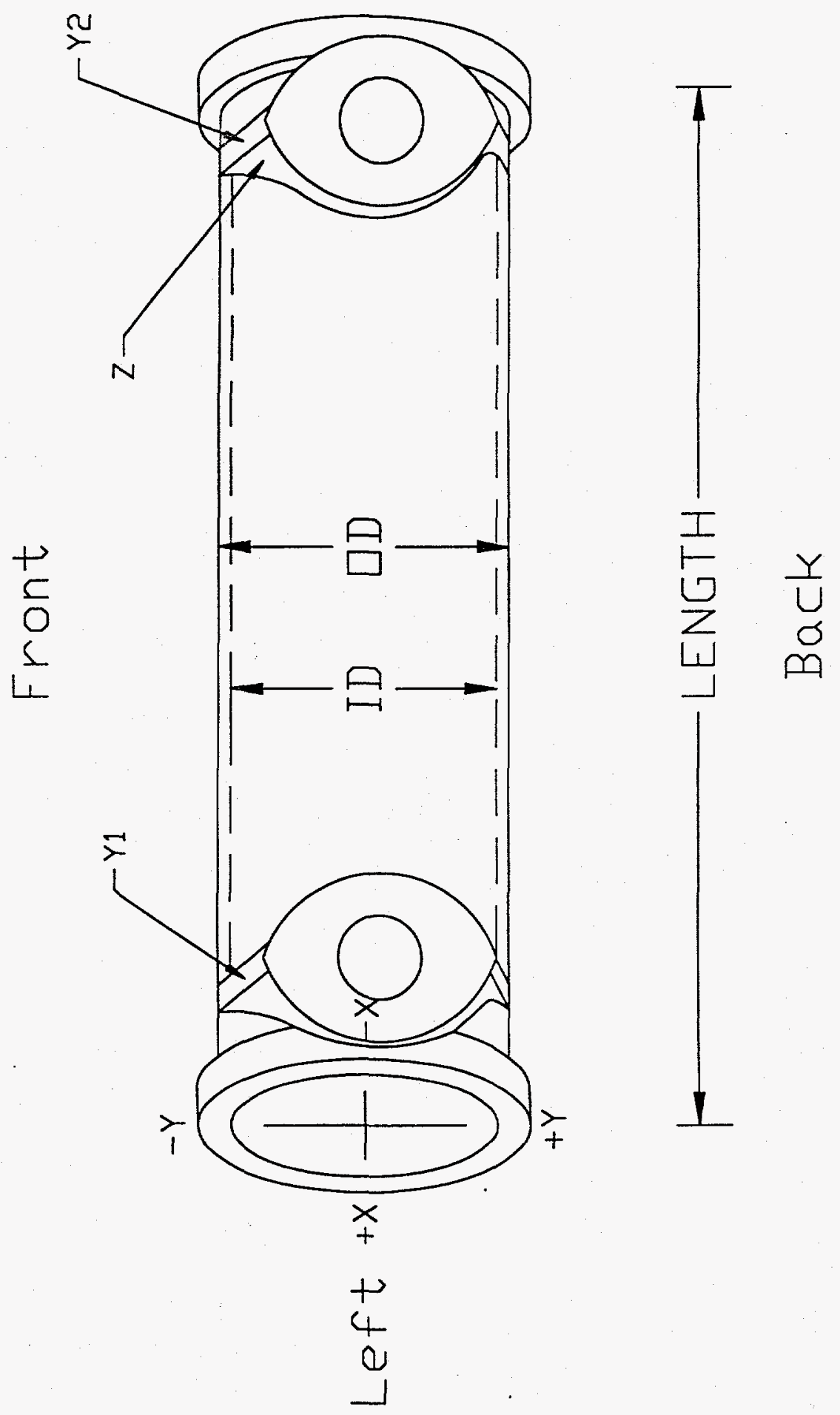

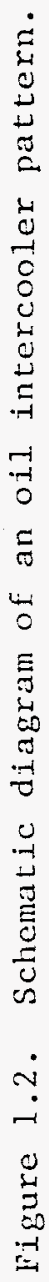


weight of the sample after immersion in the test liquid by the density of the liquid. This measurement is easily accomplished in practice by suspending a specimen from a harness attached to the balance. The buoyant weight is read directly from the balance, and the liquid density is known from pycnometer measurements made on the liquid.

\subsection{Flange Pattern Production and Aging}

1.2.1. Natural and Artificial Aging of EPS and Copolymer Flange Patterns. A flange pattern illustrated in Figure 1.1 was used to examine the effects of natural and artificial pattern aging. The pattern was a ring with a $287.0 \mathrm{~mm}$ (11.30 in.) outside diameter (O.D.) and a $155.9 \mathrm{~mm}$ ( $6.14 \mathrm{in.)}$ inside diameter (I.D.) bore. Eight bolt holes were equally spaced around the flange.

Two fill guns were used to fill the pattern cavity at the locations indicated. The pattern cavity was formed in a cast and machined aluminum box conforming to the outside dimensions of the pattern being blown. The inside diameter of the pattern tool ranged from $155.9 \mathrm{~mm}(6.140 \mathrm{in.})$ in the $0^{\circ}-180^{\circ}$ direction to $156.0 \mathrm{~mm}$ (6.142 in.) in the $90^{\circ}-270^{\circ}$ orientation. The outside diameter was 287.0 $\mathrm{mm}(11.30 \mathrm{in.})$ in both orientations.

1.2.2. Air Gauge $R \& R$ on the Flange Pattern. A gauge reproducibility and repeatability ( $R \& R$ ) study was performed on the air gauge using two different procedures. The first procedure consisted of using three operators who measured ten foam patterns two times each. The gauge $R$ \& $R$ ranged from 0.0205 to $0.061 \mathrm{~mm} 10.00081$ to 0.0024 in.). The total gauge $R$ \& $R$ is the spread that covers 99\% of the measurement variation due to the combination of operator and machine. (1) 1

In order to remove any variations that might be caused by partto-part variations, another gauge $R \& R$ was calculated. A single part was measured two times by three different machine operators. The gauge $R \& R$ measured using this procedure ranged from 0.0254 to 0.071 $\mathrm{mm}(0.0010$ to 0.0028 in.).

1.2.3. Flange Pattern Processing. The purpose of the experimental series on the flange pattern was to establish the effect of natural and artificial aging on the aging shrinkage of EPS and copolymer patterns. A target shrinkage from cold tool dimensions was sought. All patterns were blown on a machine which used vacuum to assist both cooling and water removal from the patterns. numbers.

${ }^{1}$ Numbers in brackets at the end of sentences are reference 
The volatiles content (in both the raw beads and the preexpanded beads), fill pressure, fill time, blow-back time, chest-purge time, cross-steaming time and pressure, autoclaving time and pressure, dwell time, duration of the water spray, duration of vacuum application, and the demolding temperature for both types of beads were considered in the experiment.

Approximately 80 parts were blown in each group of patterns. Each part was serialized and time stamped as it was extracted from the blowing machine. Parts were delivered to the dimensional analysis laboratory as soon as possible after production. A time lapse of about two hours occurred between blowing and the first dimensional measurements.

After the first dimensional measurements, the batch of foams was broken down into groups of ten parts each, and each group was either naturally aged at room temperature or artificially aged at $52^{\circ} \mathrm{C}$ or $65^{\circ} \mathrm{C}$ $\left(125^{\circ} \mathrm{F}\right.$ or $\left.150^{\circ} \mathrm{F}\right)$. The artificial aging periods were $2,4,6,7,8,9$, and 10 hours in a recirculating air furnace. After a group of parts had been artificially aged for a particular time at the elevated temperature, they were removed from the furnace, cooled to room temperature $\left(27^{\circ} \mathrm{C}\right.$ or $\left.80^{\circ} \mathrm{F}\right)$ and measured. Subsequent dimensional measurements were made after additional aging at room temperature. Parts were not returned to the furnace for further artificial aging after the initial elevated temperature aging period.

Dimensional measurements were made on both the inside diameter (I.D.) and outside diameter (O.D.) in the $0^{\circ}-180^{\circ}$ direction and the $90^{\circ}-270^{\circ}$ direction, as schematically illustrated in Figure 1.1 . The $O . D$. and I.D. percentage difference from the cold tool dimension in both directions was plotted as a function of time after ejection from the mold.

1.2.4. O.D. Shrinkage Summary on EPS and Copolymer Flanges. Observations made regarding the outside diameter shrinkage occurring during natural and artificial aging of flange foam patterns at $52^{\circ} \mathrm{C}$ or $65^{\circ} \mathrm{C}\left(125^{\circ} \mathrm{F}\right.$ or $\left.150^{\circ} \mathrm{F}\right)$ are summarized as follows:

1. Very little change was seen in the copolymer flange O.D. dimension during aging at an elevated temperature.

2. Increased time at artificial aging temperatures progressively decreased the EPS flange $O . D$.

3. The shrinkage from the tool dimensions associated with artificial aging of EPS foams was higher for any given aging time than the shrinkage observed at room temperature. 
4. The outside diameter shrinkage of the flange patterns was uniform in both the 0 to $180^{\circ}$ direction and the 90 to $270^{\circ}$ direction.

1.2.5. Density Variations in Copolymer Patterns. There was a difference in I.D. dimensions in the copolymer patterns between the 0 - $180^{\circ}$ and the $90-270^{\circ}$ directions. This difference suggested some internal nonuniformity in the material. Systematic studies were undertaken to determine the cause of these differences. The focus of these studies centered on density variations in the pattern that might account for differences in shrinkage behavior. Density measurements were made using the immersion technique described in section 1.1.5. Density data were obtained as a function of circumferential and radial position in copolymer patterns. Fill guns were located at the $0^{\circ}$ and $225^{\circ}$ circumferential positions on the pattern.

Observations regarding I.D. shrinkage associated with aging of copolymer patterns are summarized as follows:

1. The I.D. shrinkage was always less than the O.D.

2. The I.D. of the pattern always had a higher density than the O.D., and this higher density was associated with less pattern shrinkage.

3. The shrinkage was not symmetrical on the I.D. circumference. The initial pattern shrinkage was always greater in the 0 to $180^{\circ}$ direction which on average had a lower pattern density. The shrinkage was generally lower in the 90 to $270^{\circ}$ direction where pattern material generally had a higher density.

4. A through-thickness density gradient existed in all flanges.

1.2.6. Molding Variable Effects on Pattern Density Gradients. The following tool descriptions and machine operating parameters can be used to explain the density gradients observed in both the copolymer and EPS flange patterns. The bottom half of the mold was fixed and cooled with water sprays. The cores used to form the flange bolt holes were a part of the bottom tool half, and a press-fit ring mounted in the bottom mold half that formed the flange center hole. The cavity for the flange pattern was in the top mold half as illustrated in Figure 1.3. The tool operation consisted of filling the tool, cross-steaming the cavity, autoclaving, spraying water on the bottom tool, applying vacuum to the chest for 25 seconds, and demolding.

The I.D. bore of the flange pattern had the highest density because the thermal mass of the ring mounted in the bottom mold half 


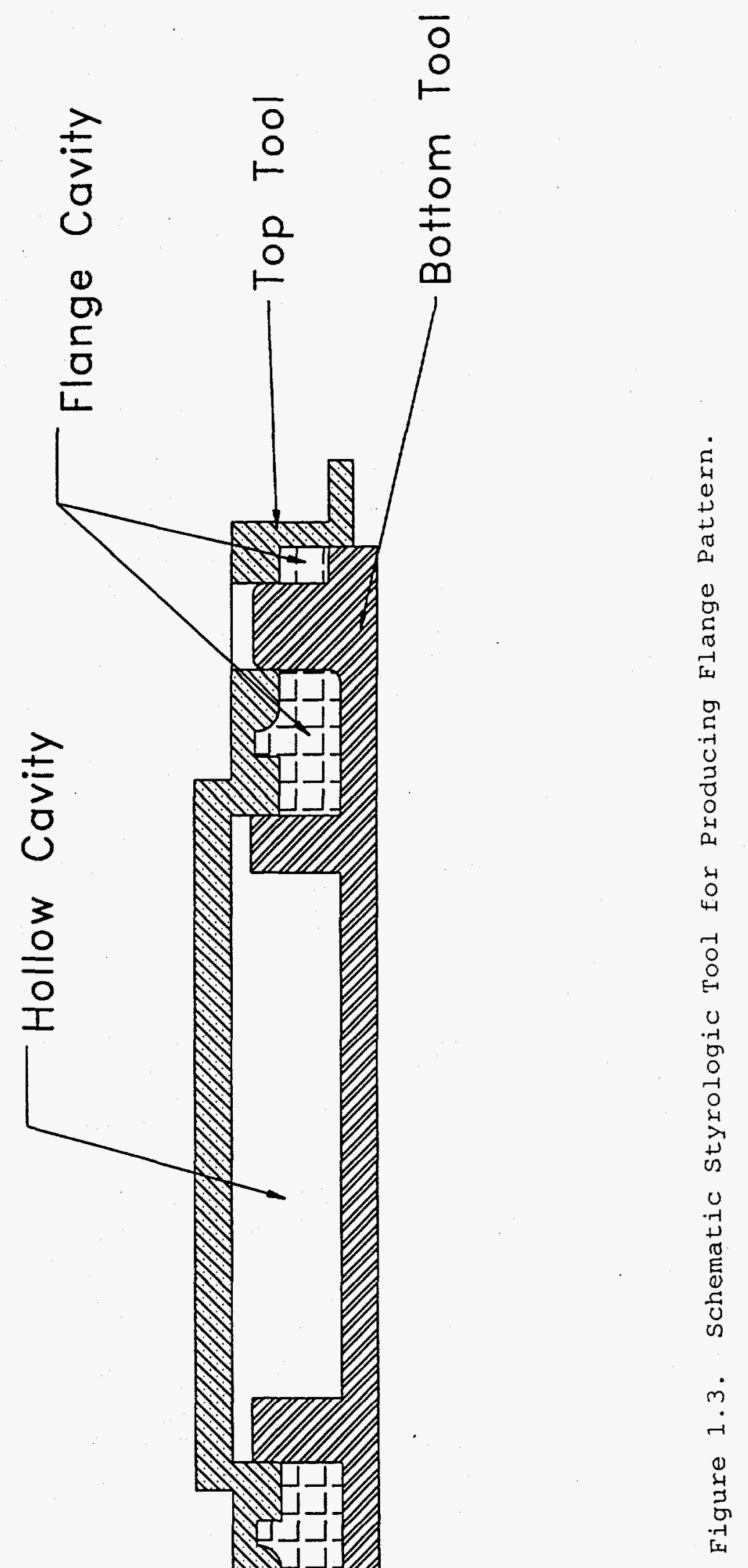


to form the flange bore was high. This ring had no direct cooling; and hence, when heated, it stayed hot and allowed bead compression and densification to occur for a relatively long period during the molding and cooling cycle.

The bottom of the tool stayed hot for an intermediate time because it was cooled for only six seconds with a water spray. Since the water ran off the tool, residual water was unavailable to aid adiabatic cooling that otherwise would have occurred when the vacuum was applied.

The top of the tool cooled more quickly than either the ring insert or the bottom because there was condensed water on top of the tool that began to boil and cause evaporative cooling when a vacuum was applied. This water would boil at a temperature of $71^{\circ} \mathrm{C}\left(160^{\circ} \mathrm{F}\right)$ under the applied vacuum of $34 \mathrm{kPa}$ ( 5 psia).

The density variations in both the EPS and copolymer patterns are in direct relation to the time that the local tool temperature was above the pattern glass transition temperature. The center core was hot for the longest time, followed by the bottom tool half, and finally by the top tool half. The densities were highest on the flange I.D. followed by the flange bottom, the flange top, and finally, by the midwall except under the fill guns. These density gradients result in internal stress gradients as parts are demolded and cooled to room temperature.

\subsection{Intercooler Pattern Production and Aging.}

The foam patterns for this portion of the study were oil intercoolers which consisted of a barrel-shaped part with parallel-end flanges and two side flanges. The objectives of the intercooler experimental matrix were (1) to determine the dimensional aging response of EPS having different raw bead sizes and expanding agents and (2) produce test castings with these patterns in different compactors in order to correlate distortion with compactor operation.

The experimental bead matrix is illustrated in Table 1.1 , and the machine operating conditions used during blowing are given in Table 1.2. The desired process variables included the bead type, bead size distribution, and degree of surface fusion. The air gaging system previously described was used to track the dimensional changes of selected patterns as a function of time after foam blowing.

All of the materials were pre-expanded using steam. After ejection of the beads from the pre-expander, they were screened, blown into a bag and aged, and then transferred through the plant bead 
TABLE 1.1

BEAD BLOWING MATRIX FOR OIL INTERCOOLER PATTERN

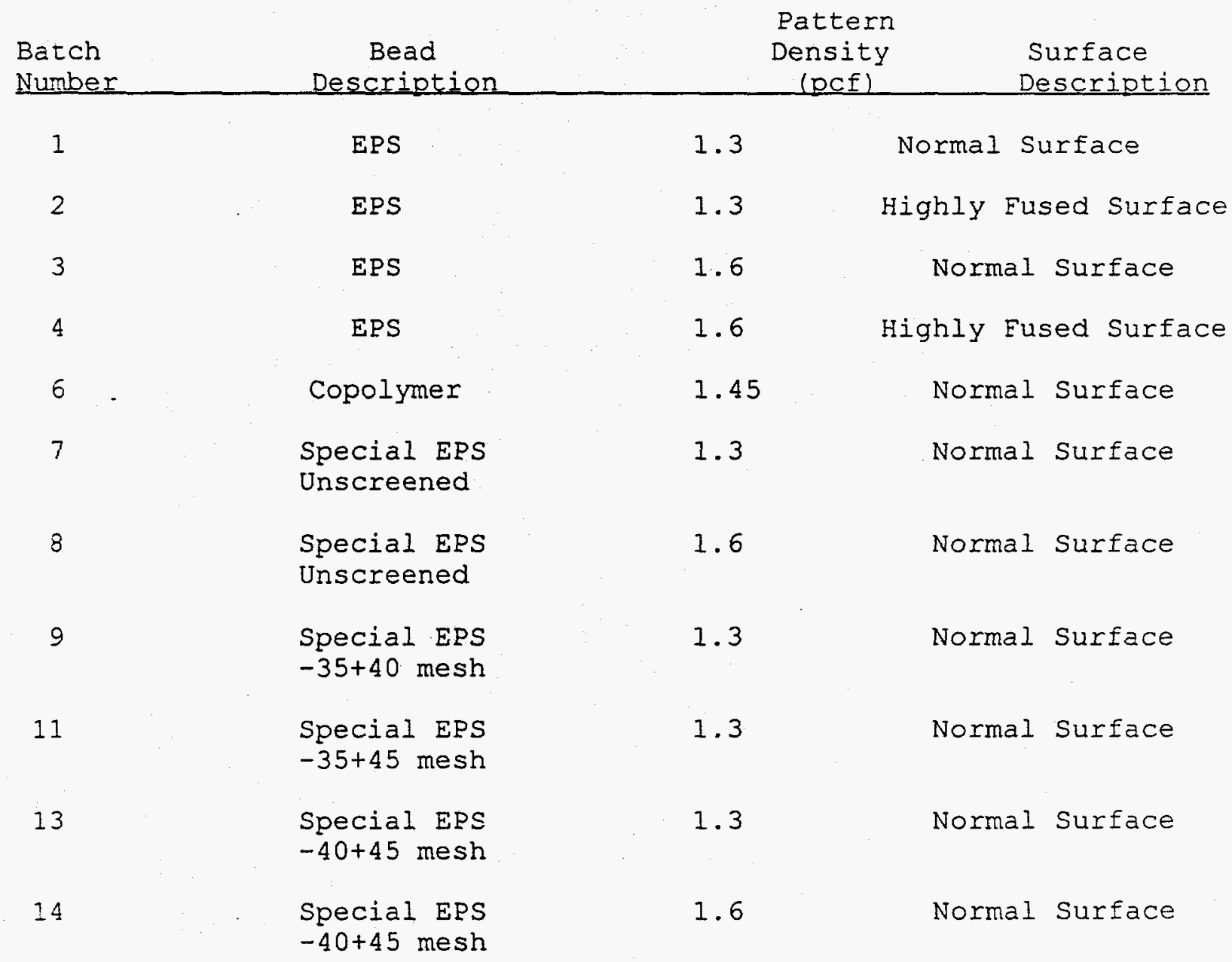


TABLE 1.2

INTERCOOLER CYCLE SEQUENCING

Cycle Sequence

Duration

Pressures

Utility

1) Press in open position $N / A$

2) Preheat cavity

4 seconds

3) Manual blow out

10 seconds

4) Press close

$\mathrm{N} / \mathrm{A}$

5) Pulls extend

2 seconds

(Upper \& Lower)

6) Pulls extend (Sides) 1 second

7) Filling with beads 8 seconds

8) Mold Purge

3 seconds

9) Cross Steam

6 seconds

(Upper and lower pulls

10) Fusion steam

(All chest and pulls)

11) Pause (Hot)

12) Cooling

13) Aging

14) Transfer

15) Pull retract (Sides)

16) Pulls retract (Top \& Bottom)

17) Transfer (2)

18) Press open (slow with air)

19) Press open (Fast)

20) Part eject with Air (Stationary side)

21) Cycle Complete

and moving side chest

12 seconds

2 seconds

12 seconds

25 seconds

1 second

1 second

2 seconds

1 second

1 second

$\mathrm{N} / \mathrm{A}$

2 seconds

$\mathrm{N} / \mathrm{A}$
$\mathrm{N} / \mathrm{A}$

18 psig

35 Ibs.

$\mathrm{N} / \mathrm{A}$

100 lbs

40 Ibs

45 lbs

18 lbs

18 Ibs

18 lbs

$\mathrm{N} / \mathrm{A}$

80 lbs

$30 \mathrm{lbs}$

40 lbs

100 lbs

30 lbs

30 lbs

$\mathrm{N} / \mathrm{A}$

$25 \mathrm{lbs}$

$N / A$

$\mathrm{N} / \mathrm{A}$

Steam

Air

$\mathrm{N} / \mathrm{A}$

Air

Air

Air

Steam

Steam

Steam

$\mathrm{N} / \mathrm{A}$

Water N/A

$\mathrm{N} / \mathrm{A}$

Air

Air

Air

Air

Air

$\mathrm{N} / \mathrm{A}$

Air

$\mathrm{N} / \mathrm{A}$ 
distribution system to the machine set up to blow intercooler patterns.

As each part was blown, a unique label was applied indicating the foam batch number, individual part number in the batch, and the time the part was blown. Dimensional changes were measured and reported"as a function of lapsed time after blowing.

Three bead types were used: 1) Arco EPS, 2) Copolymer, and 3) special EPS beads supplied by Styrochem International. Patterns were produced using the EPS beads and blown to densities of 1.3 and 1.6 $\mathrm{lb} / \mathrm{ft}^{3}$. Patterns were blown with both normal and, in some cases, wellfused surfaces. The change in surface fusion was accomplished by changing the steam dwell time.

Copolymer beads were used to blow patterns to a density of 23.23 $\mathrm{g} / \mathrm{L}\left(1.45 \mathrm{lb} / \mathrm{ft}^{3}\right)$ with a normally fused surface. Four different Styrochem EPS bead size distributions were used including an unsieved bead similar to Arco EPS beads. Patterns were produced with a normal fused surface using the styrochem beads with densities of $20.8 \mathrm{~g} / \mathrm{L}$ and $25.6 \mathrm{~g} / \mathrm{L}\left(1.3 \mathrm{lb} / \mathrm{ft}^{3}\right.$ and $\left.1.6 \mathrm{lb} / \mathrm{ft}^{3}\right)$.

Measurements on the patterns consisted of O.D. and I.D. measurement at $90^{\circ}$ intervals around the circumference at two locations along the pattern length. In addition, the length was measured in four places at $90^{\circ}$ intervals. The inlet flange flatness was also measured at four positions.

1.3.1. Intercooler Pattern Aging. Dimensional changes in these patterns occurring during ten weeks of natural aging at room temperature were determined. In general, the patterns were extracted from the tool with a shrinkage about $0.1 \%$ to $0.2 \%$ below the tool dimension. Initially, the patterns expanded as air diffused into the cells. When the patterns were about 0.5 to $1.5 \%$ larger than the tool dimension, they began to contract.

1.3.2. Intercooler Length Changes. After aging for 100 hours, the patterns blown with $20.8 \mathrm{~g} / \mathrm{L}\left(1.3 \mathrm{lb} / \mathrm{ft}^{3}\right)$ EPS beads having a normal surface fusion were approximately $0.1 \%$ under the tool dimension. The patterns blown with $1.3{\mathrm{Ib} \backslash \mathrm{ft}^{3}}$ EPS beads having a more highly fused surface and the $1.6 \mathrm{lb} / \mathrm{ft}^{3}$ EPS beads with both normal and highly fused surfaces were about $0.2 \%$ shorter than the cold tool dimensions when the patterns were extracted from the tool.

A slightly different behavior was observed in the aging of the patterns blown with both the copolymer and Styrochem EPS beads. Most of these patterns were demolded with a length dimension about 0.1 to $0.2 \%$ below the mold tool dimension. During aging at room temperature, the patterns blown with the Styrochem EPS beads expanded to approximately $0.2 \%$ above the cold tool dimension, and then began to 
shrink to a value near the cold dimension over a four day period. However, the patterns blown with copolymer beads only expanded to approximately the cold tool dimension.

The dimensional data obtained for the intercooler pattern also indicated some variations in both the demolded pattern dimensions and initial pattern growth. The patterns produced with a highly fused surface blown from EPS $20.8 \mathrm{~g} / \mathrm{L}\left(1.3 \mathrm{lb} / \mathrm{ft}^{3}\right)$ beads had a much narrower dimensional spread. Similarly, the patterns blown with the higher density 1.6 EPS beads exhibited a much narrower dimensional spread with both normal and highly fused surface conditions. The higher density EPS patterns had a short plateau of dimensional stability after demolding.

The shrinkage in length from the tool dimension for each bead and surface condition is summarized in Table 1.3 for aging times of two, four, and six weeks. The ARCO EPS pattern shrinkage was about 0.25 to $0.35 \%$ after two weeks, 0.35 to $0.50 \%$ after four weeks, and 0.4 to $0.55 \%$ after six weeks. The shrinkage of the copolymer and the Styrochem beads were similar and somewhat lower than shrinkage of ARCO EPS under the conditions evaluated.

Although the initial portions of these growth/shrinkage curves are quite different, all of the bead types exhibited quite small dimensional differences after 3000 hours (18 weeks) with the exception of the EPS patterns molded with the higher density of $1.6 \mathrm{lbs} / \mathrm{ft}^{3}$. Beads with both normally and highly fused surfaces exhibited considerably more shrinkage. The implication is that foundries purchasing patterns from foam molders must allow for aging to fit the casting dimensional requirements.

\subsection{Conclusions - Eoam Stabilization}

Pattern dimensional precision is related to the bead blowing and curing techniques. Although there appears to be some advantage in initial dimensional stability of the copolymer beads over EPS beads, the long-term stability of both bead types is similar.

The discovery of density variations within a pattern is significant. At least two casting defects in foundries have been related to extremes in density in foam patterns. In both cases, density gradients in the foams were corrected by processing changing the foam blowing variables, and casting defects were eliminated. other conclusions drawn are listed as follows:

1. For dimensional consistency, it is imperative that consistent and reproducible foams and blowing conditions be used. 
TABLE 1.3

\section{INTERCOOLER PATTERN IENGTH CHANGES FROM THE COLD TOOL DIMENSION AFTER 2, 4, AND 6 WEERS AGING TIME}

Pattern

Material

\section{SHRINKAGE}

2 Weeks

$-0.25$

ARCO "T" EPS

( 1.3 pcf) normal

ARCO "T" EPS

$-0.25$

(1.3 pcf) fused

ARCO "T" EPS

$-0.35$

(1.6 pcf) normal

ARCO "T" EPS

( 1.6 pcf) fused

EOSECO Copolymer -0.15

(1.45 pef) normal

Styrochem A

$-0.15$

(1.6 pcf) normal

Styrochem B

$-0.10$

(1.3 pcf) normal

Styrochem C

$-0.15$

(1.3 pcf) normal

Styrochem D

$-0.15$

( 1.3 pcf) normal

Styrochem D

( 1.6 pcf) normal

ARCO EPS

$-0.35$

( 1.3 pcf) Mueller Series

\section{Weeks}

$-0.35$

$-0.40$

$-0.35$

$-0.40$

$-0.50$

$-0.55$

$-0.45$

$-0.50$

$-0.25$

$-0.30$

$-0.25$

$-0.30$

$-0.25$

$-0.30$

$-0.25$

$-0.30$

$-0.25$

$-0.30$

$-0.25$

$-0.30$

$-0.40$

$-0.45$ 
2. Variations in blowing cycle can substantially alter pattern dimensions.

3. Demolding after short cooling cycle can produce

a. O.D. growth above tool dimensions

b. I.D. growth below tool dimensions

c. Both O.D. and I.D. growth.

4. Density variations were found to be a function of the tool temperature variations.

\subsection{PATTERN COATING CONTROL}

The pattern assembly operation is complete when the pattern is attached to the sprue and gating system to form a complete cluster. Before the cluster can be poured with liquid metal, however, it must be coated to develop a refractory shell, the shell dried, the assembly placed in a flask and surrounded with sand, and the sand compacted to provide support during pouring.

Pattern coatings contain several ingredients including the refractory filler, dispersant, binder, thixotropic agent, and carrier. Coatings are liquid thixotropic mixtures of components usually suspended in a water carrier with refractory being the primary constituent. The permeability of the coating is principally controlled by the size, size distribution, and shape of the refractory used in the coating. The refractories commonly used are silica, alumina, zircon, chromite, and alumino-silicates such as mullite and pyrophylite.

The refractory particles are typically held together with one binder to provide adhesion and cohesion before drying and a second binder to provide strength after drying and during pouring. In addition to the binders, the system may also include suspension agents for the refractory and surfactants to insure that the coating will wet and coat the pattern. Coating formulation, application, and control are important in the success of the Lost foam casting process.

The coating and surrounding sand can be considered as the mold which receives and contains the molten metal during pouring. Several requirements are placed on the coating and sand under these conditions. The coating must have sufficient bond strength when dried to withstand abrasion by the sand during the compaction process. Lost Foam coatings do not have sufficient strength to withstand the hydrostatic forces of the liquid metal, and consequently sand must be compacted around the coated pattern to provide coating support during pouring. Inadequately compacted sand and/or insufficiently filled and 
compacted pattern cavities lead to mold wall collapse followed by metal penetration into the sand. Inward mold wall collapse can also occur when excessive coating permeability allows a large gap to form between the advancing metal and the pattern. Other casting defects such as laps, folds, and metal porosity can occur if the coating is unable to remove the liquid degradation products from the pattern prior to casting solidification. The coating must be carefully formulated and controlled in order to achieve these requirements.

The ability of a coating to allow gas pyrolysis products to escape is generally referred to as its permeability. Iron castings are poured at temperatures of about $1375^{\circ} \mathrm{C}\left(2500^{\circ} \mathrm{F}\right)$, and permeability to gases is quite important. Aluminum castings are poured at about $760^{\circ} \mathrm{C}\left(1400^{\circ} \mathrm{F}\right)$, and the coating must provide more liquid permeability to allow high molecular weight liquid products to be absorbed.

Coatings for aluminum castings have a different formulation from those used for iron castings. The decomposition of the foam during pouring of aluminum causes a large heat loss from the advancing metal front. The heat lost from the advancing metal front goes into the foam and causes pyrolysis.

Coatings for aluminum castings must be thermal insulators to reduce the second major source of heat loss which is conduction through the coating into the sand surrounding the pattern. It is highly desirable that the coatings be insulators, but because they are used in thin layers, usually in thicknesses of less than 0.010 in, they can never be perfect insulators. Coatings without sufficient insulating properties allow metal in thin-walled castings to freeze before the foam pattern can be completely displaced. Inadequate surface insulation caused either by improper material selection or inadequate thickness results in laps and folds as the metal is depleted of the heat needed for fusion where the metal fronts meet.

There are presently no rules for selecting the best coating for a particular casting. Coating selection is a trial and error process based on past experience. Once a basic formulation has been tried, minor variations in the mixture may be made to modify or optimize the coating viscosity and application thickness for specific products. The final control on the selected coating is usually based on solution density, solids content, and application weight. Variations in coating density are included in most coating evaluations to insure the results obtained relate to the conditions likely to be encountered during use.

The target coating thickness is typically in the range of $0.25-$ $0.50 \mathrm{~mm}(0.010-0.020 \mathrm{in.})$. Higher pouring temperatures and higher metal head pressures make thicker coatings more appropriate. Permeability for liquids and gases must be maintained even in thick coatings. Weighing clusters before and after the coating is dry 
allows a determination of the dry coating weight. This is one of the more informative measurements of coating uniformity and consistency.

A wide variety of coating formulations have been developed in the past ten years for use in making iron and aluminum castings. The coatings are usually described in terms that describe their heat transfer characteristics (insulating, high conductivity, etc.) and gas flow characteristics (low, medium, and high permeability). These coatings have been developed with years of effort and experience. Much effort has been required because there are no accepted laboratory methods for describing the properties of interest. The developments generally require careful plant trials and correlations with formulations by the casting suppliers.

The objective of the coating consistency task in the current project was to develop procedures for monitoring coating properties that control the metal/pattern exchange and determine the variability in some existing coatings. Coatings for aluminum and iron castings were of primary interest. The ultimate objective was to develop and provide operating foundries with measurement procedures that could be used to monitor and control coating properties. In addition, these procedures were intended to assist coating manufacturers in developing and maintaining consistent properties in products supplied to the industry.

\subsection{Casting Eill Model}

In addition to providing some mechanical support, the coating serves as a "valve" to control metal flow into the cavity. It does so by controlling the rate of escape of gas from the mold cavity. A model of the foam pattern displacement process is illustrated in Figure 2.1. In this model, a coated foam pattern is surrounded by unbonded sand as a molten metal front moves through the mold cavity. As molten metal fills the mold cavity, a gap forms between the advancing metal front and the receding pattern material. This gap, or "kinetic zone," contains a mixture of air and foam pyrolysis products. The foam pyrolysis products can consist of liquid and gaseous hydrocarbons produced by melting and decomposition of the pattern. Pyrolysis of EPS produces both liquid and gaseous products whereas pyrolysis of PMMA produces predominantly gaseous products.

When molten aluminum is poured into a mold formed using an expanded polystyrene pattern, the pyrolysis products are mostly liquid and the gap is rather small. When iron is poured, the gap is larger and contains more gaseous decomposition products because of the higher iron pouring temperature.

As molten metal fills the mold cavity, the air, gas, and liquid must escape at a rate determined by pattern geometry, foam density, 


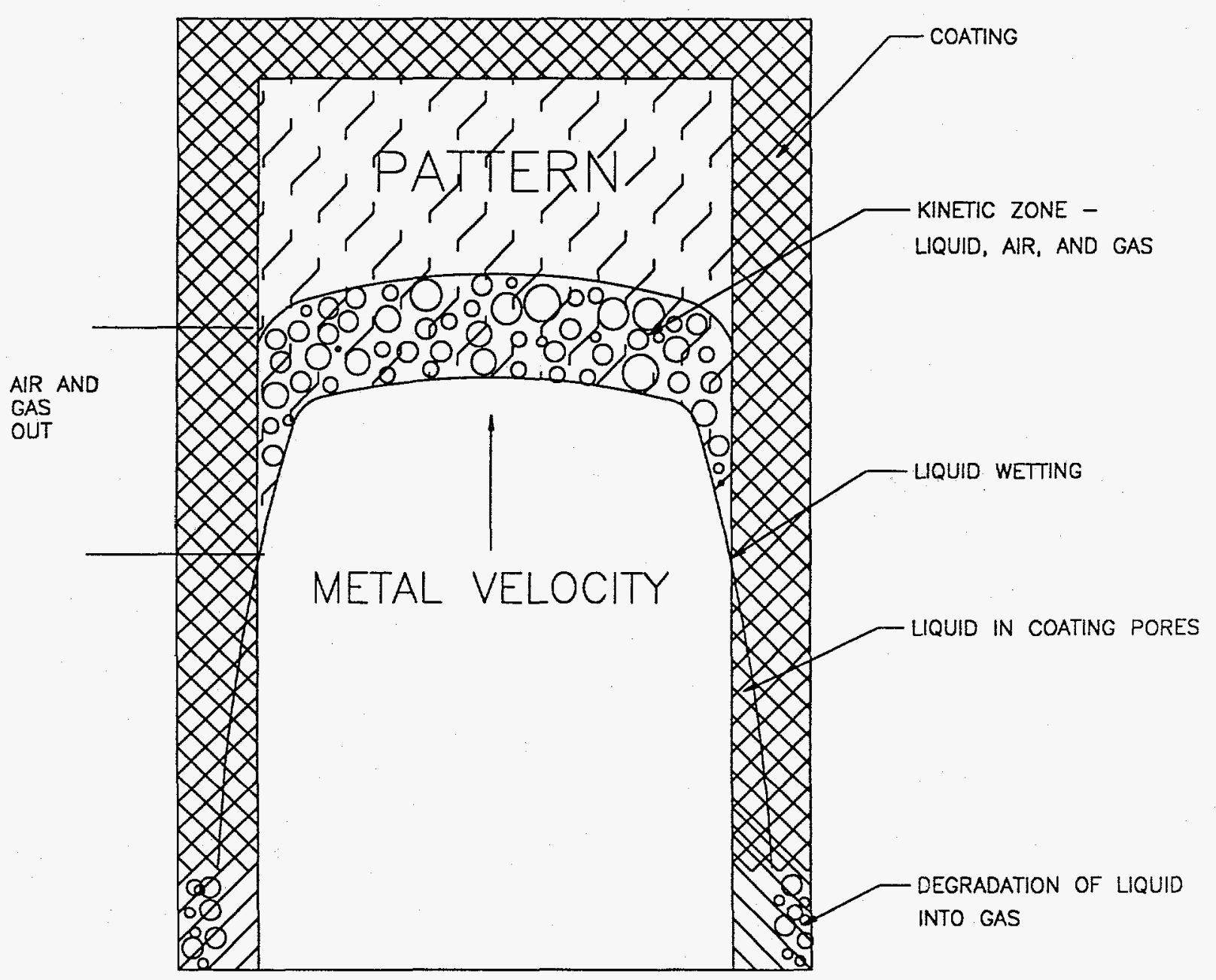

Figure 2.1 Physical Model of Metal/Pattern Interface. 
and metal front velocity. The air and gaseous decomposition products escape through the coated surface between the metal front and the solid foam pattern. This must be accomplished before the liquid pyrolysis products reach the temperature at which they wet and wick into the coating. Liquid polystyrene wets the refractory coating at a temperature of approximately $250^{\circ} \mathrm{C}\left(480^{\circ} \mathrm{F}\right)$. (2) When this occurs, the coating pores become clogged and no further transport of air and gaseous products through the coating can occur. (3)

During mold filling, liquid pyrolysis products may adhere to the coating surface but not wet and wick into the coating until the metal front has passed. As molten metal passes, the liquid pyrolysis products are heated to a sufficiently high temperature to cause the liquid to wick into the coating and start decomposing into gases. The gaseous products migrate into the sand where they may cool and be condensed or they may exit the flask.

If the liquid pyrolysis products are not removed from the metal surface as the mold is filled, the carbonaceous residue trapped between the casting and the coating causes casting surface defects sometimes called "worm tracks". The coating must also absorb the pyrolysis products to permit metal bonding where the metal fronts meet. If the pyrolysis products are not absorbed, they inhibit metal front fusion and produce fold defects where the fronts meet.

Several variables including pattern density, density gradients within the pattern, metal pouring temperature, metallostatic head height, and pattern geometry are known to influence metal fill rate and defect formation.(4) However the permeability of the refractory coating is the dominant variable controlling the metal fill velocity and metal front shape. Metal fill velocity and metal front shape control most defect formation in lost foam castings.

High metal velocities in the mold cavity cause porosity in both iron and aluminum castings and carbon defects in iron castings by entrapping liquid pyrolysis products. These liquid pyrolysis products are degraded as they are heated by the molten metal and form gas pockets in the casting.

Excessively low fill velocities cause misruns and folds in aluminum castings and mold collapse in iron castings. In order to control the metal fill rate and thus minimize defect formation in lost foam castings, the permeability of the coating to air, gas, and pyrolysis liquids must be accurately controlled.

Iron castings are poured at temperatures of about $1370^{\circ} \mathrm{C}$ $\left(2500^{\circ} \mathrm{F}\right)$, and permeability to gases and liquids is quite important because of the large amount of gas formed. Aluminum castings are poured at about $760^{\circ} \mathrm{C}\left(1400^{\circ} \mathrm{F}\right)$, and the coating may need to provide more liquid permeability to allow liquid products to escape. Fewer 
gases are formed at aluminum pouring temperatures, but a quantitative relationship between pouring temperature and the volume of gas formed has never been established.

Based on this understanding of the events occurring during pattern replacement, two apparatuses have been developed to provide coating property measurements. These are referred to as the "air flow apparatus" and the "liquid flow apparatus". The air flow apparatus measures the flow of air through a coating of known thickness under a known pressure to determine the characteristic properties of the coating. Similarly, the liquid flow apparatus measures properties related to the ability of the coating to absorb liquid pyrolysis products.

\subsection{Air Flow Apparatus}

An air flow apparatus was developed to measure gas flow rates at various pressures, and a schematic of the air flow apparatus is illustrated in Figure 2.2. The resulting data is used to calculate two physical constants, $A_{0}$, the tortuosity coefficient, and $B_{\circ}$, the viscous coefficient. These coefficients are used in classical flow equations to calculate the gas and air flow rates at various pressures through coatings of various thickness. These fundamental properties can be used to calculate gas permeability under a wide range of pressures and temperatures.

\subsection{Liquid Flow Apparatus}

A liquid flow apparatus was developed to record the real time weight of liquid absorbed into a coating as influenced by external pressure and capillary pressure. This apparatus is schematically illustrated in Figure 2.3.

During pouring, the metal exerts pressure on the gases and liquids in the mold cavity during pouring. Capillary pressure is always present as a naturally occurring phenomenon. Typical pressures during the aluminum casting process range from 6.89 to $20.6 \mathrm{kPa}$ ( 1 to 3 psig) and typical pressures when iron is poured range from 1 to 5 psig. Capillary pressures are dependent on pore sizes and are typically 3.4 to $17.2 \mathrm{kPa}(0.5 \mathrm{psig}$ to $2.5 \mathrm{psig})$.

A typical coating response is illustrated in Figure 2.4. The non-linear portion of this curve is a result of capillary and pressure driven flow of liquid into the coating pores. When the coating pores are filled, the curve becomes linear as flow is controlled by the rate of liquid flowing through the coating. The important feature of the weight/time response in Figure 2.4 is the initial slope. This slope provides a measure of the rate at which liquid pyrolysis products 


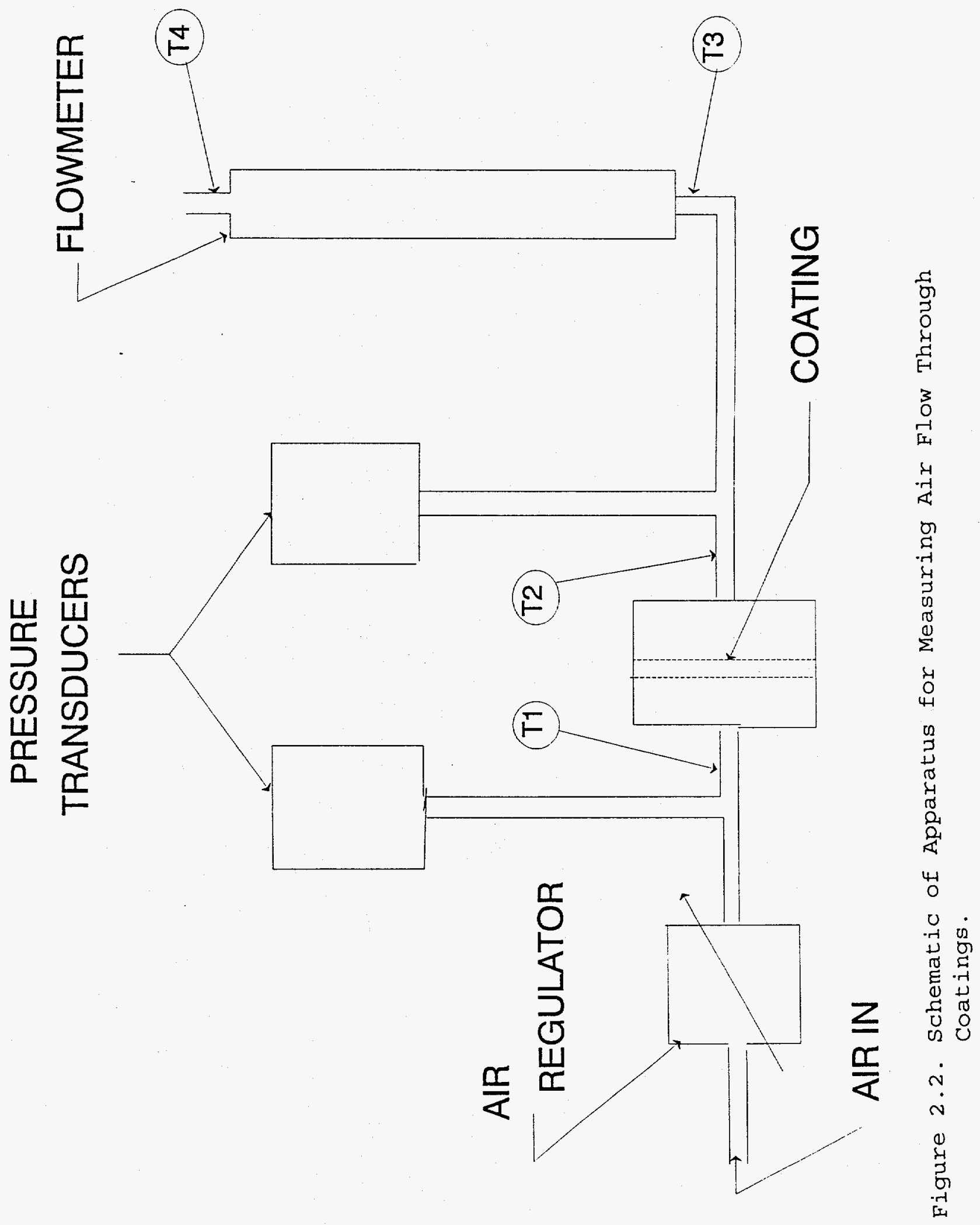




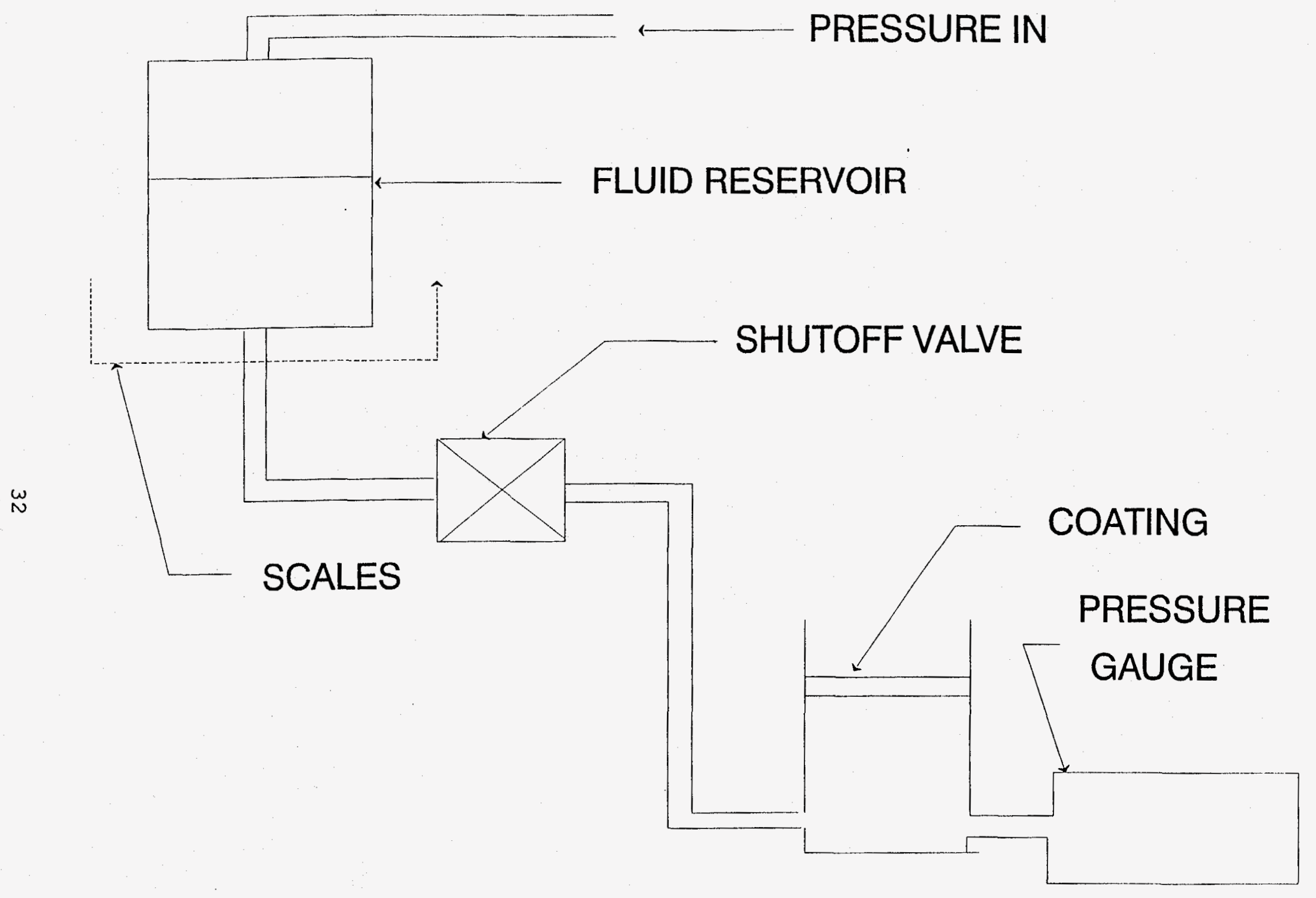

Figure 2.3. Schematic of Flow Apparatus for Measuring Liquid Flow into and Through Coatings. 


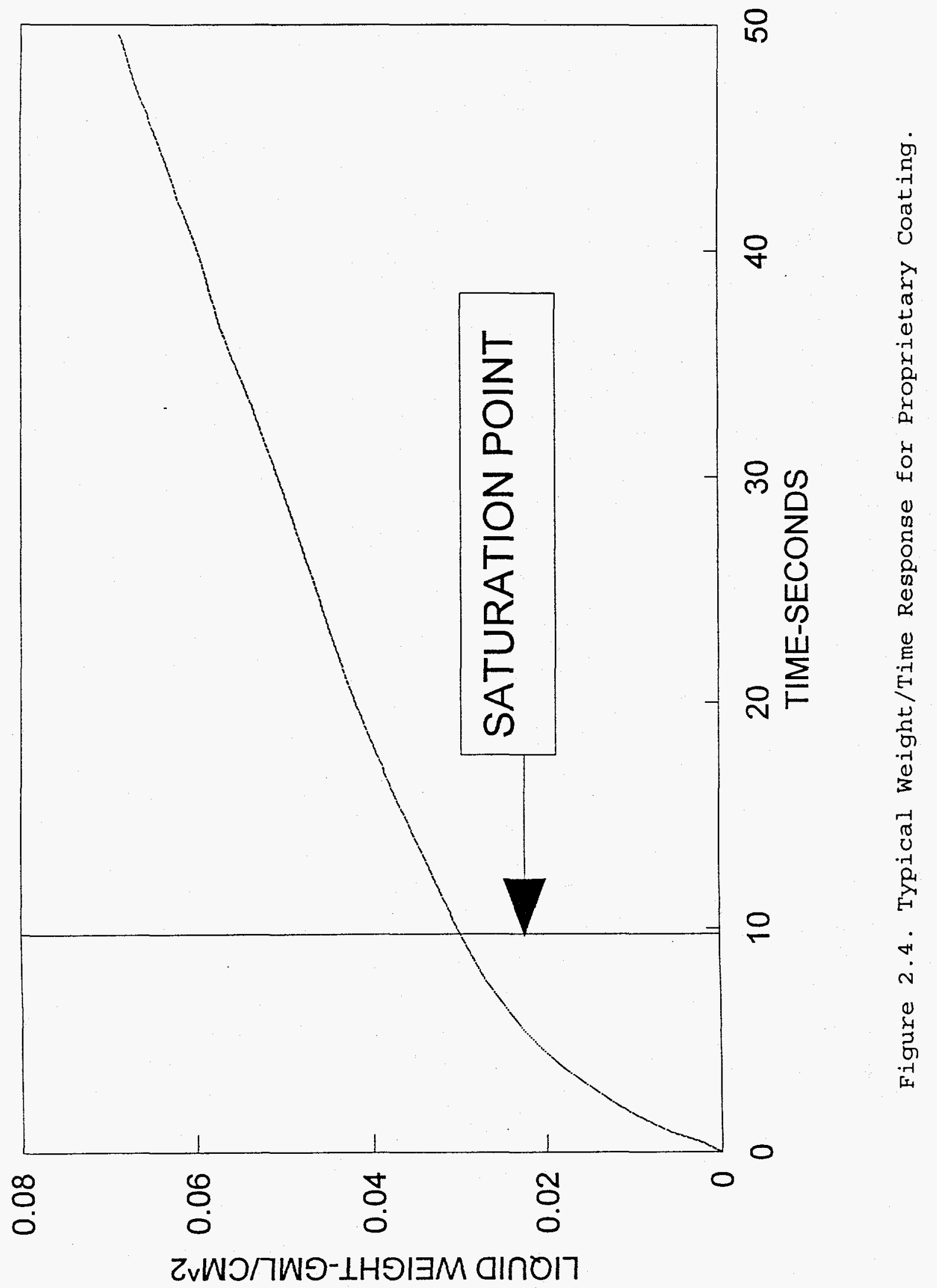

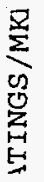

年 
(LPP) can be removed from the mold cavity during the metal-pattern exchange.

A study of coating variability was conducted over a four-month period using weekly samples from six foundries. Data on coating property variability was collected. Significant variations in air flow rates and liquid absorption rates were seen in each coating. These variations are related to the incidence of casting defects including laps, folds, and porosity.

The procedures developed for measuring the liquid and gaseous permeability of coatings were used in an extensive series of experiments on coatings used in one aluminum foundry. Increased coating consistency resulted in reducing casting defects from $7 \%$ to a consistent $1 \%$. These measurement procedures were also used to isolate the coating as the cause of a sudden scrap increase in one iron foundry.

The liquid absorption procedure consists of placing a disk of the coating of known thickness on the surface of a container of olive oil. Olive oil has approximately the same viscosity and density as the liquid polystyrene pyrolysis products. The initial dry weight and the final saturated weight of the disc provides a measure of open porosity and total liquid absorptive capacity. The time required to achieve saturation provides a measure of the rate of liquid absorption by the coating.

These data can be used in conjunction with the physical constants determined in the air flow apparatus to calculate the liquid absorption rate caused by both capillary and pressure driven flow. These calculations are based on a coating model with all pores having the same length and radius. Although this model does not represent a real coating, the results of the analysis agree quite well with measured coating response as illustrated in Figure 2.5. The value of this approach lies in calculating pore size, pore length, and number of pores. These parameters provide numerical constants that describe an idealized coating that produces the same air flow and liquid absorption response as the coating being evaluated.

\section{4 Summary and Conclusions - coating control}

1. Procedures have been developed to accurately measure the rate of air flow through the coating (permeability) as a function of pressure.

2. The coating permeability for gas, especially air, is the primary factor controlling the rate of pattern replacement by molten metal. 
$\varsigma \varepsilon$

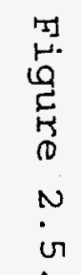

$\begin{array}{ll}\Omega & 2 \\ 0 & 0 \\ 5 & 3 \\ 0 & 0 \\ 0 & 0 \\ 4 & 5 \\ 0 & 5 \\ 0 & 0 \\ 0 & 0 \\ 0 & 0\end{array}$

ณ

농음

量 3

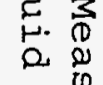

巴点

( 0

인

함.

‥ 옹

.

范已

(น)

O

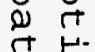

战

उ

त

点.

$\stackrel{\varrho}{\models}$

LIQUID WEIGHT-GM/CM^2

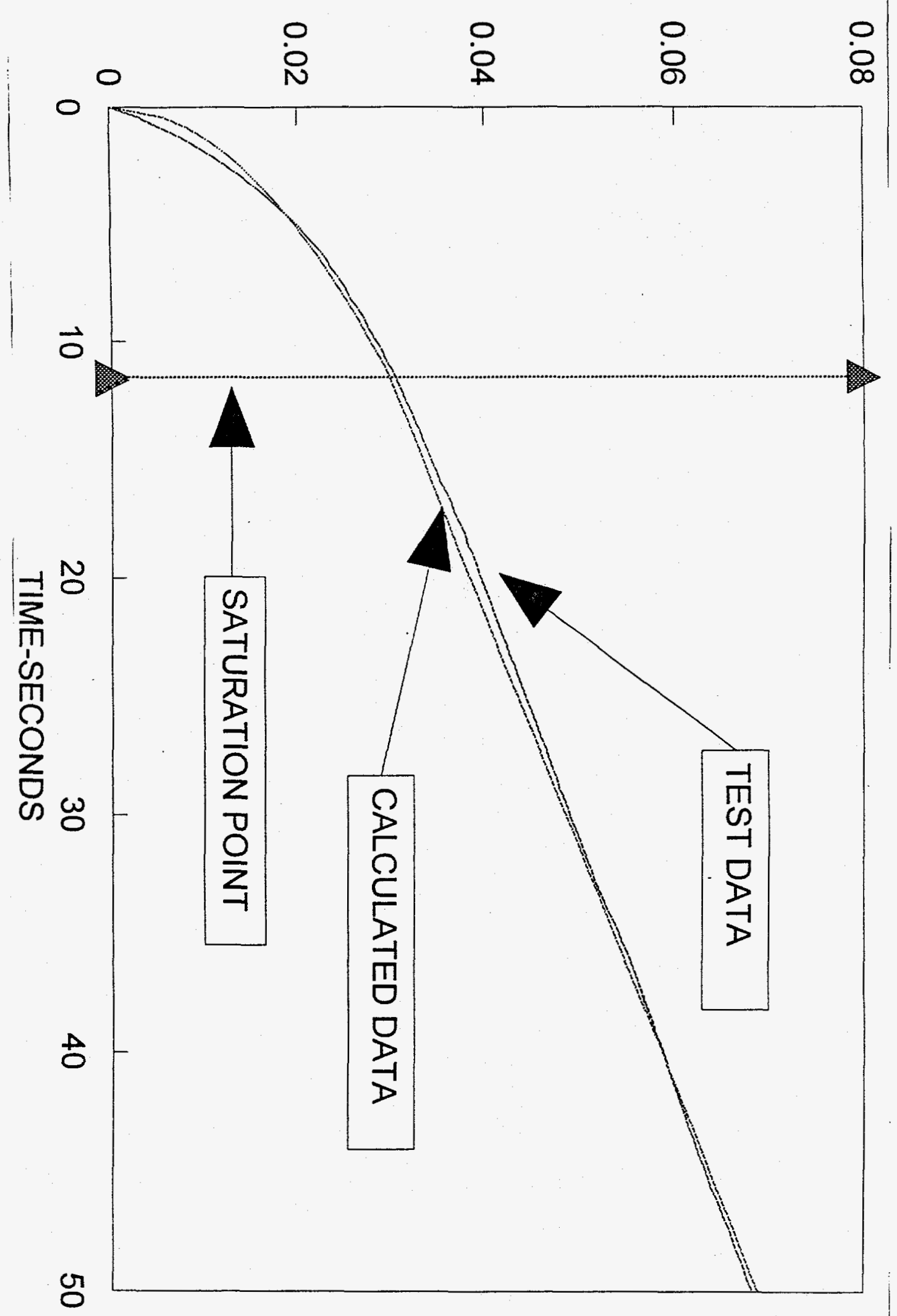


3. Air and gas removal from the mold cavity must occur prior to the time that the Iiquid wets the coating. Wetting by pyrolysis products occurs at about $250^{\circ} \mathrm{C}\left(480^{\circ} \mathrm{F}\right)$ and closes the coating pores.

4. Room temperature permeability measurements of coatings are reasonably good measures of permeability during pouring. The pores are open until pyrolysis products soak into and close the pores.

5. Procedures have been developed to measure the liquid absorption rate of coatings.

6. Liquid pyrolysis products must be removed at a rate equal to their rate of generation to prevent accumulation at either the metal/pattern interface or the metal coating interface. Failure to remove the liquid pyrolysis products at the metal pattern interface results in a defect known in the industry as "worm tracks". Failure to remove the products at the Iiquid metal interface results in incomplete metal bonding where metal fronts meet.

7. Air/gas flow rates and liquid absorption rates largely control coating performance during pouring.

8. A correlation was developed between coating properties and causes of casting scrap in one aluminum foundry.

Excessively high permeability was associated with short pour times and excessive porosity occurred in the resulting

aluminum castings. Excessively low permeability was associated with long pouring times and laps and misruns in the castings.

9. Careful quality control to maintain consistency in a micabased coating resulted in a scrap reduction in one aluminum foundry from seven percent to under one percent.

10. The coating quality control procedures have been extended and are applicable for measuring properties of coatings used on iron castings.

3.0 SAND AND COMPACTION EEFECTS

\subsection{Introduction}

A cluster or tree of foam patterns is ready to be backed up with sand in a flask after it has been coated with a thin layer of 
refractory and thoroughly dried. The sand fill and compaction cycle must result in filling all pattern passages and compacting the sand in all positions inside and outside the pattern to provide support and rigidity during pouring.

Vibration during flask filling has two main objectives. The first is to cause sand flow into pattern cavities, and the second is to compact the sand to produce a rigid mass with sufficient stiffness and density to resist metal and gas pressures developed during pouring. During cavity filling, the fluidized and flowing sand has a density in the range of 93-98 $\mathrm{lb} / \mathrm{ft}^{3}$. During compaction, the sand density should increase to a value in the range of 0.168 to $0.176 \mathrm{~g} / \mathrm{Cc}$ (103-108 lb/ $\left.\mathrm{ft}^{3}\right)$ depending on the exact sand being used. Sand must continually migrate from upper regions of the flask into pattern cavities as densification occurs.

Both fill and compaction must be accomplished without pattern distortion. Understanding, controlling, and maintaining reproducible sand fill and compaction is essential if dimensionally accurate castings with a good surface finish are to be produced.

The duration of the sand fill and compaction cycle is principally controlled by the time required to fill internal pattern cavities. Sand densification occurs rapidly inside these cavities, but considerable amounts of time may be required to fill the cavities. There is always a desire to minimize fill and compaction time to maximize the number of flasks that can be poured each hour. This sometimes causes operators to use fast fill cycles with high table accelerations which cause rapid sand migration at the expense of pattern distortion.

Historically, developing the fill and compaction cycle for each new pattern cluster was based on cumulative employee experience and trial and error. Castings are typically poured after compacting patterns with various rates of fill, table accelerations, and acceleration dwell times. When castings with an acceptable accuracy, precision, and surface condition are achieved, the cycle for that part and cluster configuration is recorded for future use. This process works and continues to be used, but it often requires considerable amounts of time to develop the correct cycle, analyze and qualify the castings produced, and make changes in the tree arrangement or cycle to achieve consistent and acceptable results.

The objective of this task of the Lost Foam Project was to extend the understanding of sand fill and compaction to minimize pattern and casting distortion. In achieving this objective, a need developed for a methodology that could be used to advance the understanding and reduce the time of qualifying new parts for production. This report outlines some approaches to filling these needs. This will be done in 
the context of the operation of the two major types of compaction equipment.

This discussion is divided into two main sections. The first deals with basic fill and compaction parameters in clamped and unclamped flasks including:

1. sand motion in flasks during vibration,

2. forces involved in horizontally and vertically vibrated flasks, and

3. requirements for achieving sand migration and densification.

The second section provides guidelines for controlling the important fill and compaction variables.

\subsection{Basic Fill and Compaction Parameters}

3.2.1. Clamped and Unclamped Flasks. All horizontal compactors operate with clamped flasks, and most vertical compactors operate with unclamped flasks. The availability of different flask and compactor designs has raised questions about which design provides the most rapid and efficient sand migration and compaction. The basic question to be answered is not whether the flask is clamped or unclamped, but how does the sand respond to the cyclic loading in the two types of flasks. Since the flask is the structure through which forces are transmitted to the sand, it is desirable to understand the flask response to externally applied forces before dealing with sand migration within the flask.

Flask response to external forces is dependent on its physical structure, geometry, and the amount of sand in the flask and is largely independent of the mode of force input (sine wave or impact). A flask deforms during vibration in many directions, but the deformation is greatest in the low stiffness direction. This principle is mathematically stated in Equation (1) which describes natural vibration of elastic bodies.

$$
f=N^{2} x(E I / W)^{n}
$$

where:

$$
\begin{aligned}
\mathrm{f} & =\text { Flask natural frequency }(\mathrm{Hz}) \\
\mathrm{N} & =\text { Boundary conditions of body } \\
\mathrm{EI} & \left.=\text { Flexural rigidity (lb-in }{ }^{2}\right) \\
\mathrm{W} & =\text { Weight per unit length (lb/in) }
\end{aligned}
$$

This equation indicates that the natural or resonant frequency (f) of a structure increases as the square root of the flexural rigidity (EI) 
and implies that any structure will vibrate under the influence of a suddenly applied force.

The amplitude of vibration is described by Equation (2).

$$
A=G g /(2 \pi f)^{2}
$$

where:

$$
\begin{aligned}
& A=\text { Amplitude (in.) } \\
& G=\text { Number of g's acceleration } \\
& \left.g=\text { Acceleration of gravity (in/ } \sec ^{2}\right) \\
& f=\text { Frequency }(\mathrm{Hz})
\end{aligned}
$$

Combining Equations (1) and (2) yields Equation (3) which describes the vibrational amplitude in terms of the physical structure:

$$
A=\operatorname{GgW} /\left(4 \Pi^{2} N^{4} E I\right)
$$

This equation predicts that a body with a suddenly applied external force will vibrate at an amplitude proportional to the inverse of its stiffness. In the case of a structure with an unsymmetrical geometry, the direction of maximum vibrational amplitude is the direction of least stiffness. Vibrations at lower amplitudes will occur in other directions having higher stiffness values.

Equation (3) predicts that a cylindrical flask will vibrate with a larger amplitude across its diameter compared to a direction along its vertical axis. A square flask similarly vibrates with a larger amplitude across the top compared to a direction along its vertical axis. In both cases, the transverse vibrational amplitude is greater near the open top compared to the flask bottom because of the lower flexural rigidity near the top.

These vibrational predictions have been confirmed by measurements made on both bench scale and commercial round and square flasks. The maximum flask deformation occurred horizontally as illustrated in Figures 3.1 and 3.2 for round and rectangular flasks, respectively. The flask deformation pattern was independent of the type of force input, i.e., the applied forces could be a result of either impact or sine wave loading. More importantly, the flask deformation pattern did not change with the direction or the location of the input force.

The importance of this vibrational phenomena is that vertically and horizontally driven compactors have both horizontal and vertical vibrational components introduced by flask wall deformation. These vibrational components are superimposed on the compactor table motions. One table may be more efficient than another in fluidizing and compacting sand, but the direction of flask vibration is largely controlled by flask geometry and stiffness in particular directions. 
FLASK WITH HIGH

NATURAL FREQUENCY
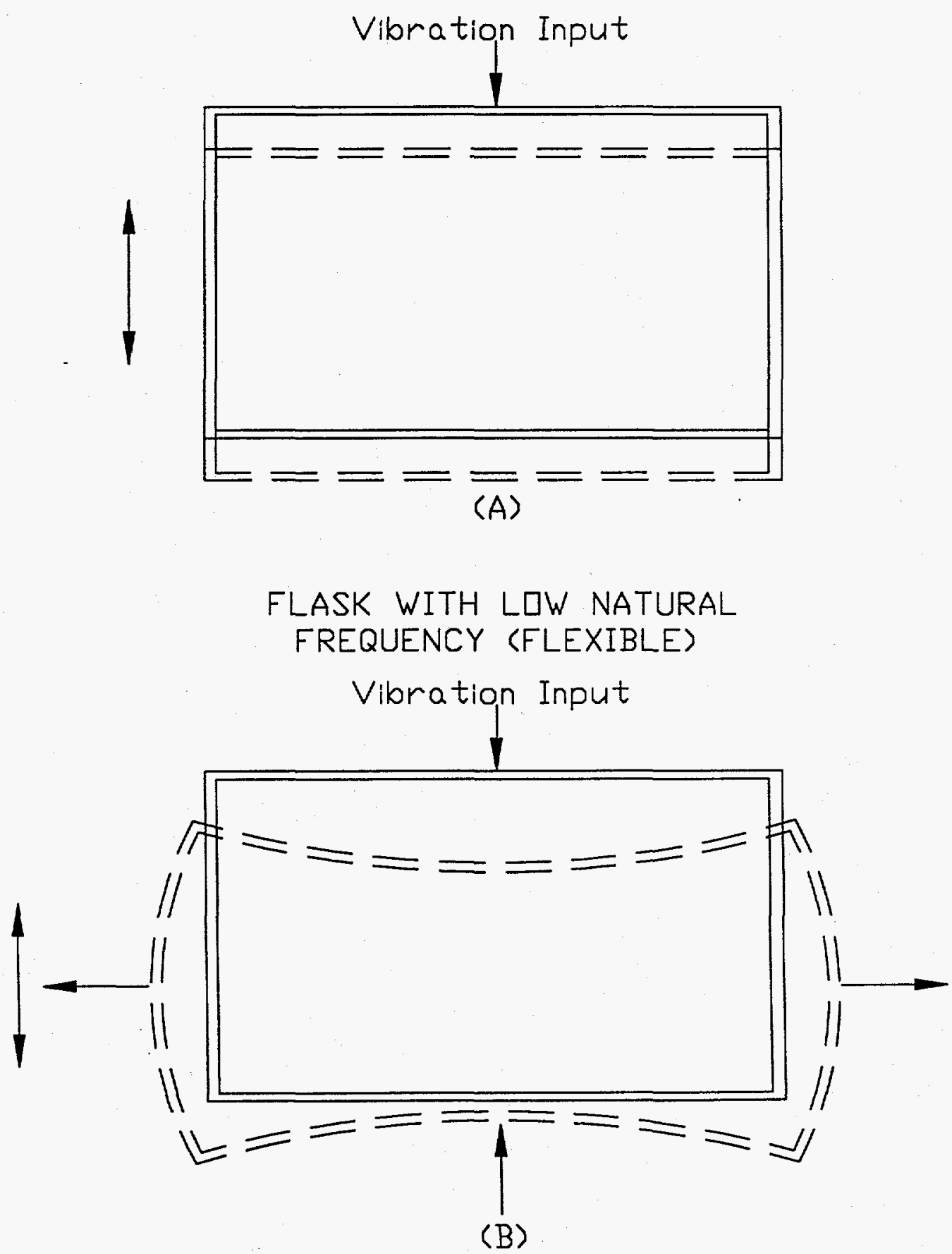

Figure 3.1. Deformation of Empty Flask Walls from Impact Loading on a Round Flask. 

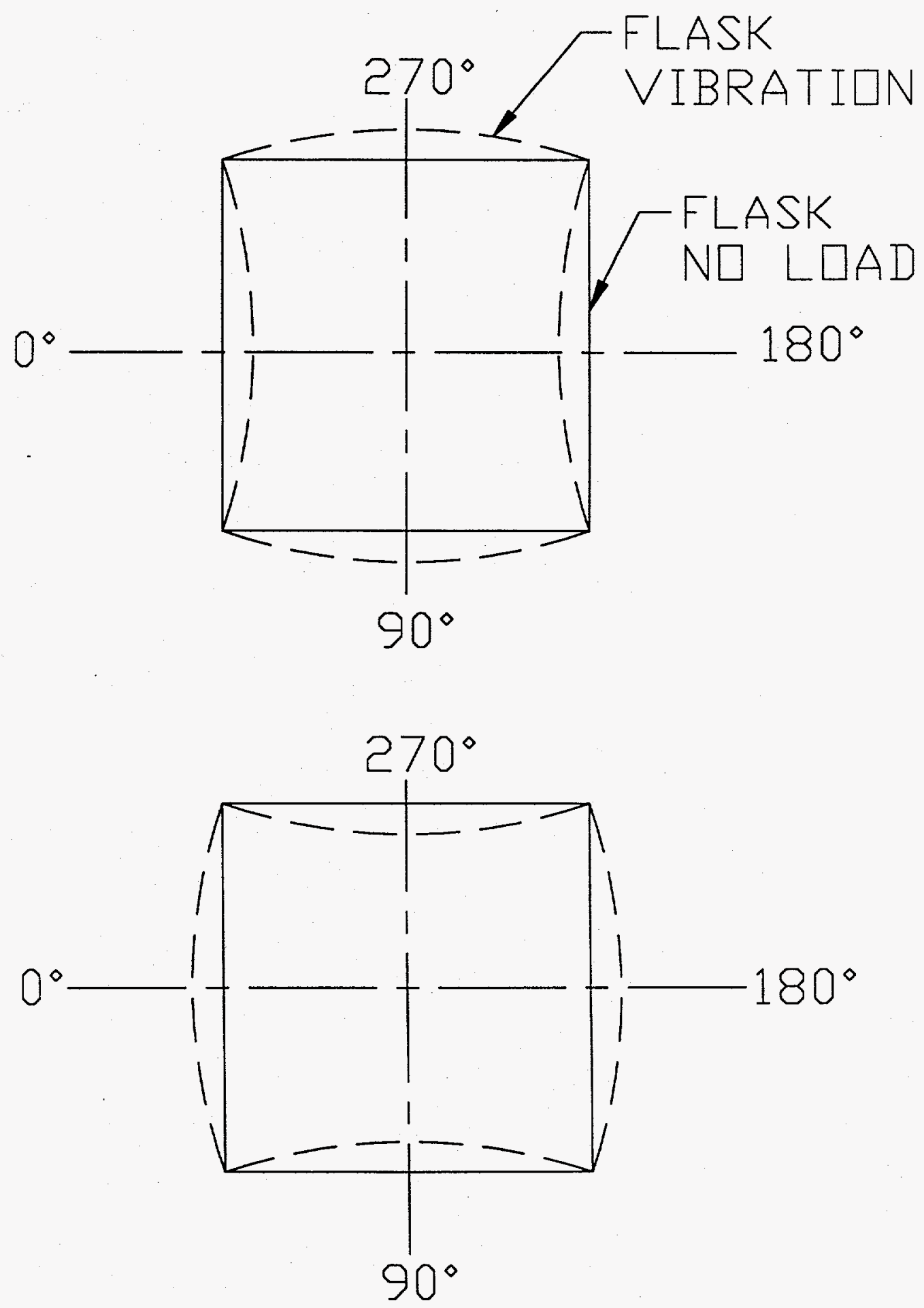

Figure 3.2 Deformation of Empty Flask Walls from Impact Loading on a Square Flask. 
Vertical compactors produce high vertical accelerations in the sand, but associated horizontal accelerations may be much higher. The ratio of horizontal to vertical accelerations depends on the ratio of vertical to horizontal flask stiffness, sand density, and the amount of off-axis loading. Off-axis loading occurs as the table pedestals contact the flask at positions remote from the axis of symmetry. Typical natural frequencies are usually in the range of $1500 \mathrm{~Hz}$ in the vertical direction and $300 \mathrm{~Hz}$ in the horizontal direction in commercial round flasks. Higher natural frequencies imply higher flask stiffness.

The addition of sand to a flask has a significant damping effect on vibration. As sand is added, the flask vibrational frequency approaches the frequency of the input force, but the pattern of flask deformation does not change, i.e., the vibrational amplitude is still highest in the low stiffness direction.

The significance of the flask wall deformation can be seen in both round and square flasks during vibration. Sand movement in a round flask on a vertical compactor occurs upward along the flask centerline and downward at the flask walls while the sand is fluidized. Sand movement in horizontal compactors similarly occurs upward along the flask centerline and perpendicular to the direction of vibration.

These phenomena are a result of the flask wall deformation patterns illustrated in Figures 3.1 and 3.2. The inward deformation of opposite walls introduces compression waves into the sand which travel toward the flask center. When these compression waves meet, the sand moves in the least restricted direction, which is upward toward the free sand surface. At $90^{\circ}$ to the compression wave, the flask walls move outward creating areas of lower sand density near the flask wall. Hence sand flow occurs toward the walls, but the horizontal velocity is not as high as the vertical velocity because the side walls produce some restraint to the flow. Flask wall movement is dependent on the flask stiffness and can be controlled by flask design.

3.2.2. Horizontal and Vertical compactors. The flask serves as the energy transport medium between the compactor table and the sand. Even though the drive table may have principally a horizontal or vertical direction of motion, other vibrational modes are introduced into the sand because of flask wall deformation.

Flask deformation can be amplified beyond normal ringing when vertical accelerations above $1.0 \mathrm{G}$ are used, because the impact loading on the pedestals of a vertical table produces rotational moments on the flask about a horizontal axis. This occurs any time 
the flask impacts the table at a point off of the system (flask plus sand) center of gravity.

Horizontal flask accelerations of $20 \mathrm{G}$ have been measured in flasks vibrated on vertical tables operated with vertical accelerations of $2.0 \mathrm{G}$. These high horizontal accelerations create compression waves in the sand and produce the sand flow patterns illustrated in Figure 3.3.

A horizontally vibrated square flask produces elliptical flow patterns as illustrated in Figure 3.4. Sand flow occurs upward along the flask centerline as the compression waves converge along a plane perpendicular to the direction of table vibration.

Both square and round flasks have some areas where local sand acceleration values are low. Such areas have been mapped inside flasks with accelerometers. Cavities in foam patterns in the dead zones were found to fill quite slowly.

Foam pattern cavities in a round flask on a vertical compactor filled considerably faster when:

(1) the cavity openings were positioned near the flask wall,

(2) the cavity openings faced the wall, and

(3) the openings were positioned halfway between the pedestals.

Cavities filled about twice as fast on horizontal compactors as on vertical compactors when the same frequencies, orientations, and accelerations were used so long as the accelerations were above one $G$. In both vertical and horizontal compactors, the pattern cavities filled more slowly when located in the dead zones and when oriented such that cavity openings were not perpendicular to the direction of high amplitude flask wall vibration.

Horizontal vibration moves sand into cavities more quickly than vertical vibration in flasks vibrated above one $G$. On a vertical table, sand is accelerated upward by the table but accelerated downward only by gravity $(1.0 \mathrm{G})$. The downward motion of the sand is controlled entirely by gravity while the upward motion is controlled by the acceleration imparted by the table. The upward acceleration tends to compact the sand, but the free fall downward motion may result in some loss of density. If the vertical displacement is too high, the sand may not recompact under the influence of gravity.

During horizontal vibration, sand grain movement occurs as a rubbing, tumbling action in both directions of motion. Gravity assists the nesting of sand grains, and nesting occurs as the flask 


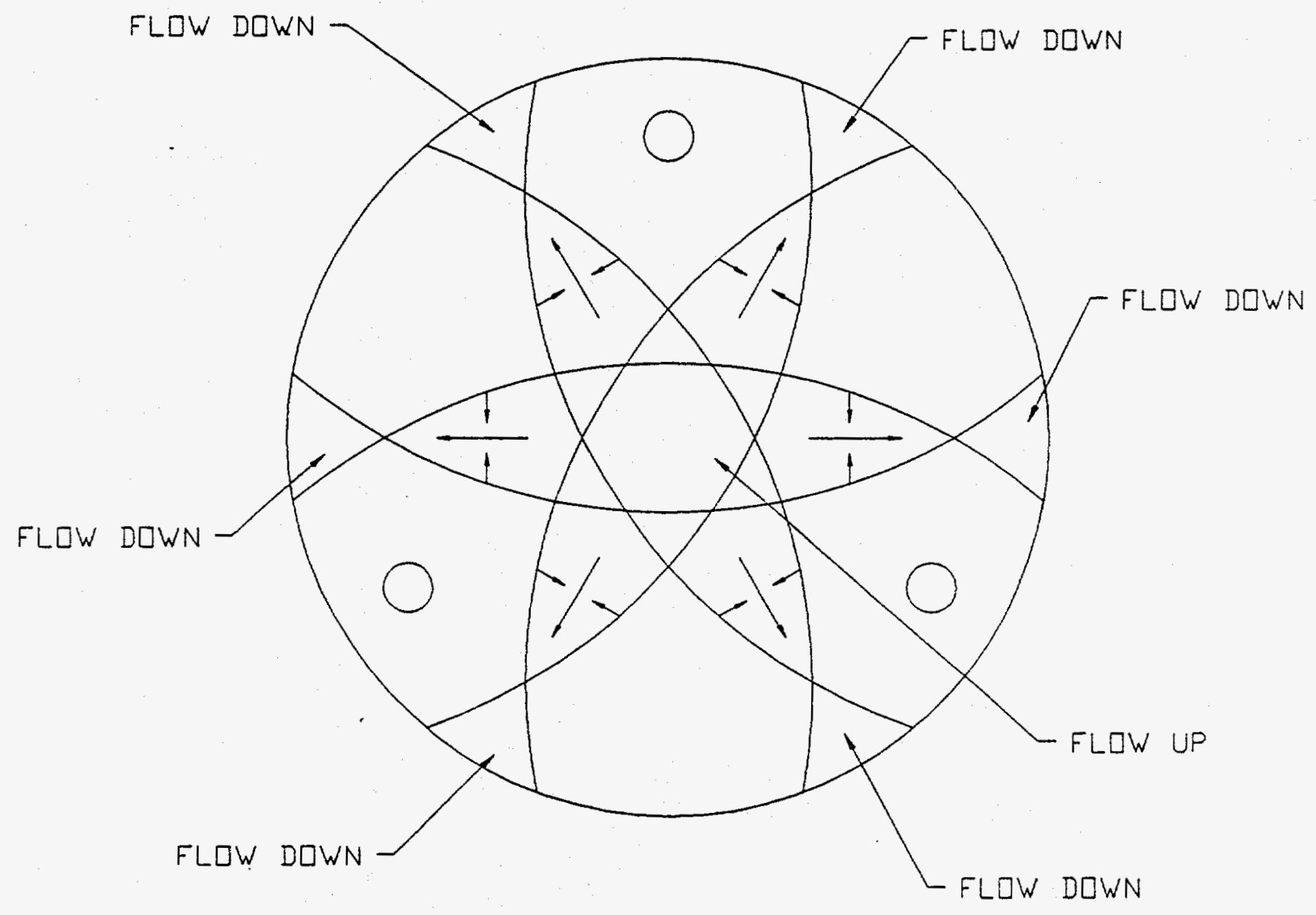

616-189b

Figure 3.3. Sand Flow Pattern in a Vertical Unclamped Flask. 

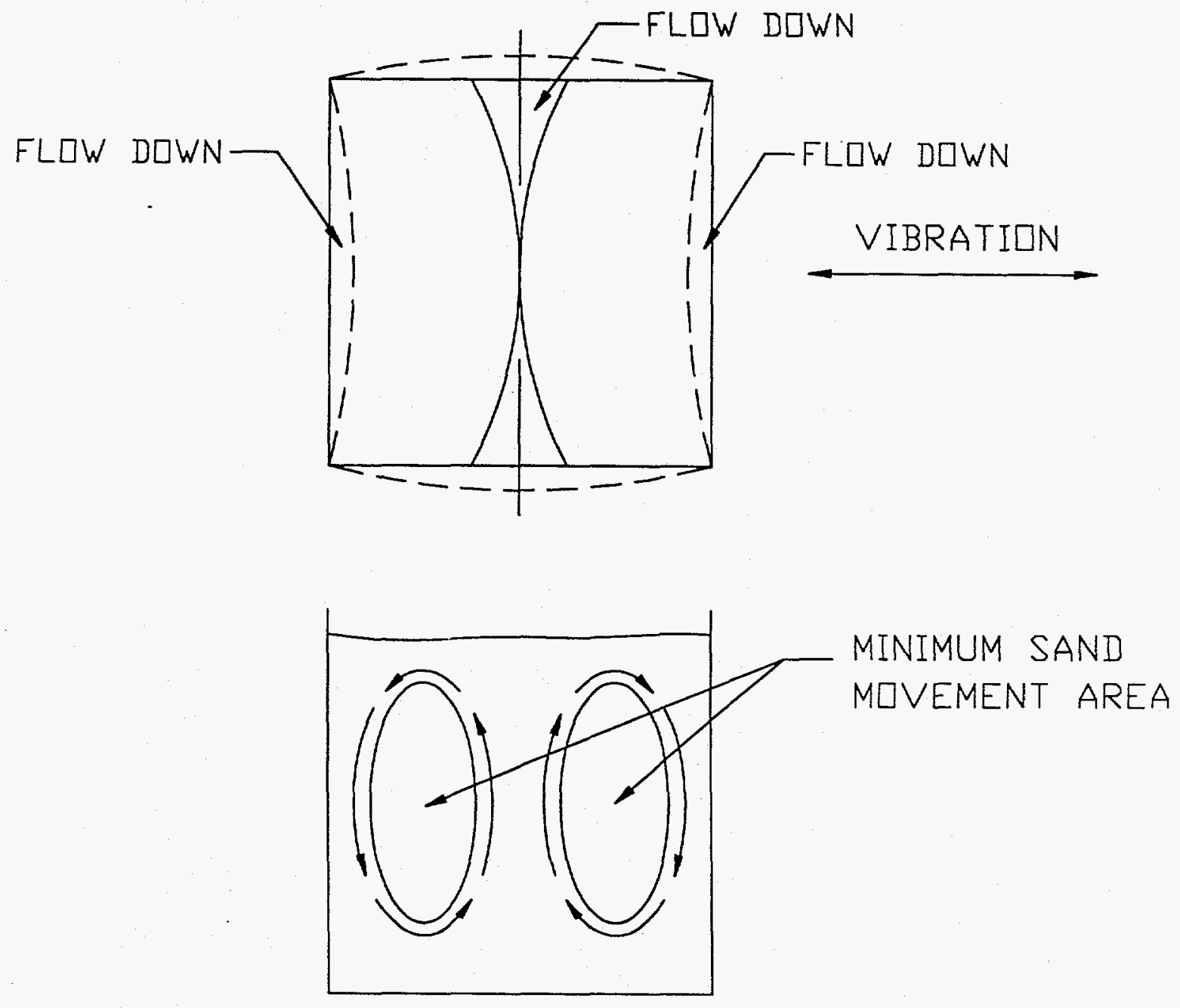

Figure 3.4. Flow Pattern in a Horizontal Clamped Flask. 
moves in both horizontal directions. Less time is required to migrate, fill, and densify the sand at equivalent frequencies and flask amplitudes compared to vertically accelerated flasks.

Although horizontal vibration would appear to be more efficient in filling and compacting sand, the flask geometry and sand flow patterns must also be considered. Horizontally vibrated flasks are typically rectangular which places some restrictions on pattern placement. Patterns with internal cavities must be placed with cavity openings facing the active flask walls to maximize the filling rate. More pattern placement options exist in round, vertically vibrated flasks since there are three active flask wall locations.

\subsection{Guidelines for Fill and Compaction}

Certain operational features are required of both vertical and horizontal compactors employing either clamped or unclamped flasks. Sand densification in the flask and pattern cavities must progress in a systematic, controlled manner beginning at the bottom of the flask and moving toward the top. This requirement is schematically illustrated in Figure 3.5. It is desirable to have a 25 to $75 \mathrm{~mm}$ (2 to 3 in.) thick layer of fluidized sand at the top sand surface with densified sand below the fluidized layer. These layers should move in a controlled manner from flask bottom to top to facilitate cavity filling and densification. Cavity filling occurs from and within the fluidized layer. Densification occurs below the fluidized layer as sand moves downward to decrease the void volume.

The sand addition rate should be controlled by a raingate that can deliver sand to produce flask fill rates not exceeding about 40 $\mathrm{mm} / \mathrm{sec}(1.5 \mathrm{in.} / \mathrm{sec}$ ) if maximum sand migration rate in the top $150 \mathrm{~mm}$ (6 in.) of sand in the flask is to be achieved. For patterns with large cavities that must be filled through relatively small openings, the sand addition must be halted when the sand level is 50 to $75 \mathrm{~mm}$ (2 to 3 in.) above the cavity opening. This can be accomplished with sand weighing systems built into the compactor table and with the use of programmable raingates.

Many sand delivery systems (raingates) deposit sand into a flask at relatively high rates without providing sufficient time for cavity filling and densification. Cavity filling deep within the sand can only be accomplished with relatively high accelerations, typically 3 to $4 \mathrm{G}$. Although high $\mathrm{G}$ levels aid sand migration and cavity filling, the sand motion and migration during densification can cause pattern warpage.

There are two basic modes of vibration. The first mode consists of almost total sand fluidization accompanied by mounding of sand at 


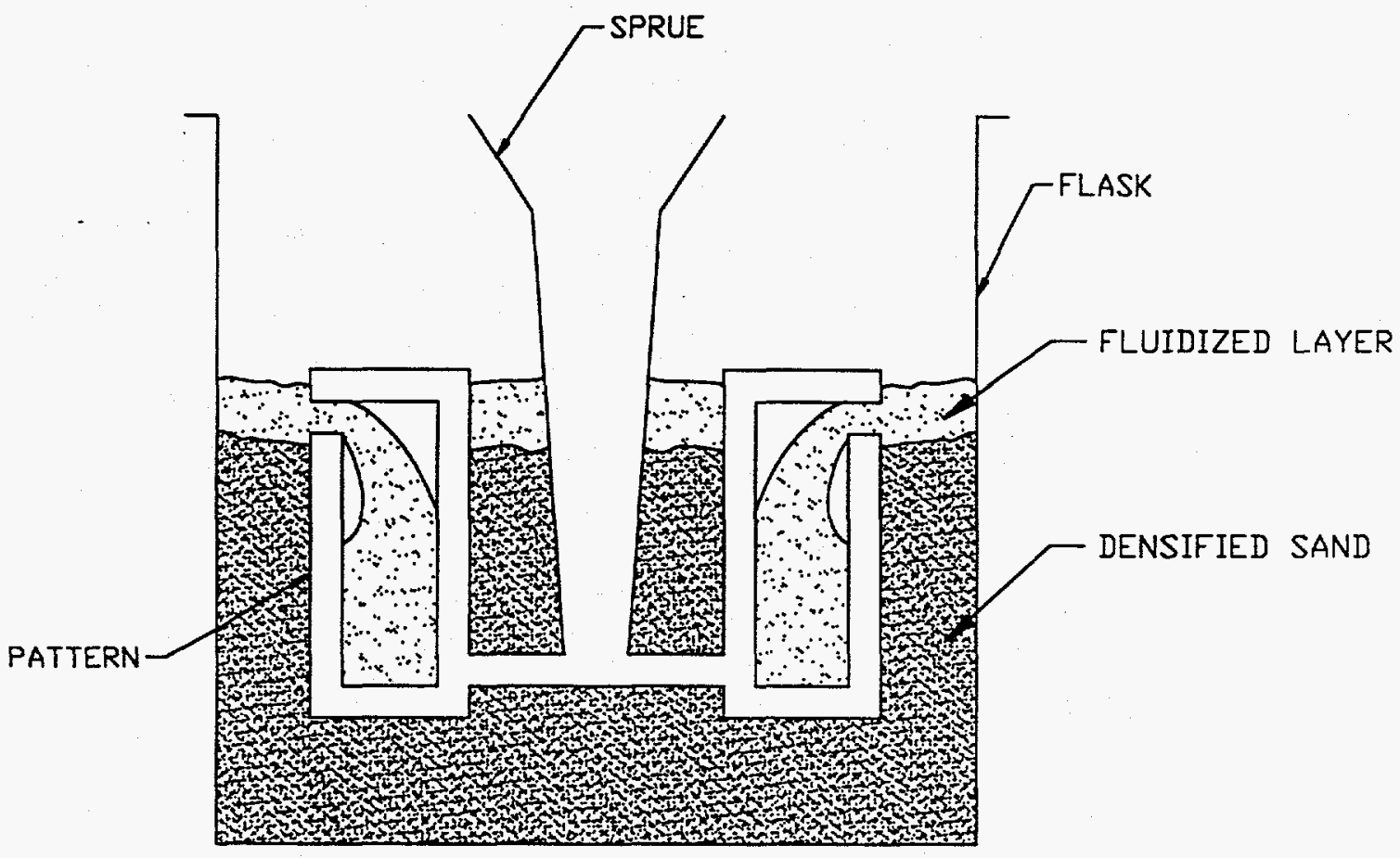

Figure 3.5. Fluidized Layer Filling of Cavities. 
the flask centerline. In round flasks, the mounding is produced as sand flows upwards along the centerline, outward on the free surface, and down along the flask wall. In the square flask, the mounding occurred on a line across the flask perpendicular to the direction of forced vibration. (In all cases, the round flasks studded were unclamped and vertically driven, and the square flasks were clamped and horizontally driven.)

The second vibrational mode consists of significantly less fluidization, as observed by the sand movement on the free surface. This condition exists in both round and square flasks at vibration amplitudes sufficient to cause fluidization. Evaluations of flask stiffness showed that flasks with lower stiffness produced more fluidization at a given vibrational amplitude, and flasks with higher stiffness produced more sand densification. This was consistent in all comparisons with one exception. An analysis of the exceptional system revealed that the cyclic force input (produced by rotating eccentric weights) was not rigidly clamped to the flask, and this produced some impact loading. Apparently, the impact loading of the stiff flask was sufficient to deflect the flask walls and cause high amplitude waves in the sand.

The two modes of flask vibration are illustrated in Figure 3.6 for a rectangular flask. The stiff flask transmits the cyclic input force with little flask wall deflection, as schematically illustrated in Figure 3.6(A). In this case, a compression wave is introduced into the sand in a controlled cyclic manner, and the wave travels across the flask at the speed of sound in sand. In normal size flasks and usual operating frequencies, this wave hits the opposite wall before the cycle is reversed.

If the flask is insufficiently stiff to resist the cyclic vibrational input force, the flask walls deflect in the manner illustrated in Figure 3.6(B). This wall movement pattern produces high amplitude compression waves in the sand traveling from opposite walls simultaneously and meeting in the middle. These wave impingements cause the sand movement upward toward the free surface.

\section{4 Summary and Conclusions of Compaction Studies}

Both sand fill and compaction in pattern cavities must be accomplished without pattern distortion. Improper equipment or equipment use can result in pattern distortion and/or poorly compacted areas (areas of low sand density) that result in metal penetration during pouring. Understanding, controlling, and maintaining reproducible sand fill and compaction is essential if dimensionally accurate castings with a good surface finish are to be produced. The significant results obtained in this area of study are summarized as follows: 
FLASK WITH HIGH

NATURAL FREQUENCY

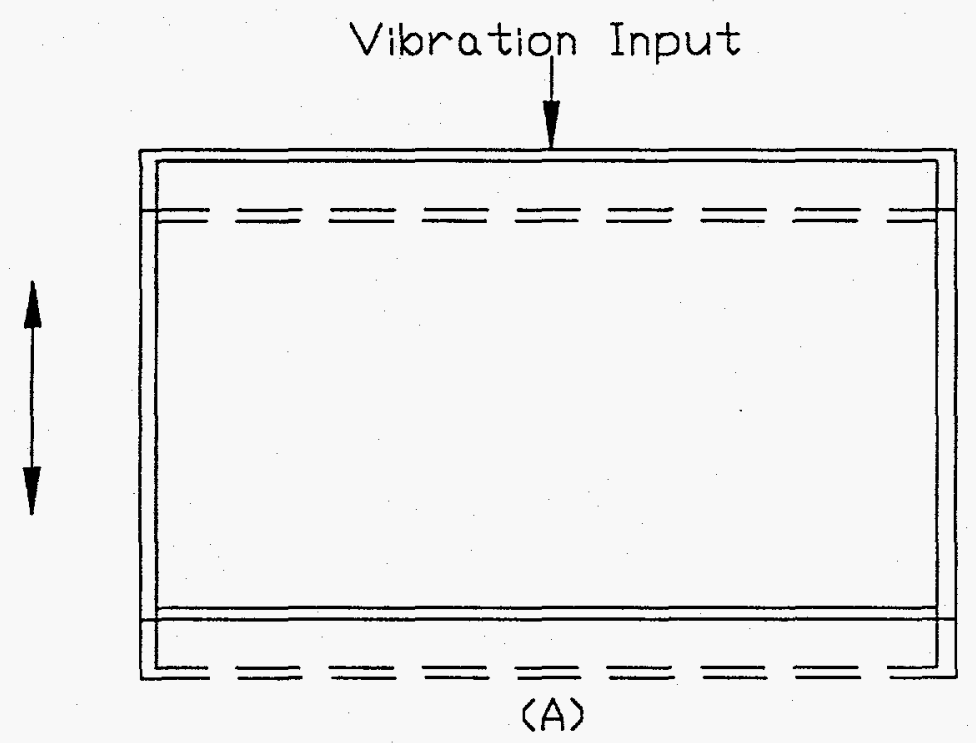

FLASK WITH LOW NATURAL

FREQUENCY (FLEXIBLE)

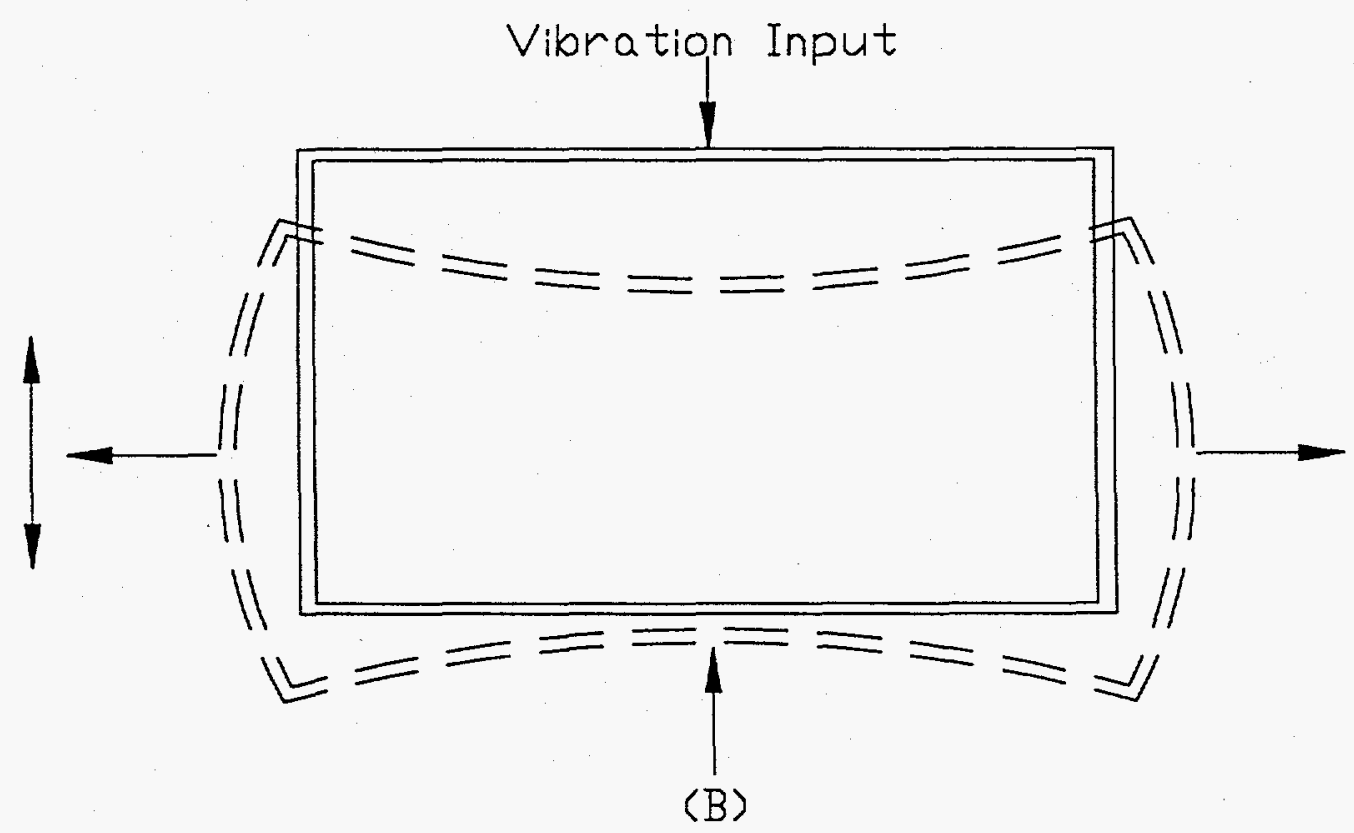

Figure 3.6. Basic Modes of Vibration in (A) Stiff and (B) Flexible Horizontally Driven Rectangular Flasks. 
1. The flask serves as the energy transfer medium between the compactor table to the sand. Even though the drive table may have principally a horizontal or vertical direction of motion, other vibrational modes are introduced into the sand because of flask wall movement.

2. Flasks that are vibrated principally by vertical forces have both horizontal and vertical components introduced by flask wall movement. The ratio of horizontal to vertical accelerations depends on the ratio of vertical to horizontal flask stiffness, sand density, and the amount of off-axis loading.

3. Horizontally vibrated flasks similarly develop vertical vibrational components because of off-axis loading and flask movement.

4. Horizontal vibration moves sand into cavities more quickly than vertical vibration in flasks at equivalent vibrational amplitudes with accelerators above one $G$.

5. Certain operational features are required of both vertical and horizontal compactors employing either clamped or unclamped flasks. Sand densification in the flask and pattern cavities must progress in a systematic manner beginning toward the bottom of the flask and moving toward the top. It is generally desirable to have a 50 to $75 \mathrm{~mm}$ ( 2 to 3 in.) layer of fluidized sand at the top sand surface, with densified sand below the fluidized layer. Cavity filling should occur from within the fluidized layer. Densification occurs below the fluidized layer as sand moves downward to reduce the sand fraction.

6. There are two basic modes of sand vibration within flasks. The first consists of fluidization accompanied by mounding of sand along the flask centerline. In round flasks, mounding is produced as sand flows upward along the centerline, outward on the free surface, and downward along the flask wall. In square flasks, the mounding occurs on a line across the flask perpendicular to the direction of forced vibration.

7. A second vibrational mode is associated with extremely rigid flasks and has significantly less sand fluidization associated with it. This condition has been found in both round and square flasks at vibrational forces equal to those in flasks where total fluidization occurred. Flasks with a low stiffness produced more fluidization at a given vibrational amplitude. Flasks with high stiffness produced more rapid sand densification.

8. Filling of pattern cavities and densification of sand within the cavities must occur simultaneously to prevent sand collapse 
defects at the top cavity surface during pouring. Sand collapse can be minimized or avoided by filling the flask slowly to allow complete sand migration and compaction before the depth of sand above the cavity becomes too great.

The discovery of casting distortion caused by sand expansion is significant. Sand expansion not only distorts castings but is thought to be the root cause of most metal penetration defects. Alternate low expansion materials are currently being evaluated for physical and thermal properties which will yield dimensionally accurate castings.

\subsection{METAL FLOW AND GATING}

\subsection{Introduction}

Raymond Monroe, in his book Expendable Pattern Casting, describes several design considerations for an effective gating system in lost foam casting.(5) The gating system should:

- assure no damage to the mold during filling

- assure no damage to the metal during filling

- permit the polymer decomposition products to escape in a timely manner

- assure that the cavity fills completely

- serve as a riser to produce a sound casting

- support the casting cluster, including providing proper orientation in the flask, minimizing distortion of the pattern, and helping to support the cluster during handling

The decomposition of the polymer and removal of the pyrolysis products are particularly influential in assuring complete filling and the production of sound, defect-free castings.

The emphasis in the current research has been to develop an understanding of how the processing variables influence the disposition of pattern decomposition products to produce a clean casting free of surface and internal defects. This requires an understanding of the mechanism by which decomposition products are eliminated from the system, how the metal flow assists or detracts from transfer of decomposition products to the coating, and finally how gating systems can be designed to achieve the appropriate metal flow.

\subsection{Definition of Gating.}

Monroe states in his book, "Gating provides for the efficient flow of the molten metal into the mold cavity."(5) Therefore the 
gating system must deliver metal at an optimum rate that will assure complete filling of the mold without causing damage to the metal by turbulence. If this definition is accepted for gating in the lost foam process, gating requires a careful design not just of the traditional sprue, runners, and gates, but also, in concert, matching of the rate of heat transfer and foam decomposition to the rate of pyrolysis product removal from the cavity. Gating in lost foam becomes an exercise not just in fluid dynamics but in heat and mass transfer.

\subsection{Reconsideration of Previous Data}

In previous research an effort was made to develop a physical model to explain how the foam pattern decomposes and the decomposition products are transported through the coating and into the molding sand. Many of the process parameters that are inherent in the model were deliberately varied to determine their effects on fillability (the ability of the molten metal to completely displace the foam pattern), fill time, and metal front velocity. Some work was also done to relate the model to the formation of casting defects, particularly in a series of aluminum alloys. In some cases, the gating system was selected as one of these process variables; however, relatively little emphasis was paid to gating in the earlier experiments.

Based on a variety of experiments, involving both aluminum and cast iron, it became apparent that the filling time, metal velocity, and cavity fillability are nearly independent of the size of the gates. The number of gates may not significantly affect cavity fill time or metal velocity in aluminum castings, and unless other variables are properly controlled, multiple gates can lead to defects, such as laps, where two metal streams meet.

Fill times, metal velocities, fillability, and many casting defects are more closely related to the mechanism and rate at which the foam decomposes and the pyrolysis products removed from the system than to the gate size. Consequently, the type of foam, size and geometry of the pattern, nature of the coating, pouring temperature, metallostatic pressure, and other casting variables exert a more profound effect on mold filling than the gate size.

\subsection{Current Research on Gating and Filling}

Several studies have been conducted on pattern gating and mold filling during pouring. The results are summarized as follows. 
4.4.1. Pouring Temperature and Fill Rate. The fill times and metal velocities for a variety of alloys (zinc, aluminum, copper-base, and cast iron) have been measured over a range of pouring temperatures. The intent of these experiments was to resolve some conflicting observations concerning the effect of pouring temperature on metal fill velocity during pouring. In castings with a wall thickness of less than about $12 \mathrm{~mm}(0.5 \mathrm{in.})$, the aluminum flow velocity reached a stable value of about $12 \mathrm{~mm} / \mathrm{sec}(0.5 \mathrm{in}$. per sec).

However, metal fill velocity decreased continuously with increasing pouring temperature when pouring cast iron. This phenomena was a result of the fact that higher pouring temperatures produce more gas during pattern pyrolysis, and the larger gas volume creates a back pressure that reduces the metal fill rate. In castings thicker than about $25 \mathrm{~mm}$ ( $1 \mathrm{in.}$ ), or in castings with a high surface area to volume ratio, increasing the pouring temperature usually increased the metal velocity. The high casting surface area allows pyrolysis products to escape through the coating and thus minimize the back pressure.

The metal fill velocity increased continuously with increasing pouring temperature over a wide temperature range for all alloys. The fill velocity also increased for thicker patterns and when using higher permeability coatings. These effects can be explained by the rate of foam decomposition and the transport of the decomposition products from the casting. However, for very high pouring temperatures, the foam may be decomposed faster than the products can be transferred and the metal velocity may be reduced. Higher temperatures are required to reach this stage when a high permeability coating or a thick pattern is used.

4.4.2. Effect of Gate size and other Process Parameters on Fill in cast Iron. Statistically designed screening experiments and a full factorial experiment were performed in which variations in gating system were used to compare mold filling times and cast iron fill velocity. One of the purposes of these tests was to determine the influence, if any, of gating.

The experimental data show that for iron the fill times and metal velocities depend primarily on the type of foam and the type of coating. Gating provided an effect only by influencing the metallostatic pressure head (i.e. side versus bottom filling).

4.4.3. Effect of Gating and other Process Parameters on Fill in Aluminum. Both statistically designed screening experiments and partial factorial experiments were used to determine filling using aluminum with a hat-shaped pattern; the variables included several aspects of gating, including gate area, number of gates, and bottom vs. top gating. The total filling time, the horizontal (or circumferential) velocity, the vertical velocity, and the casting quality, as determined radiographically, were measured. The main 
effects and interactions of process variables on fill times and metal velocities were determined statistically, and a critical metal velocity and fill time required to prevent entrapped foam decomposition products in the casting were found.

The traditional "gating design" parameters, such as number and size of gates, played virtually no role in mold filling and casting quality. Instead, the shape of the metal-foam interface and its velocity, dictated by the rate at which the foam decomposition products could accumulate and then be transferred from the metalcoating interface, were the predominant factors; in fact, a minimum fill time must be maintained. This implies that the permeability and absorptive properties of the coating are the parameters controlling casting quality, and not the casting gate size.

4.4.4. Making the Gating system the Choke. Virtually all of the tests have indicated that the size of the gates plays little or no role in controlling fillability, fill time, or metal velocities. However, there must be some critical gate size below which the fluid flow restriction becomes more important than foam decomposition or transport of foam decomposition products through the coating. A series of bottom-gated, $12.5 \mathrm{~mm}(0.5$-in.) thick plates were poured in both A356 aluminum and a $4.0 \%$ carbon equivalent gray iron.

If the gates are to control metal flow into the casting pattern, they have to be much smaller than currently used. Unfortunately, if the gates are made sufficiently small to control metal flow, they do not have enough strength to survive handling, coating, and compaction. This means that for the foreseeable future, coatings must be selected and controlled so that they control the rate of metal entry into the pattern cavity.

\subsection{Summary and Conclusions - Metal Flow and Gating}

In conventional casting processes, the gating system is designed to control liquid metal flow, and the principles of fluid dynamics are employed to control the metal velocity, mold filling time, and the path taken by the molten metal. The usual definition of the choke as the region having the smallest cross-sectional area and the one controlling metal flow is not appropriate in the lost foam process. Instead, the rate of pattern decomposition and the rate of pyrolysis product removal control the rate of metal flow into the casting. In lost foam, the "choke" controlling metal flow may be at either the metal-foam interface (if foam decomposition is the rate limiting factor) or the metal-foam-coating interface (if foam pyrolysis is the limiting step).

The objective of the gating research has been to devise a set of principles that can be used to locate and size gates for pouring both 
aluminum and iron castings. The significant conclusions from this work are summarized as follows:

1. There is little or no effect of gate size on pattern or fill time. However, the gate location (top versus side versus bottom) and number of gates (particularly when streams of metal are allowed to impinge) may influence fillability, fill time, and defect formation.

2. Fill times and metal velocities have been obtained from test castings poured using a wide range of alloys, pouring temperatures, and pattern thicknesses. Statistically designed experiments show that the coating, the type of foam, the metal pressure head, and interactions between these parameters are most significant factors influencing metal fill velocity.

3. Pattern coating properties that produced excessively high metal fill rates resulted in internal defects, or voids, attributed to entrapped foam decomposition products. The shape and progress of the metal front during filling was examined and, while the shape depended to a limited extent on the fill rate, no correlation between metal front shape and defect occurrence was found.

4. For aluminum poured using a high permeability coating, a critical gate area was found that permitted the gate, rather than the foam or coating, to act as the choke. However, the gate could not be made small enough to function as the choke because it did not provide enough casting support to handle and dip the patterns. The critical gate size for iron, poured using a high permeability coating, approached $0.5 \mathrm{in}^{2}$. A high permeability coating on the pattern, in conjunction with a bottom gate, did not change the filling sequence.

\subsection{MECHANICAL PROPERTIES OF CASTINGS}

\subsection{Experimental Procedures for Tensile Properties}

5.1.1. Tensile Bar production. Two alloys were poured, evaluated, and the results presented in this report. The alloys included class 30 gray iron and 100-70-03 ductile iron.

The foam clusters included cast-to-shape fatigue specimens and $30.5 \mathrm{~mm}$ (1.2 in.) diameter foam pattern "B" bars. "B" bars are a common test bar in gray iron foundries and consist of a bar that is $30.5 \mathrm{~mm}$ (1.2 in.) diameter by $200 \mathrm{~mm}$ (eight in.) or more in length. In the current study, $30.5 \mathrm{~mm}$ diameter foam "B" bars were poured using EPS patterns and conventional open cavity $30.5 \mathrm{~mm}$ diameter sand molds. Both types of bars were tested to provide comparative property data. 
After pouring, shakeout, and cleaning, the unrisered "B" bars were blanked to right circular cylinders $0.635 \mathrm{~mm}(0.025 \mathrm{in.})$ longer and $0.38 \mathrm{~mm}(0.015$ in.) larger in diameter for NDE testing. A section of each bar was also removed for hardness measurements. The blanked specimens were nondestructively evaluated (NDE) to determine the specimen density and ultrasonic wave transmission velocity. After NDE, the specimens were machined to the final configuration. The following sections describe the procedures employed in NDE and mechanical property measurements obtained from the "B" Bars.

5.1.2. Hardness Measurements. Brinell hardness measurements were made at midradius on sections removed from each cast bar. Hardness measurements were measured according to ASTM E10-84 using a $3000 \mathrm{~kg}$ load on iron specimens.

5.1.3. Nondestructive Characterization Density. The density of each specimen blank was determined by measuring the blank dimensions with Brown \& Sharpe micrometers accurate to within $0.0025 \mathrm{~mm}$ and weighing each specimen on a Sartorius analytical balance accurate to within 0.0001 gram. The density was then calculated as the specimen weight divided by the calculated specimen volume.

5.1.4. Ultrasonic Longitudinal Velocity. The longitudinal velocity of an ultrasonic pulse through each specimen blank was determined using a pitch-catch technique. A Metrotek MP215 signal generator was used to pulse a 2.25 MHz Ultran Piezoelectric transducer coupled to the test specimen with isopropyl alcohol. A second transducer was used to receive the signal, and the time delay between the pitch and catch events was determined using a Tektronix 2430 digital processing oscilloscope. Specimen dimensions were determined using micrometers, and the ultrasonic velocity was calculated from the specimen length and time delay.

The elastic modulus of each specimen was calculated from the density and longitudinal velocity using the following equation:

$$
E=K_{1} * \rho * V_{L}^{2} *(1+v) *(1-2 v) /(1-v)
$$

where

$\begin{array}{lll}E & =\text { Young's Modulus } & \text { Units } \\ \rho & =\text { density, } & \text { g/cc } \\ \rho & =\text { Longitudinal ultrasonic velocity } & \text { in. } / \mu \mathrm{sec} . \\ V_{L} & =\text { Poisson's ratio } & \text { in. } / \mathrm{in} . \\ \nu & & 93.59 \mathrm{sec}^{2} / \mathrm{cm}^{3} 1 \mathrm{~b} . /\left(\mathrm{g} * \text { in. }{ }^{4}\right)\end{array}$

A Poisson's ratio of 0.28 was used for gray and ductile iron. 
5.1.5. Tensile Property Measurement. The tensile testing apparatus was an Instron Model 1332 hydraulic tensile testing machine. The primary components included the load frame, mechanical drive system, strain analyzers, and associated instrumentation for measuring load and strain. Tensile properties were measured in accordance with ASTM Standards B557-84 and E8.

Strain measurements were made with clip-on extensometers consisting of two clip-on arms and a spring. The arms transformed the deformation of the specimen to a clip-on spring. The clip-on spring was instrumented with a strain gauge bridge to provide an electrical output proportional to the relative movement of the ends of the clipon arms. Two clip-on extensometers mounted on opposite sides of the specimen were used simultaneously, and the signals from the two were averaged.

Typical instrumentation included a strip chart recorder and an $X Y$ recorder. The strip chart was used to monitor specimen load versus time. The rate of loading was controlled by manually following a predetermined load-time slope. An XY recorder was used to record load and strain continuously during each test. If strain gauges were used, additional recorders were used to monitor their output.

The data normally obtained from each evaluation included initial elastic modulus, yield strength, ultimate tensile strength, and strain-at-fracture. Fracture modes are also noted. The initial modulus was taken as the slope of the initial linear portion of the stress-strain curve. Strain gauges were also applied to the tensile specimens in selected cases to determine the Poisson's ratio and obtain another measure of the elastic modulus. The threaded $12.83 \mathrm{~mm}$ (0.505 in.) diameter tensile specimen used for the majority of the tensile tests is illustrated in Figure 5.1 .

The specimen had a relatively large length to diameter ratio in the gripping area to insure good alignment. All surfaces in the gripping area were cylindrical to make precision machining easier and repeatable from specimen to specimen. This specimen configuration had a uniform gauge section that gave definable volumes of material under stress and permitted accurate measurements of strain. The flags for measuring axial strain were positioned $25.4 \mathrm{~mm}$ (one in.) apart so unit strain was recorded directly.

\subsection{Tensile Property Results and Discussion}

5.2.1 Class 30 Gray Iron. Tensile properties of Class 30 gray iron were determined from bars cast using $30.5 \mathrm{~mm}$ (1.2 in.) diameter foam patterns and conventional $30.5 \mathrm{~mm}$ (1.2 in.) diameter open cavity "B" bars. The molds were poured at a commercial lost foam casting foundry from the same ladle of iron. The class 30 gray iron contained the following: 


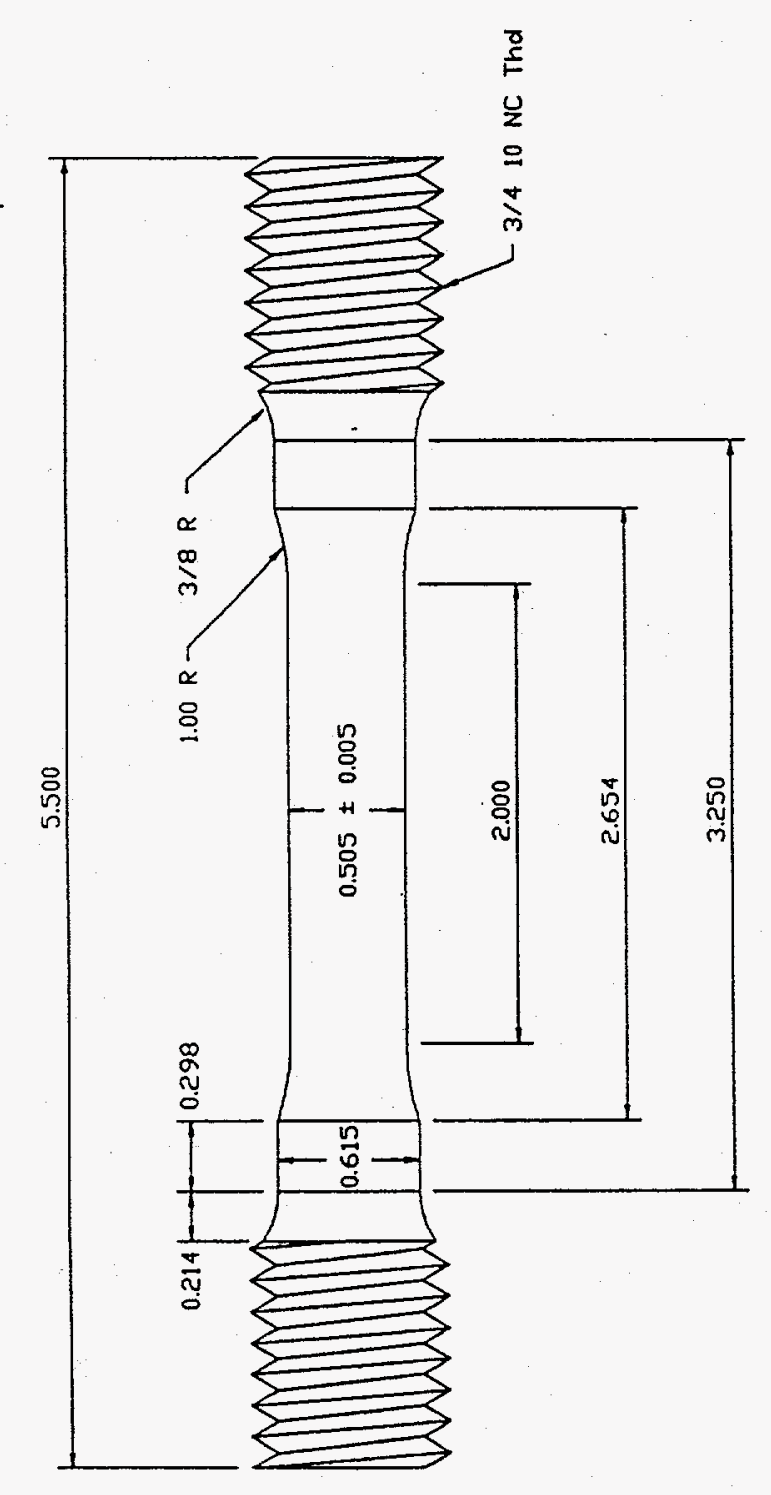

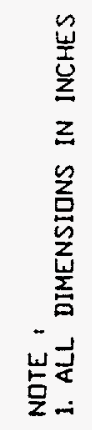

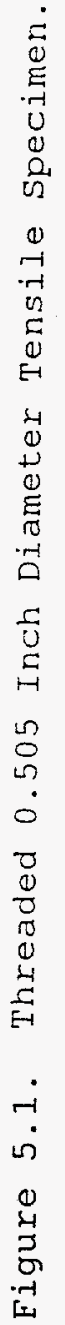




$\begin{array}{ll}\text { Carbon } & 3.13 \% \\ \text { Silicon } & 1.89 \% \\ \text { Manganese } & 0.314 \% \\ \text { Sulfur } & 0.011 \% \\ \text { Phosphorus } & 0.015 \% \\ \text { Chromium } & 0.032 \% \\ \text { Nickel } & 0.009 \% \\ \text { Copper } & 0.239 \% \\ \text { Molybdenum } & 0.006 \%\end{array}$

The test matrix included comparisons of properties of bars cast using $22.4 \mathrm{~g} / \mathrm{L}\left(1.4 \mathrm{lb} / \mathrm{ft}^{3}\right)$ EPS patterns, $24.1 \mathrm{~g} / \mathrm{L}\left(1.5 \mathrm{lb} / \mathrm{ft}^{3}\right)$ EPMMA patterns, and conventional open cavity "B" bars cast in oil bonded sand molds.

The NDE results, hardness, and tensile property data on casting made using $22.4 \mathrm{~g} / \mathrm{L}\left(1.4 \mathrm{lb} / \mathrm{ft}^{3}\right)$ EPS pattern and sand cast Class 30 gray iron are presented in Table 5.1. All of the specimens were machined to produce threaded $12.5 \mathrm{~mm}(0.505 \mathrm{in})$ diameter tensile specimens.

Specimens 5 through 8 were cast in standard open cavity $30.5 \mathrm{~mm}$ ( 1.2 in.) diameter bar molds. These specimens had a density of 7.2418 $\mathrm{g} / \mathrm{cc}$, an ultrasonic modulus of $126.2 \mathrm{GPa}$ (18.30 mpsi), and an average hardness of 205 BHN. The ultimate strength of the sand cast bars averaged $273.0 \mathrm{MPa}(39.6 \mathrm{ksi})$ with a standard deviation of $11.03 \mathrm{MPa}$ (1.6 ksi). The modulus as measured by an extensometer was $116.45 \mathrm{GPa}$ (16.89 mpsi).

Specimens 1 through 4 were cast from $22.4 \mathrm{~g} / \mathrm{L}\left(1.4 \mathrm{lb} / \mathrm{ft}^{3}\right)$ EPS patterns, and these specimens had an average density of $7.2372 \mathrm{~g} / \mathrm{cc}$ and average ultrasonic modulus was $115.5 \mathrm{MPa}$ (16.75 mpsi). These specimens had an average hardness of $155 \mathrm{BHN}$, and the average ultimate strength was $253.73 \mathrm{MPa}(36.8 \mathrm{ksi})$ with a standard deviation of 13.79 MPa (2.0 ksi). The modulus measured using an extensometer was 114.32 GPa (16.58 mpsi).

The yield strengths, ultimate strengths, and modulus values from the iron cast as "B" bars were comparable to that from $30.5 \mathrm{~mm}$ (1.2 in.) diameter lost foam specimens. The only significant difference between the two sets of bars was hardness, with the sand cast bars being about $50 \mathrm{BHN}$ higher than the castings made using $22.4 \mathrm{~g} / \mathrm{L}$ ( 1.4 $1 b / \mathrm{ft}^{3}$ ) EPS patterns.

The results obtained from four 1.2" diameter bars cast using 24.0 $\mathrm{g} / \mathrm{L}\left(1.5 \mathrm{lb} / \mathrm{ft}^{3}\right)$ EPMMA patterns are also presented in Table 5.1 . Specimens 10 and 11 were cast using a sealed foam pattern.

The average density of the tensile specimens cast using EPMMA patterns was slightly higher $(7.2485 \mathrm{~g} / \mathrm{cc})$ than similar bars cast in 
Table 5.1

NDE, Hardness, and Tensile Data on Sand Cast ("B" Bar Mold), 1.4 EPS, and 1.5 EPMMA Class 30 Gray Iron. (Threaded 0.505" Dia Specimens)

\begin{tabular}{|c|c|c|c|c|c|c|c|c|c|c|}
\hline $\begin{array}{l}\text { Entry } \\
\text { Number }\end{array}$ & $\begin{array}{l}\text { Specimen } \\
\text { Type }\end{array}$ & $\begin{array}{c}\text { Specimen } \\
\text { Number }\end{array}$ & $\begin{array}{l}\text { Mold } \\
\text { Type }\end{array}$ & $\begin{array}{c}\text { Bulk } \\
\text { Density } \\
\text { (g/cc) }\end{array}$ & $\begin{array}{l}\text { Ultrasonic } \\
\text { Velocity } \\
\text { (in/usec) }\end{array}$ & $\begin{array}{c}\text { Ultrasonic } \\
\text { Modulus } \\
\text { (mpsi) }\end{array}$ & $\begin{array}{c}\text { Hardness } \\
\text { (BHN) }\end{array}$ & $\begin{array}{c}0.2 \% \text { Offset } \\
\text { Yield } \\
\text { (ksi) }\end{array}$ & $\begin{array}{c}\text { Ultimate } \\
\text { Strength } \\
\text { (ksi) }\end{array}$ & $\begin{array}{c}\text { Modulus } \\
\text { (extensomer) } \\
\text { (mpsi) }\end{array}$ \\
\hline 5 & Tensile & GI0087 & "B" Bar & 7.2376 & 0.1862 & 18.37 & 197 & 30.7 & 38.9 & 16.93 \\
\hline 6 & Tensile & G10088 & "B" Bar & 7.2441 & 0.1858 & 18.31 & 197 & 31.1 & 38.2 & 16.44 \\
\hline 7 & Tensile & G10089 & "B" Bar & 7.2432 & 0.1859 & 18.33 & 207 & 31.2 & 39.3 & 16.44 \\
\hline \multirow[t]{3}{*}{8} & Tensile & G10090 & "B" Bar & 7.2421 & 0.1852 & 18.18 & 217 & 31.2 & 41.9 & 17.74 \\
\hline & & & Average $=$ & 7.2418 & 0.1858 & 18.30 & 205 & 31.1 & 39.6 & 16.89 \\
\hline & & & Std. Dev. = & 0.0029 & 0.0004 & 0.08 & 10 & 0.2 & 1.6 & 0.61 \\
\hline 1 & Tensile & G10079 & 1.4 EPS & 7.2360 & 0.1787 & 16.92 & 158 & 29.9 & 36.3 & 17.14 \\
\hline 2 & Tensile & GI0080 & 1.4 EPS & 7.2386 & 0.1829 & 17.73 & 158 & 32.6 & 39.8 & 17.37 \\
\hline 3 & Tensile & Gl0081 & 1.4 EPS & 7.2396 & 0.1753 & 16.29 & 152 & 27.5 & 35.6 & 15.79 \\
\hline \multirow[t]{3}{*}{4} & Tensile & G10082 & 1.4 EPS & 7.2345 & 0.1742 & 16.07 & 152 & 27.2 & 35.5 & 16.01 \\
\hline & & & Average $=$ & 7.2372 & 0.1778 & 16.75 & 155 & 29.3 & 36.8 & 16.58 \\
\hline & & & Std. Dev. = & 0.0023 & 0.0039 & 0.74 & 3 & 2.5 & 2.0 & 0.79 \\
\hline 10 & Tensile & G10083 & 1.5 EPMMA & 7.2578 & 0.1822 & 17.64 & 212 & 30.0 & 30.9 & 16.12 \\
\hline 11 & Tensile & GIOOS84 & 1.5 EPMMA & 7.2570 & 0.1822 & 17.64 & 229 & 33.4 & 37.3 & 15.57 \\
\hline 12 & Tensile & G10085 & 1.5 EPMMA & 7.2378 & 0.1781 & 16.81 & 217 & 31.8 & 40.4 & 17.22 \\
\hline \multirow[t]{3}{*}{13} & Tensile & GI0086 & 1.5 EPMMA & 7.2413 & 0.1804 & 17.25 & 219 & 32.0 & 39.8 & 17.19 \\
\hline & & & Average $=$ & 7.2485 & 0.1807 & 17.33 & 219 & 31.8 & 37.1 & 16.53 \\
\hline & & & Std. Dev. $=$ & 0.0104 & 0.0019 & 0.40 & 7 & 1.4 & 4.3 & 0.82 \\
\hline
\end{tabular}


the $30.5 \mathrm{~mm}$ ( 1.2 in.) diameter open cavity molds. These open cavity cast bars exhibited densities of about $7.2418 \mathrm{~g} / \mathrm{cc}$. The hardness of the bars cast using $24.0 \mathrm{~g} / \mathrm{L}\left(1.5 \mathrm{lb} / \mathrm{ft}^{3}\right)$ EPMMA patterns was comparable to the open cavity $30.5 \mathrm{~mm}$ (1.2 in.) diameter bars at 219 BHN and 205 BHN, respectively.

The average ultimate strength of the bars cast using EPMMA patterns was about $17.24 \mathrm{MPa}(2.5 \mathrm{ksi})$ lower than those cast in the oil bonded sand molds. However, entry No. 10 showed an unusually low tensile strength of $213.1 \mathrm{MPa}(30.9 \mathrm{ksi})$. The three remaining bars had comparable ultimate strengths. Extensometer modulus values from the open cavity $30.5 \mathrm{~mm}$ ( 1.2 in.) diameter sand cast bars were similar to the castings made using $24.0 \mathrm{~g} / \mathrm{L}\left(1.5 \mathrm{lb} / \mathrm{ft}^{3}\right)$ EPMMA patterns.

The Brinell hardness of the castings made using the $24.0 \mathrm{~g} / \mathrm{L}$ (1.5 lb/ft ${ }^{3}$ ) EPMMA patterns was slightly higher than the sand cast bar hardness and the bars cast using EPS patterns. Both yield and ultimate strength and extensometer modulus values were approximately the same for all bars.

A composite plot of tensile stress-strain curves for the castings made using $22.4 \mathrm{~g} / \mathrm{L}\left(1.4 \mathrm{lb} / \mathrm{ft}^{3}\right)$ EPS pattern cast bars is illustrated in Figure 5.2. The two sealed bars designated by the solid symbols show a slightly higher ultimate strength but slightly lower strain-tofailure than bars cast using unsealed patterns.

A composite plot of stress-strain curves from bars cast using $24.0 \mathrm{~g} / \mathrm{L}\left(1.5 \mathrm{lb} / \mathrm{ft}^{3}\right)$ EPMMA patterns is illustrated in Figure 5.3 . Both sealed bars exhibited a decrease in strain-to-failure and ultimate strength. It is possible that the sealant retarded the exit of foam pyrolysis products from the cavity and caused some residue defects in the castings.

A composite plot of the tensile stress-strain curves from specimens machined from open cavity $30.5 \mathrm{~mm}$ (1.2 in.) diameter sand cast bars is illustrated in Figure 5.4. The curves are uniform and match each other well.

A composite plot of all gray iron stress-strain curves is illustrated in Figure 5.5. With the exception of one specimen, all of the ultimate strengths fell within a fairly narrow band and were acceptable for Class 30 gray iron. Strain-to-failure, however, for bars cast using sealed lost foam patterns seemed to be lower than obtained with unsealed foam patterns and sand cast bars.

The microstructures of class 30 gray iron cast using unsealed and sealed 1.4 EPS foam is illustrated in Figure 5.6 at a magnification of 25x. Both microstructures appear typical for Class 30 gray iron. 


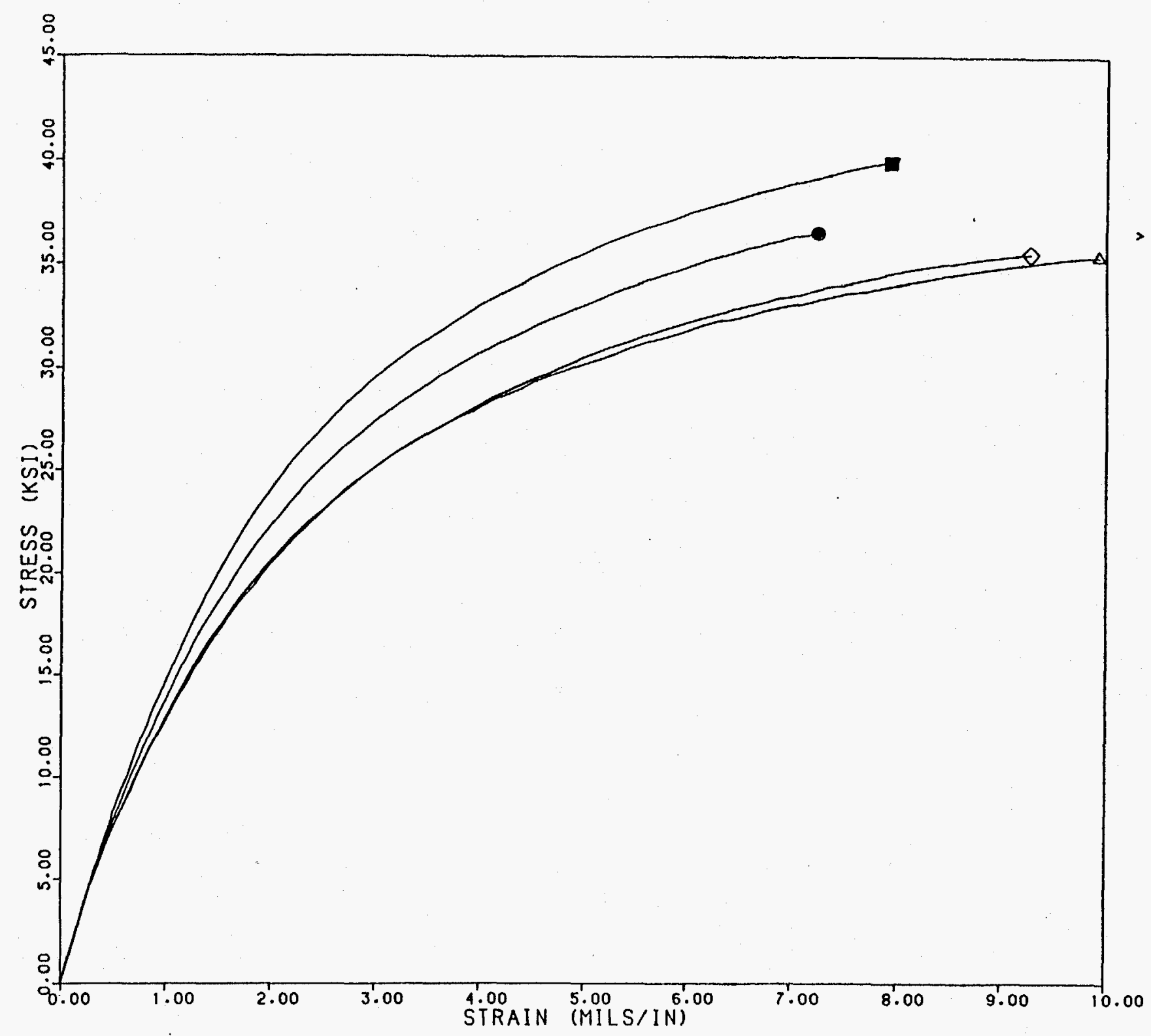

PROJECT NUMBER:7184-50

MATERIAL:CLASS 30 GRAY IRON

TEMPERATURE:TO

1.4 EPS- (S) - IN-AX-79

1.4 EPS- (S) $-\mathrm{TN}-A X-80$

01.4 EPS $-(N)-T N-A X-81$

$>\triangle 1.4$ EPS $-(N)-T N-A X-82$ - Curve oxtends post
plotied boundery.

Eigure 5.2. Composite Tensile Stress-Strain Curves for Cast Gray Iron Cast as 1.2 inch Diameter Bars Using 1.4 pef EPS Patterns. 


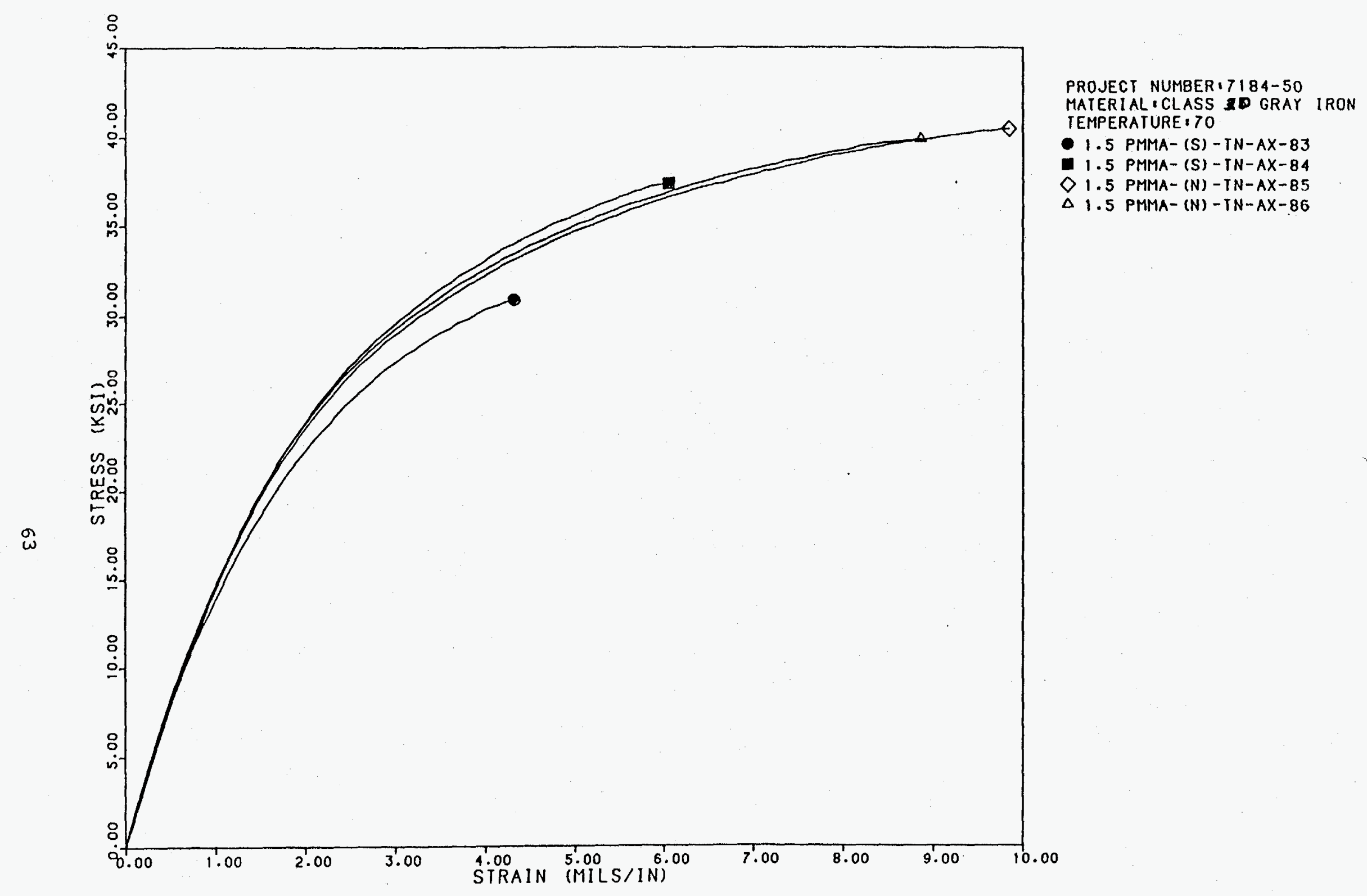

Figure 5.3. Composite Tensile stress-Strain Curves for Gray Iron Cast as 1.2 inch Diameter Bars Using 1.5 pcf EPMMA Ratterns. 


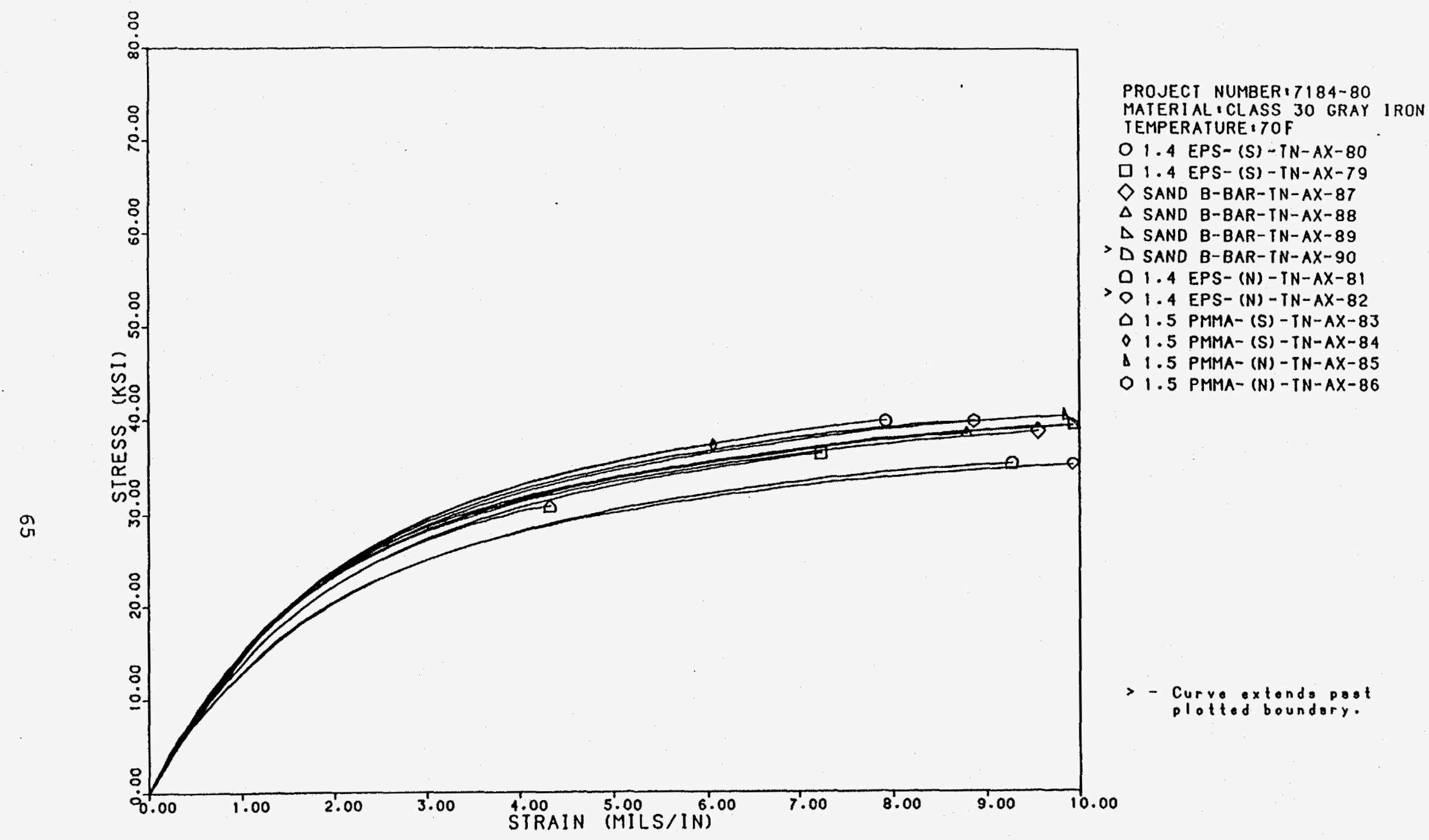

Figure 5.5. Composite Tensile Stress-Strain Curves for Gray Iron Cast as 1.2 inch Diameter Bars Using 1.4 pcf EPS and 1.5 pcf EPMMA Foam Patterns and in Sand Molds. 
The microstructures of the class 30 gray iron cast using an unsealed and a sealed $24 \mathrm{~g} / \mathrm{l}\left(1.5 \mathrm{lb} / \mathrm{ft}^{3}\right)$ EPMMA foam patterns are illustrated in Figure 5.7. The microstructure of the unsealed gray iron is unremarkable. The microstructure of the iron produced in the sealed pattern, however, contained large Type A graphite flakes with some very fine Type $D$ graphite. This section was removed from the tensile specimen that had the lowest ultimate strength $213.1 \mathrm{MPa}$ (30.9 $\mathrm{ksi}$ ) of all the gray iron specimens tested. The atypical coarse graphite flakes would account for the low ultimate tensile strength.

The microstructure of a tensile specimen cast in a open cavity $30.5 \mathrm{~mm}$ (1.2 in.) diameter sand mold is illustrated in Figure 5.8 . This microstructure is similar to most of the other lost foam cast gray irons.

In general, the density, modulus, yield and ultimate strength, and elastic modulus of the lost foam cast bars were typical of class 30 gray irons and were comparable to the conventionally cast bars. The greatest difference found was in hardness where castings made using $22.4 \mathrm{~g} / \mathrm{l}\left(1.4 \mathrm{lb} / \mathrm{ft}^{3}\right)$ EPS patterns had lower hardness than castings made using $24.0 \mathrm{~g} / 1$ ( $\left.1.5 \mathrm{lb} / \mathrm{ft}^{3}\right)$ EPMMA patterns or in sand molds. The difference in hardness could not be accounted for microstructurally. It was also noted that the strain-to-failure values for the castings produced both in sealed EPS and EPMMA are lower than those produced in unsealed patterns. The sealer may have introduced more debris into the casting microstructure, thereby reducing the strain-to-failure. The lower cooling rate of lost foam castings may have also produced a slightly larger eutectic cell size.

5.2.2. Tensile and Fatique Properties of Class 30 Gray Iron and 10070-03 Ductile Iron. Six sets of test specimens -- three each in Class 30 gray iron and 100-70-03 ductile iron -- were cast for this program. Some of the specimens were cast in commercial foundries and some were cast at the University of Alabama at Birmingham (UAB) laboratory. In each case, one set of castings was produced in no-bake molds sufficiently close to the desired size that specimens could be fatigue and tensile tested with an as-cast surface.

The second set of bars was produced using lost foam casting patterns. These specimens were also cast and tested with an as-cast surface. The third set of bars was cast as $30.5 \mathrm{~mm}$ ( $1.2 \mathrm{in.}$ ) diameter bars using EPS patterns and machined to the desired test specimen dimensions.

The chemical composition of the SAE J431 Grade 3000 gray iron was as follows:

$\begin{array}{ll}\text { Carbon } & 3.48 \% \\ \text { Manganese } & 0.74 \% \\ \text { Silicon } & 2.27 \%\end{array}$




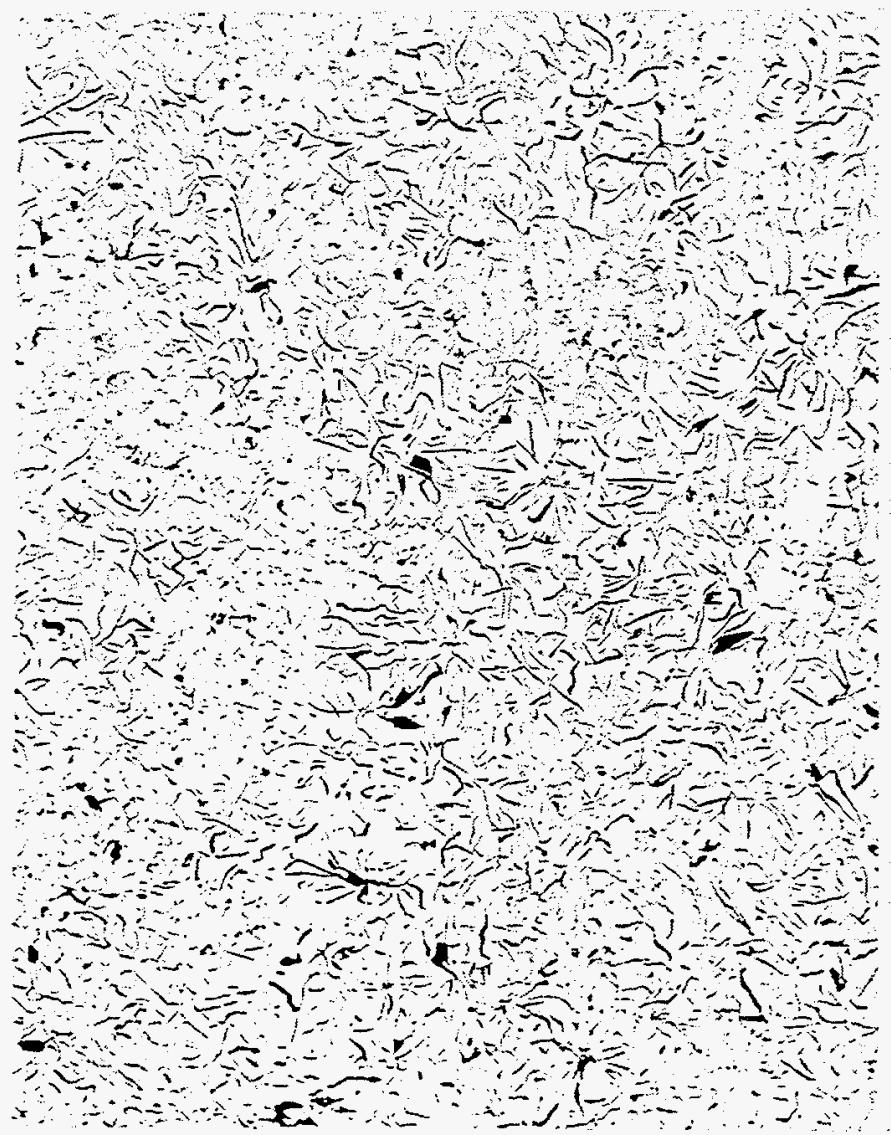

(A)

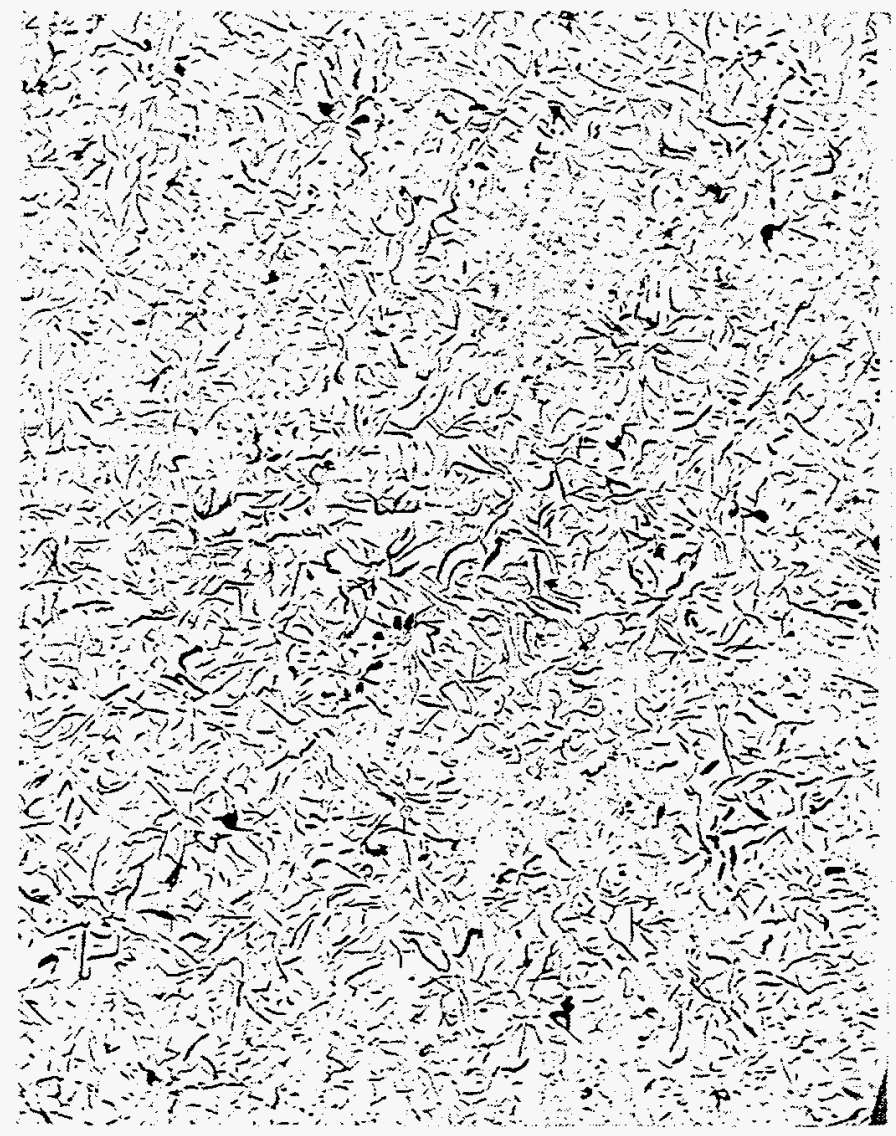

(B)

Figure 5.6:. Microstructure of Class 30 Gray Iron Cast as 1.2 inch Diameter Bars Using 1.4 pef EPS Patterns. (A) Unsealed (B) Sealed $25 \mathrm{X}$ Unetched. 
- paypzatin xsz pateas (g) pateasun (Z)

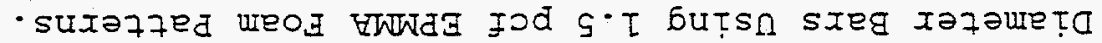

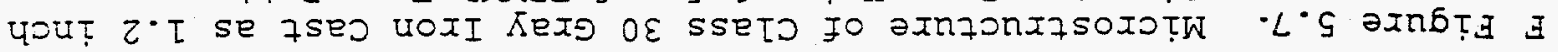

(g)

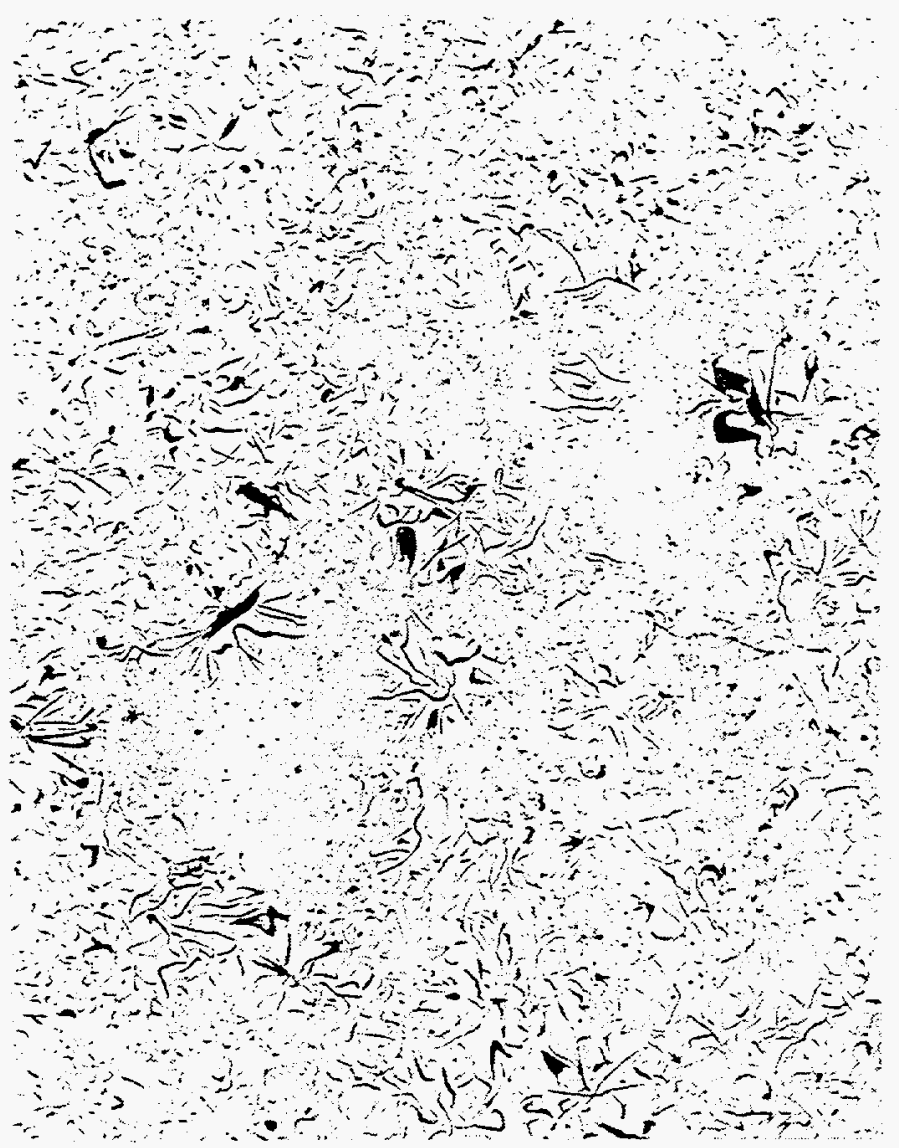

(

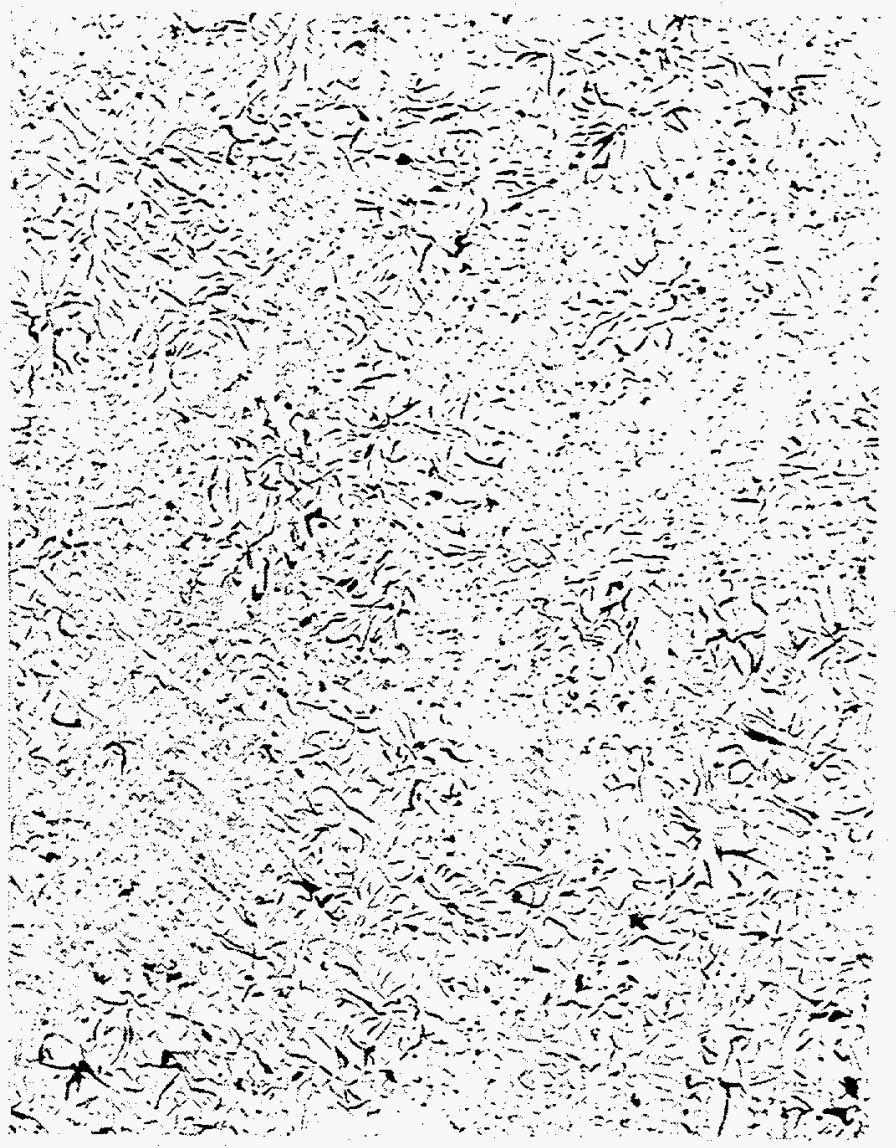




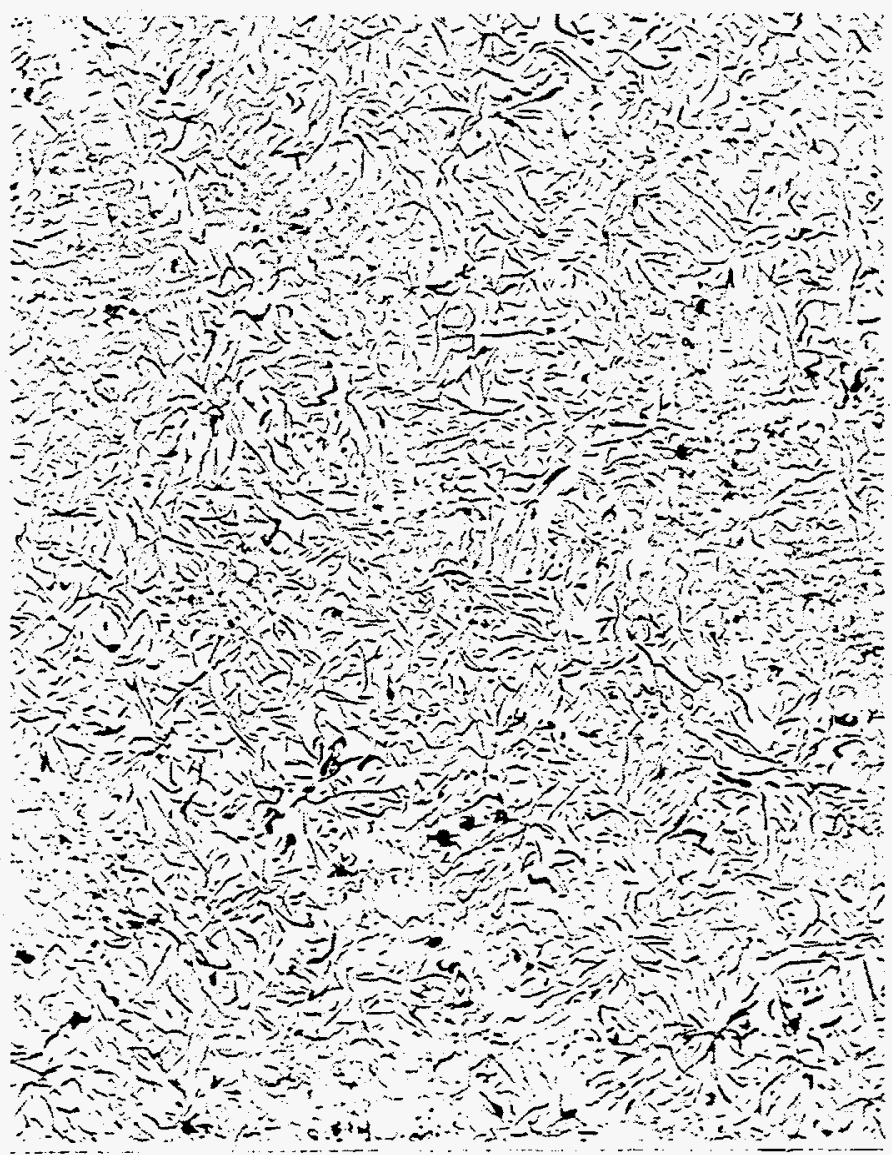

Figure 5.8. Microstructure of Class 30 Gray Iron Cast as a 1.2 inch Diameter Bar in a Sand Mold. 25X Unetched. 


$\begin{array}{ll}\text { Sulfur } & 0.010 \% \\ \text { Phosphorus } & 0.016 \% \\ \text { Nickel } & 0.06 \% \\ \text { Chromium } & 0.12 \% \\ \text { Molybdenum } & 0.04 \% \\ \text { Copper } & 0.11 \% \\ \text { Tin } & 0.01 \% \\ \text { Titanium } & 0.01 \%\end{array}$

All of the molds were inoculated with $75 \%$ ferrosilicon during filling, and the metal pouring temperature was approximately $1399^{\circ} \mathrm{C}\left(2550^{\circ} \mathrm{F}\right)$.

The chemical composition of the ASTM A536 Grade 100-70-03 ductile iron was as follows:

$\begin{array}{ll}\text { Carbon } & 3.62 \% \\ \text { Manganese } & 0.47 \% \\ \text { Silicon } & 2.33 \% \\ \text { Sulfur } & 0.009 \% \\ \text { Nickel } & 0.006 \% \\ \text { Chromium } & 0.03 \% \\ \text { Copper } & 0.713 \% \\ \text { Vanadium } & 0.001 \% \\ \text { Magnesium } & 0.045 \%\end{array}$

A single heat was used to produce all three sets of specimens. All of the molds were inoculated with $75 \%$ ferrosilicon during filling, and the metal pouring temperature was approximately $1400^{\circ} \mathrm{C}\left(2550^{\circ} \mathrm{F}\right)$.

\subsection{Eatigue Bar Production}

5.3.1. As-Cast No-Bake Specimens. Test bars to produce these specimens were cast in phenolic urethane resin-bonded silica sand molds. Test bar casting dimensions are shown in Figure 5.8. The longer end of the test bar formed a flow-off which allowed metal to pass through and heat up the gauge section prior to gauge solidification.

The grip ends of the specimens were machined prior to testing. Centers were machined into each end of the test specimen to turn the grip ends. During this operation, the machinist attempted to minimize total indicated runout (TIR) at the center of each specimen. However, since the bars were as-cast, the runout on each specimen was greater than typically found in fully machined specimens. The TIR averaged $0.67 \mathrm{~mm}(0.027 \mathrm{in.})$ for the no-bake gray iron specimens, and $0.25 \mathrm{~mm}$ (0.010 in.) for the no-bake molded ductile iron. The surface topography of one of the sand cast ductile iron specimens was measured and is illustrated in Figure 5.9. The image in this figure represents 


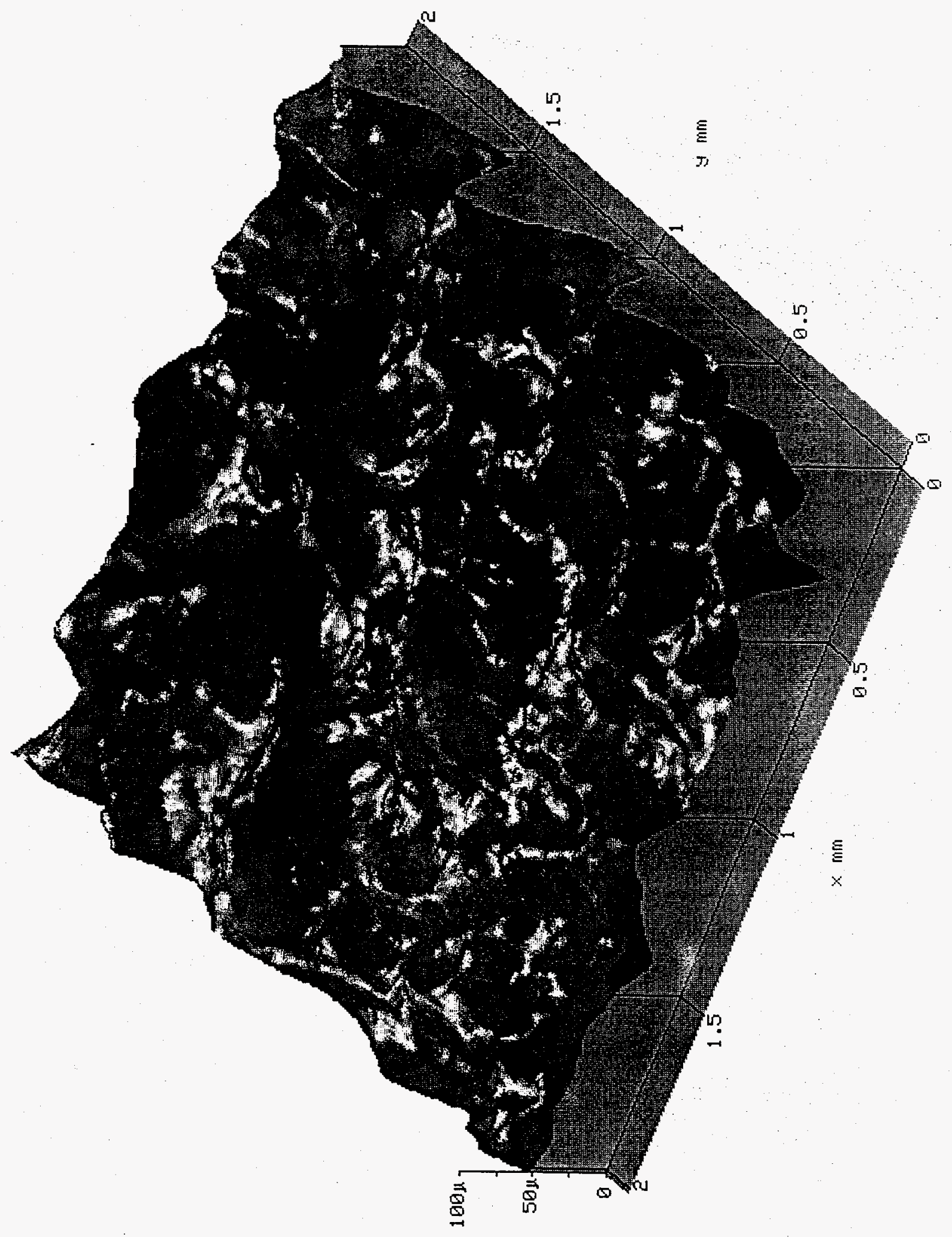

Eigure 5.9. Surface topography of As-cast No-bake Specimen 
a $2 \times 2 \mathrm{~mm}(0.079 \times 0.079 \mathrm{in.})$ area of the gauge surface. The $R_{a}$ (surface roughness) value for the area in Figure 5.9 ias $9.01 \mu \mathrm{m}$ (360.4 $\mu$ in).

5.3.2. As-Cast Lost Foam Specimens. This group of fatigue test bars was cast from a single runner using $20.8 \mathrm{~g} / \mathrm{L}$ ( $1.3 \mathrm{lb} / \hat{\mathrm{t}} \mathrm{t}^{3}$ ) EPS molded patterns for both the gray and ductile iron specimens. The foam test patterns were glued to a runner and then coated. McCormick 2300 coating, diluted with water to a viscosity of $2300 \mathrm{cps}$, was used to cast the gray iron patterns. Sand was compacted around the cluster at 2.0 G's with slow sand fill rate. The TIR averaged $0.89 \mathrm{~mm} 10.035$ in.) for the lost foam cast gray iron specimens, and $0.31 \mathrm{~mm} 10.012$ in.) for the lost foam ductile iron specimens. The surface topography of a lost foam cast ductile iron specimen is illustrated in Figure 5.10. The $R_{a}$ value for this casting was $261 \mu \mathrm{m}(6.29 \mu \mathrm{m})$.

5.3.3. Machined Specimens. These specimens were cast as $30.5 \mathrm{~mm}(1.2$ in.) diameter bars using $20.8 \mathrm{~g} / \mathrm{L}\left(1.3 \mathrm{lb} / \mathrm{ft}^{3}\right)$ EPS for the gray iron bars, and $22.4 \mathrm{~g} / \mathrm{L}\left(1.4 \mathrm{lb} / \mathrm{ft}^{3}\right)$ EPS patterns for the ductile iron bars. The foam test bars were glued to a runner and then coated. Mccormick 2300 coating at a viscosity of $2300 \mathrm{cps}$ was used on the patterns. Sand was compacted around the clusters at 2.0 G's with slow sand fill using a GK Omni Axis compaction table. Maximum total indicated runout for the machined specimens of each material type was $0.02 \mathrm{~mm} 10.0008$ in.). The surface topography of a machined specimen is illustrated in Figure 5.11. This image represents a $2 \times 2 \mathrm{~mm}(0.079 \times 0.079 \mathrm{in}$.) area of the gauge surface. The $R_{a}$ value for the area in Eigure 5.11 was $0.71 \mu \mathrm{m}(28.4 \mathrm{\mu in.})$.

\subsection{Fatigue Test and Analysis Procedures}

5.4.1. Monotonic Tensile Tests. Monotonic material properties were obtained by performing tensile tests using the ASTM E8 recommended practice for tension testing of metallic materials as a guideline. Two specimens from each test group were used for tensile tests. The cylindrical, reduced-section specimens were installed in a load frame using hydraulically actuated collet-type grips. During the tensile test, a somat series 1100 data acquisition and control unit monitored values of load and strain measured by an Interface 1220-AF load cell and an MTS $632.26 \mathrm{C}-30$ extensometer. The test was strain controlled up to a strain level of 3 percent. If a strain level of 3\% was achieved, the extensometer was removed and the tensile test was continued under stroke control until the specimen fractured.

5.4.2. Analysis of Tensile Data. The elastic modulus of the tensile data was determined by cumulatively including the initial data points of the tensile test in a linear regression until the $r$-squared value was maximized. A linear regression of the logarithms of stress and 


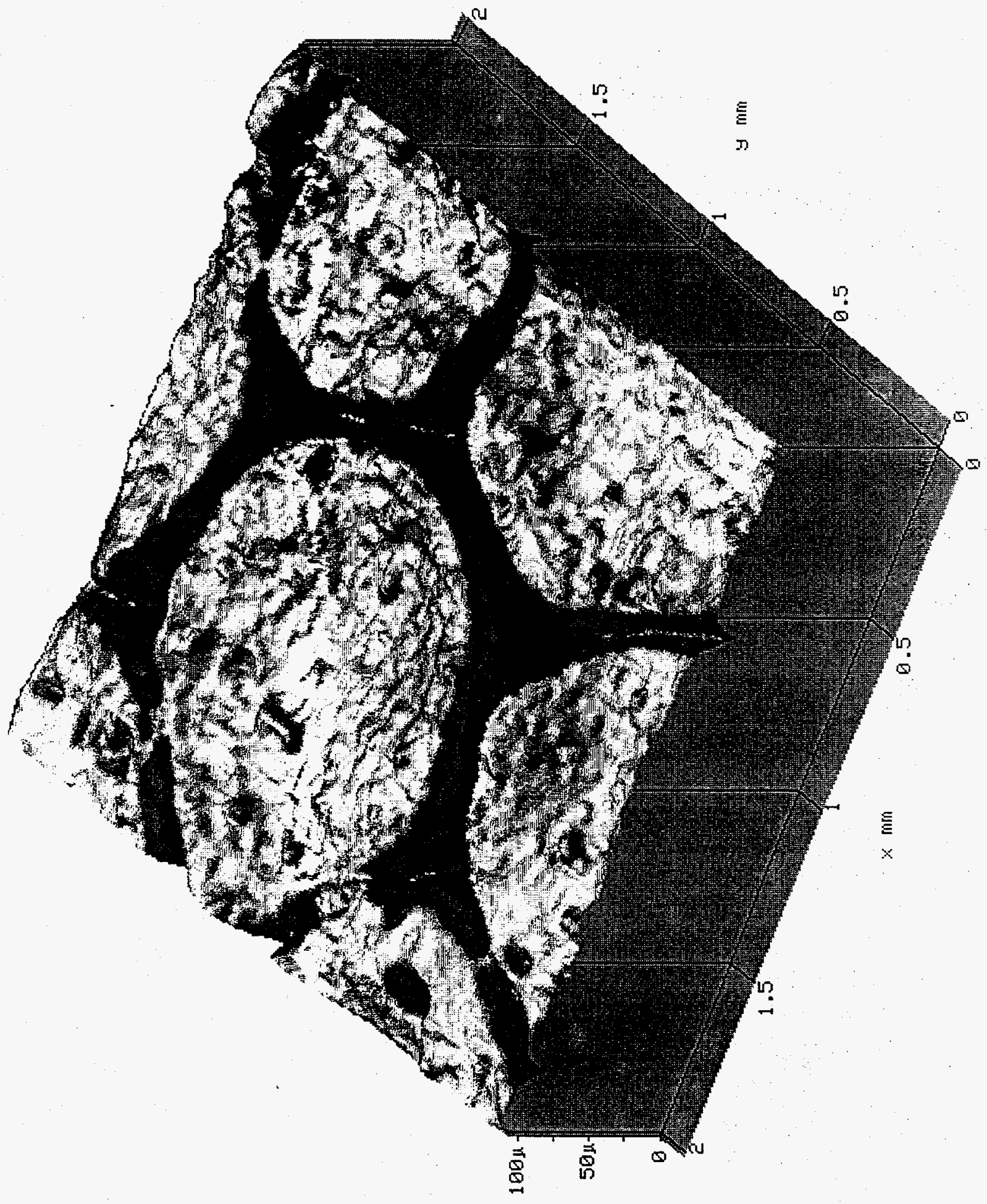

Figure 5.10: Surface topography of As-cast EP Specimen 


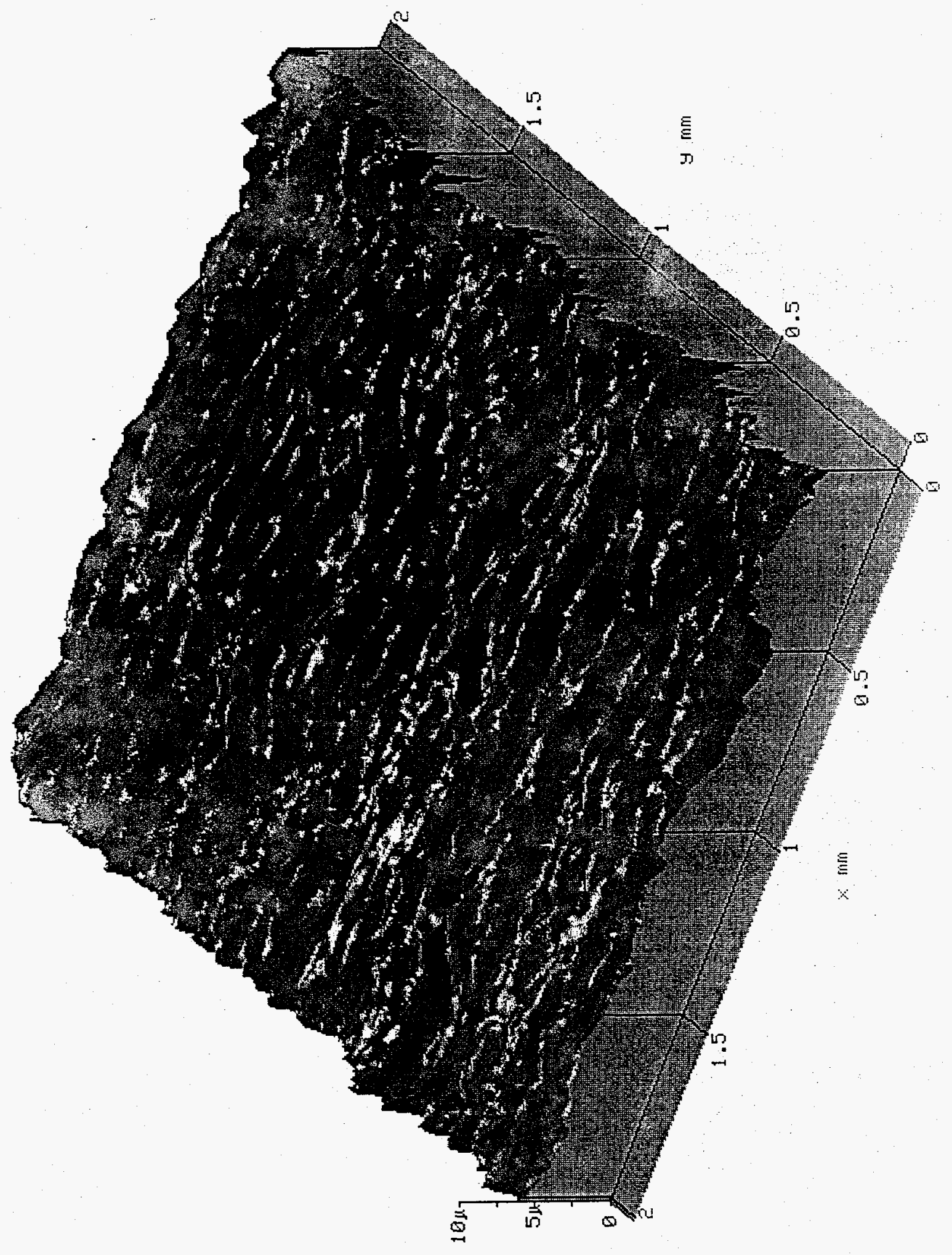

Eigure 5.11. Surface topography of Machined Specimen 
plastic strain was used to determine the strain hardening exponent which then allowed the strength coefficient to be determined. The yield strength was defined at an offset of $0.2 \%$ strain

5.4.3. Eatigue Test Procedure. Axial strain-controlled, constant amplitude fatigue tests were performed using the ASTM E606 recommended practice for constant-amplitude low-cycle fatigue testing as a guideline. Each cylindrical, reduced-section specimen was installed in a load frame using hydraulically actuated collet-type grips. Values of stress and strain were intermittently recorded by a somat series 1100 data acquisition and test control unit. All tests were run in completely reversed strain control ( $R=-1$ ) with the cycling frequency ranging from $1 \mathrm{~Hz}$ at the higher strain amplitudes up to $7 \mathrm{~Hz}$ at the lower strain amplitudes. The lower test cycle rates were used at the higher strain amplitudes to prevent specimen heating and extensometer slippage. The test specimens which did not exhibit plastic strain were switched to load control after 500,000 cycles and run at 10-12 Hz. Each specimen was fatigue tested until either the specimen failed or the life achieved two million cycles, which was considered a "runout". Eailure was identified as 50\% load drop.

5.4.4. Analysis of Fatique Data. The total strain amplitude, elastic strain amplitude, plastic strain amplitude, tensile load amplitude, and compressive load amplitude were intermittently recorded for each specimen. Values of these parameters were tabulated at the designated stable fatigue cycle for each specimen. The "stable cycle" was defined as the cycle closest to the half-life of the specimen when data were acquired unless engineering judgement required the use of a different stable cycle.

The stress-life curve was established using a best fit linear regression $\left(\log N=A+B^{*} \log S\right)$ of the data points that were not suspended data points (runouts). The slope of the best fit line was used to project each data point to a constant stress level to allow a frequency histogram of life versus percent failure to be determined for the chosen stress. A Weibull analysis was then done to establish a B50 and B10 life at the chosen stress. Using the B50 and B10 lives at the reference stress and the slope from the linear regression, the $\mathrm{B} 50$ and B10 stress-life fatigue curves were determined.

The strain-life curve was fit to the data by summing the elastic strain-life curve and the plastic strain-life curves. The elastic strain-life curve was fit using the linear regression and weibull analysis technique described above. The plastic strain-life curve was fit using a linear regression of data points with at least 50 microstrain of plastic strain. 
The standard data reduction procedure described above could not be applied to the gray iron data sets because of data scatter and the way that gray iron behaved under fatigue loading.

\subsection{Test Specimen Microstructure}

5.5.1. As-Cast No-Bake Specimens. A typical surface of a fatigue specimen cast in a phenolic urethane resin-bonded sand mold is illustrated in Figure 5.12 (A). There were two distinct features on the surface of these specimens. The surface was rough due to adhering sand in many areas. The gauge section of one specimen was sectioned normal to the longitudinal axis for examination. Pits near the surface are illustrated in Figure $5.12(B)$.

The graphite flakes illustrated in the gray iron specimens in Figure $5.13(\mathrm{~A})$ were mainly ASTM A247 Types D and E with some Type A. Graphite flake size was 6 .

The gray iron matrix microstructure, illustrated in Figure $5.13(B)$, was mainly fine to very fine pearlite generally unresolvable at $500 x$ magnification. Steadite was not observed. Traces of ferrite were present throughout the microstructure as illustrated in Figure $5.14(\mathrm{~A})$. The specimens were found to be sound with no microshrinkage and the microstructure was uniform throughout the specimen.

A typical fracture surface from the gray iron no-bake test specimens at a magnification of $10 \mathrm{X}$ is illustrated in Figure 5.14(B). Specific failure origins were very difficult to find on the no-bake gray iron fatigue specimens, but there appeared to be multiple origins. In the example shown in Figure 5.14(B), the fracture appeared to originate at the 7-8 o'clock area and propagate toward the one o'clock area.

The graphite nodules in the ductile iron specimens illustrated in Figure $5.12(B)$ and $5.15(A)$ were mainly ASTM A247 Type I with nodularity greater than $90 \%$. The nodule size was 7 and nodule count was around 300 per $\mathrm{mm}^{2}$.

The ductile iron matrix microstructure, illustrated in Figure $5.15(A)$, consisted of pearlite with less than 5\% ferrite. Steadite was not observed. A similar microstructure at the surface of a specimen is illustrated in Figure 5.15(B). Small amounts of carbides were found near the surface of this specimen. The graphite remained nodular in shape to the specimen surface, and the relative amounts of pearlite and ferrite were essentially constant from the specimen center to the surface. 


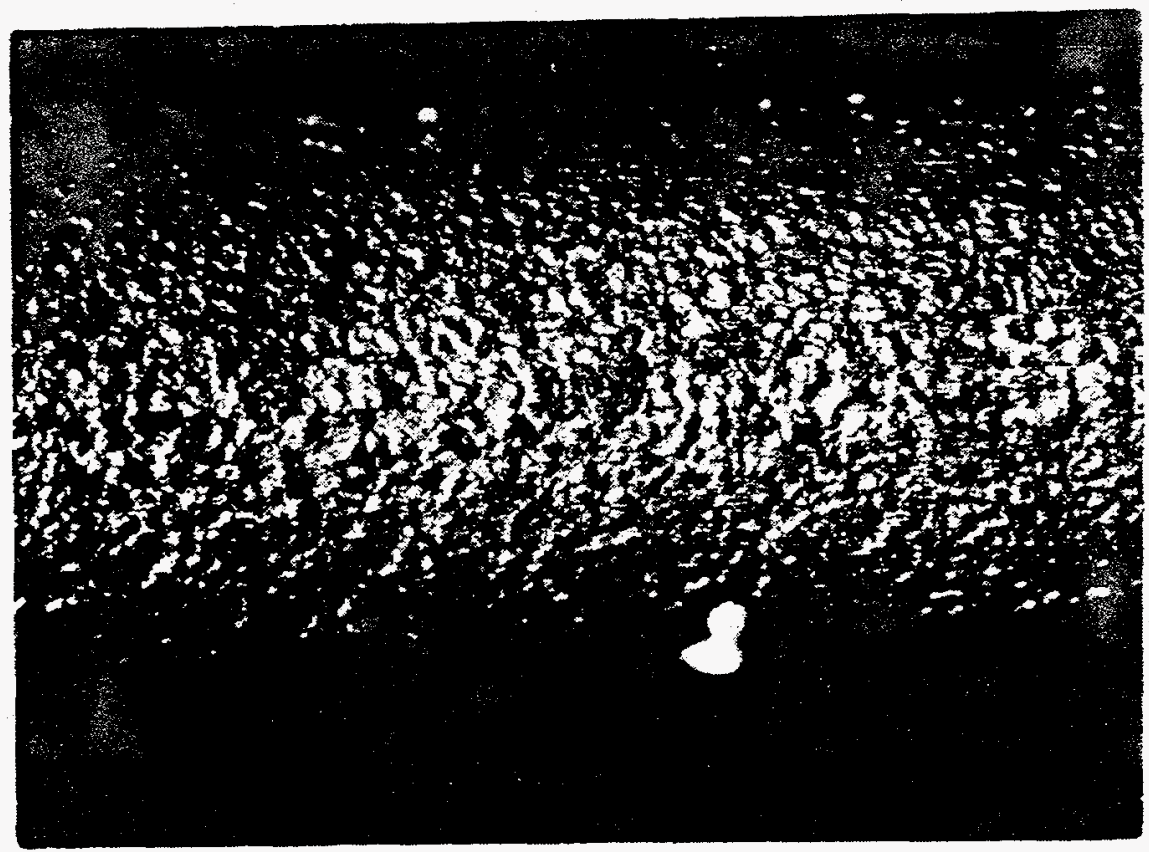

(A)

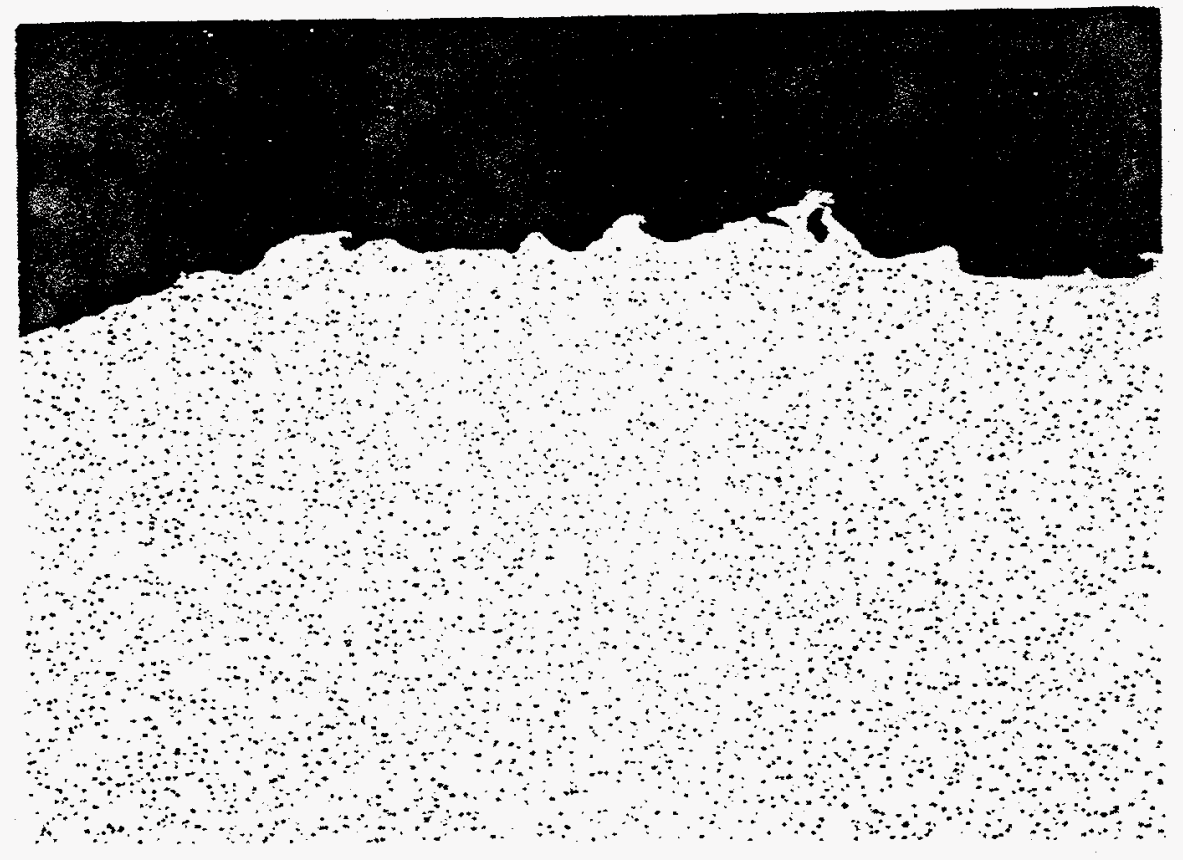

(B)

Figure 5.12. (A) Rough Sand Surface on No-bake Specimens. 10X

(B) Cross Section of Rough Sand Surface on a No-bake Specimen. 50X 

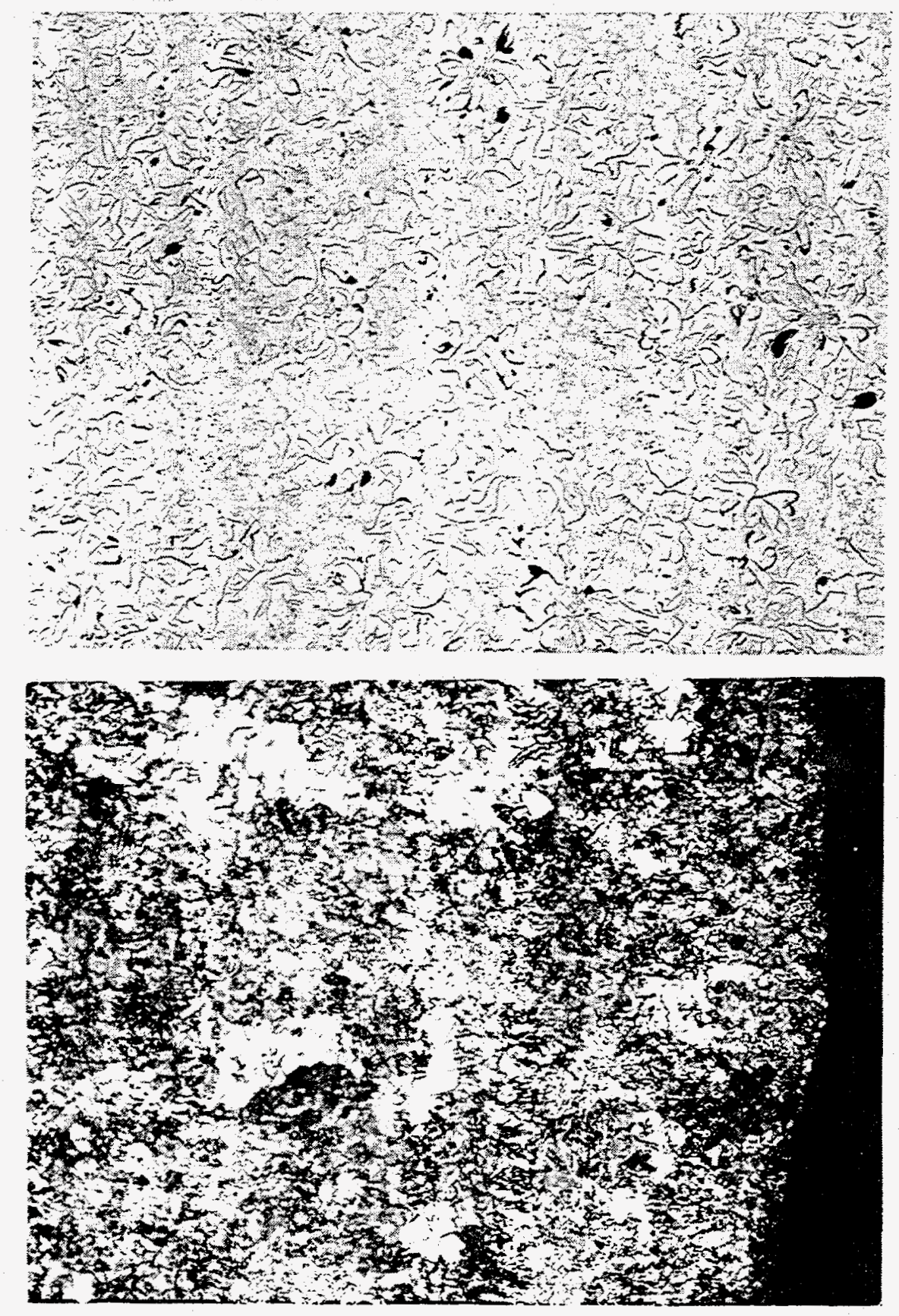

(B)

Figure 5.13. (A) Graphite Flakes in a No-Bake Gray Iron Specimen. 100x

(B) Matrix Microstructure in No-Bake Gray Iron Specimen. $200 \times 2 \%$ Nital Etch 


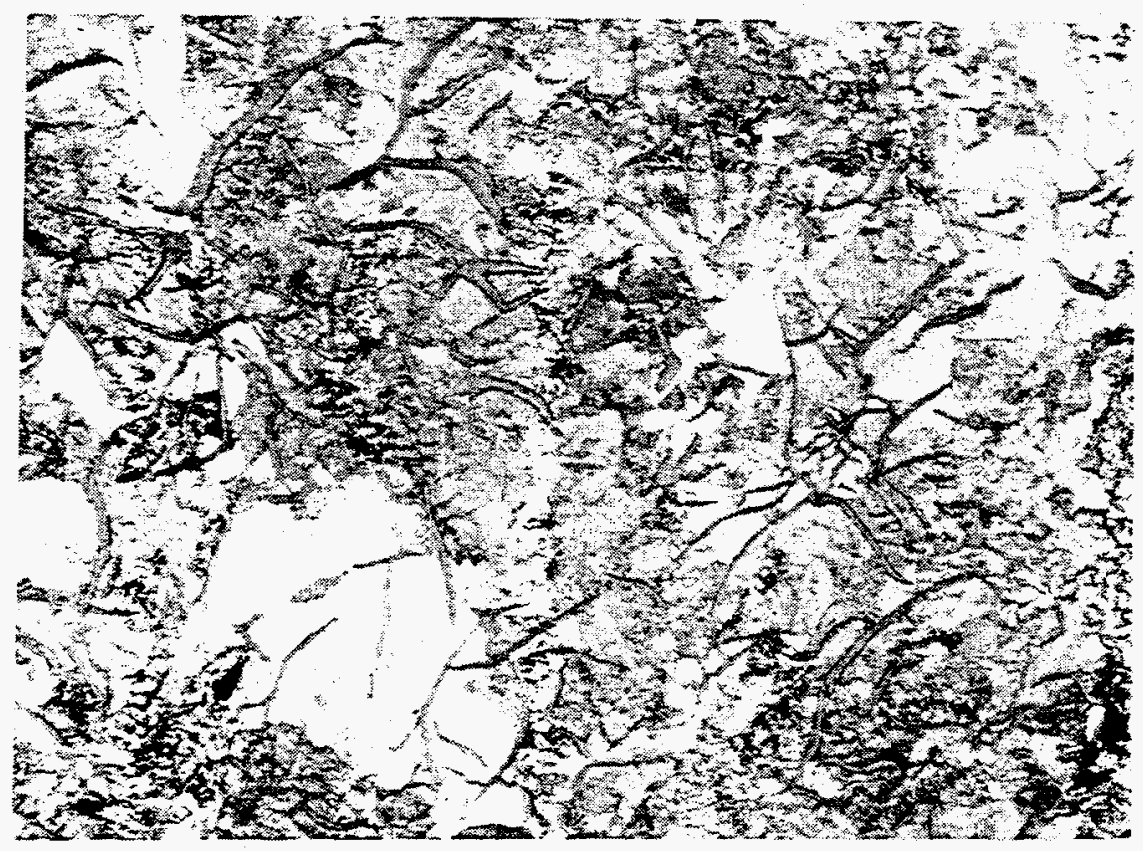

(A)

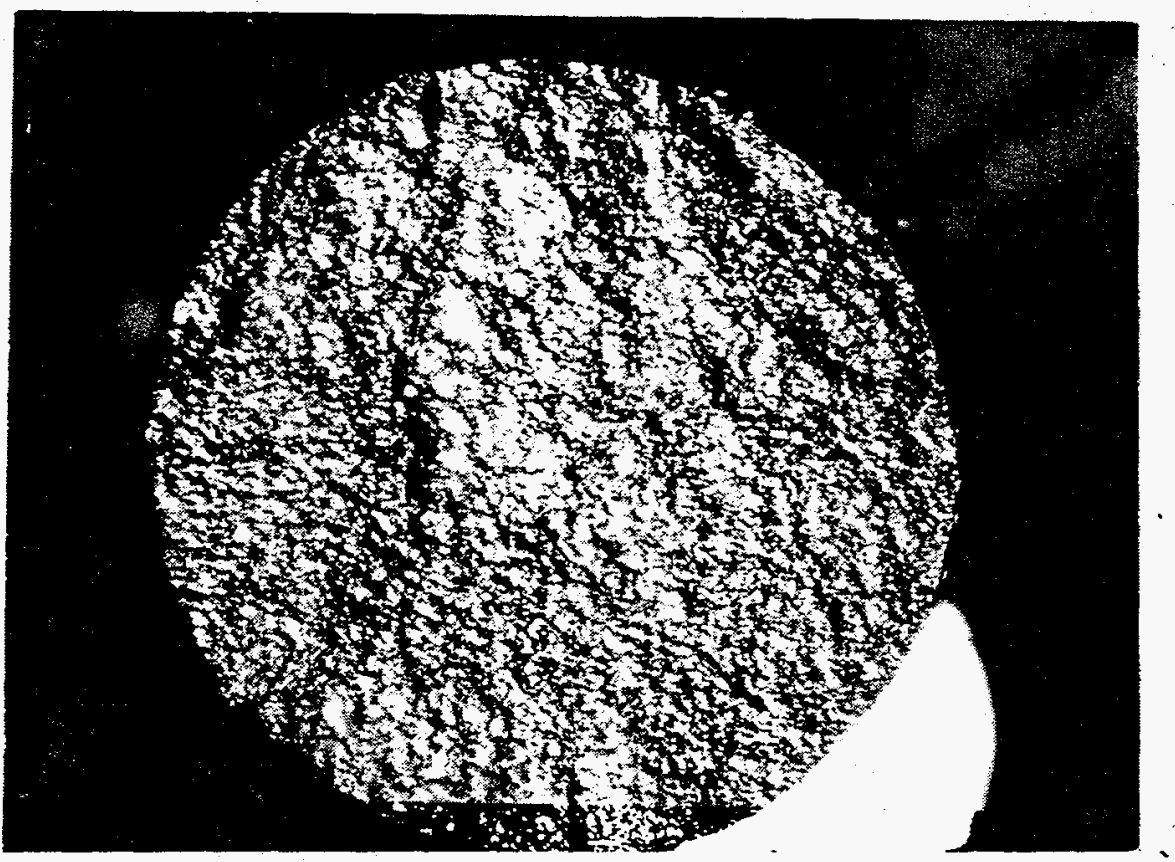

(B)

Figure 5.14

(A) Matrix Microstructure (Fig. 15.31(B) Enlarged). 500x

(B) Typical Fracture Face on Gray Iron No-Bake Specimens. $15 \mathrm{x}$ 

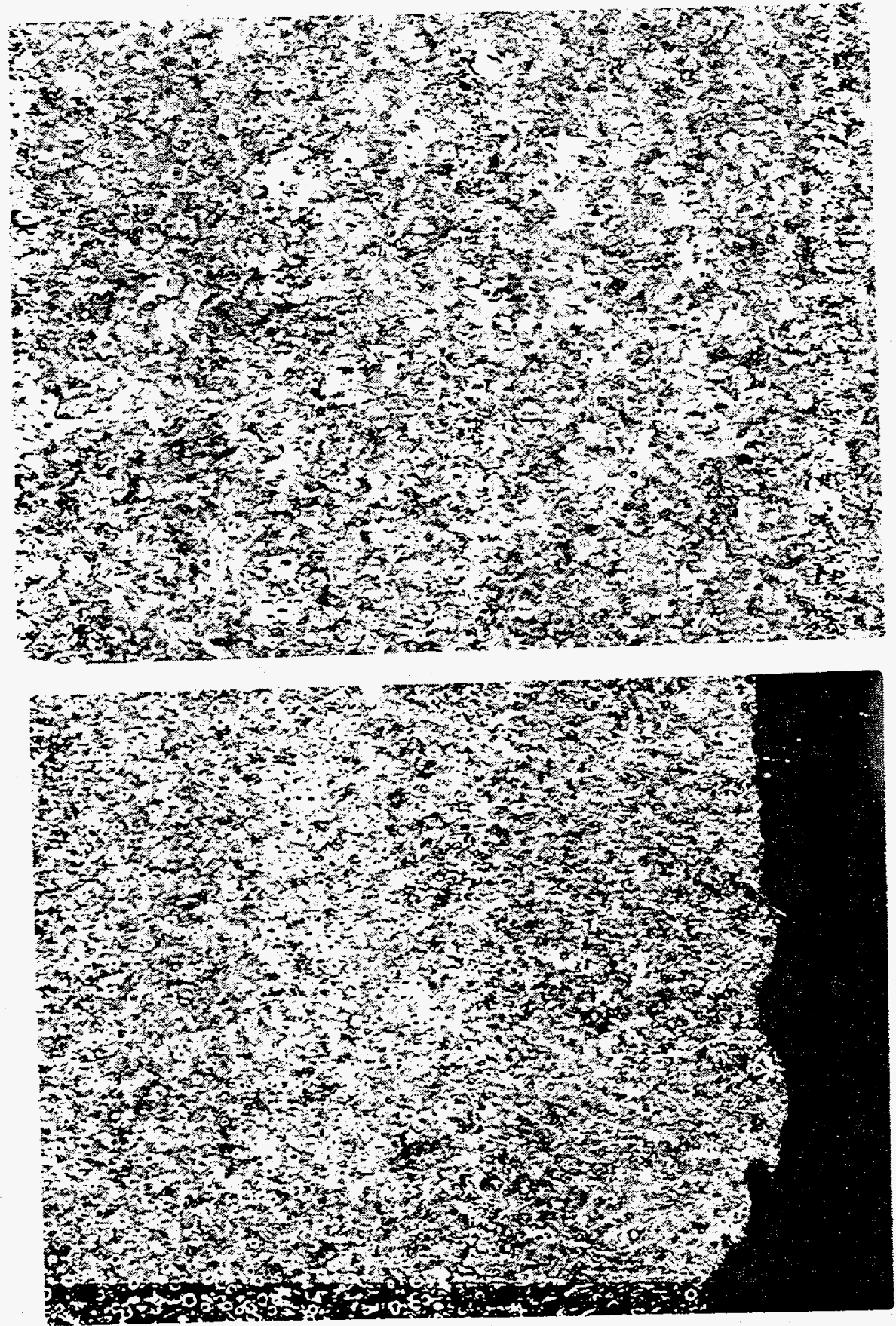

Eigure 5.15 .

(A) Matrix Microstructure in a No-sate Ductile Iron Specimen. 100x 2\% Nital Etch

(B) Surface Microstructure in a Gatud section of No-Bake Ductile Iron specimen. 10x 2\% Nal Etch. 
A typical fracture surface of a no-bake mold cast ductile iron specimen at a magnification of $10 \mathrm{X}$ is illustrated in Figure $5.16(\mathrm{~A})$. A notch resulting from sand at the surface is illustrated in Figure $5.16(B)$ and a notch caused by a pit at the surface is shown in Figure 5.17 .

5.5.2. Lost Foam Casting Specimens. A typical surface of a fatigue specimen produced by the lost foam casting process is illustrated in Eigure $5.18(\mathrm{~A})$. The surface bead pattern is obvious. The gauge portion of the specimen was sectioned normal to the longitudinal axis to prepare a metallographic specimen. A typical microstructure is illustrated in Figure 5.18(B). Surface depressions resulting from the intersection of beads are evident.

The graphite flakes in the gray iron specimens illustrated in Figure 5.19(A) were mainly ASTM A247 Types D and E with some Type A. Graphite flake size was 6 . The matrix microstructure was mostly fine to very fine pearlite, generally unresolvable at $500 x$ magnification. Ferrite was scattered throughout the microstructure as illustrated in Figures $5.19(\mathrm{~B})$ and $5.20(\mathrm{~A})$. The specimens were found to be sound with no internal microshrinkage, and the microstructure was uniform throughout.

A typical gray iron specimen fracture face is illustrated in Figures 5.20(B). Specific fatigue origins were difficult to identify, but there appeared multiple origins around the periphery of the specimens and that failures initiated at bead intersections.

The graphite nodules in the ductile iron specimens illustrated in Figure 5.21 (A) were mainly ASTM A247 Type I with nodularity greater than 90\%. The nodule size was 6 to 7 , and the nodule count was around 300 per $\mathrm{mm}^{2}$. The matrix microstructure consisted of pearlite with less than 5\% ferrite as illustrated in Figure 5.21(B). Steadite and free carbides were not found. The graphite remained nodular in form, and the relative amounts of ferrite and pearlite remained essentially constant to the specimen surface. The lost foam casting process itself did not appear to have caused any change in the graphite or matrix microstructure as illustrated by the microstructures in Figure $5.18(\mathrm{~B})$ and $5.21(\mathrm{~A})$.

Typical ductile iron specimen fracture faces are illustrated in Figures $5.22(A)$ and (B). Failures initiated at the surface of specimens at depressions located at the intersections of beads. The notch effect of the depressions is clear in Figure 5.22(B). Note that some debris (bright spots) is present on the specimen surface in Figure 5.22 (B). The debris on the fracture surface near the bead triple point was not related in any way to the specimen fractures. 


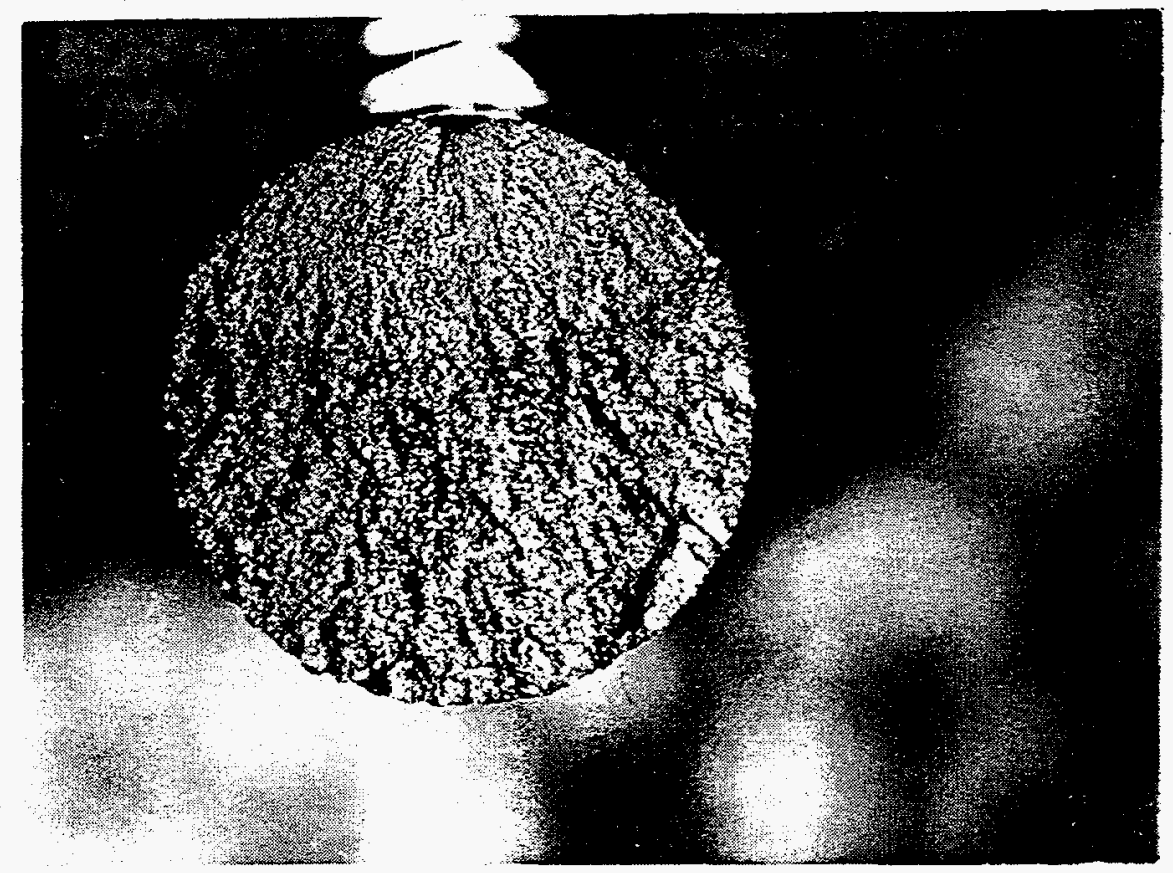

(A)

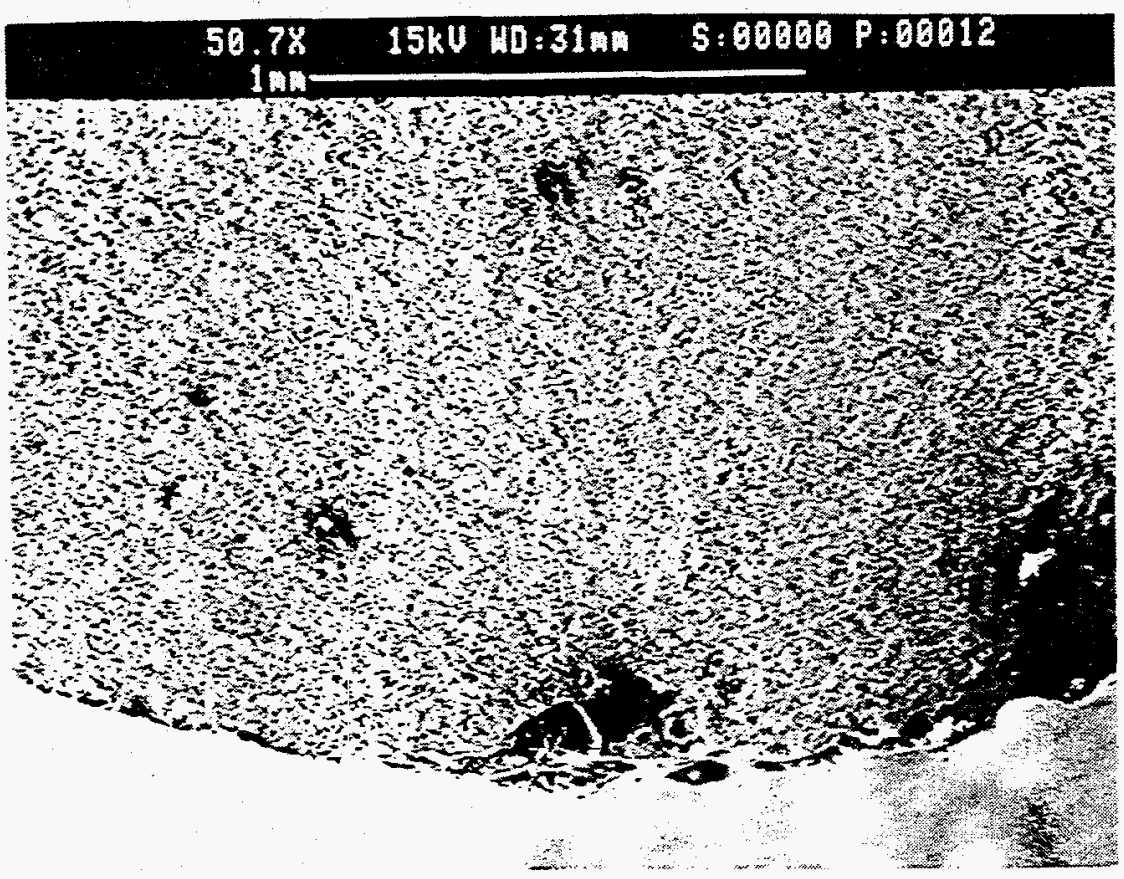

(B)

Figure 5.16. (A) Typical Fracture Face of a No-bake Ductile Iron Specimen. 10X

(B) SEM Micrograph Showing rough Sand Notch on a No-bake Ductile Iron Specimen. 50.7X 


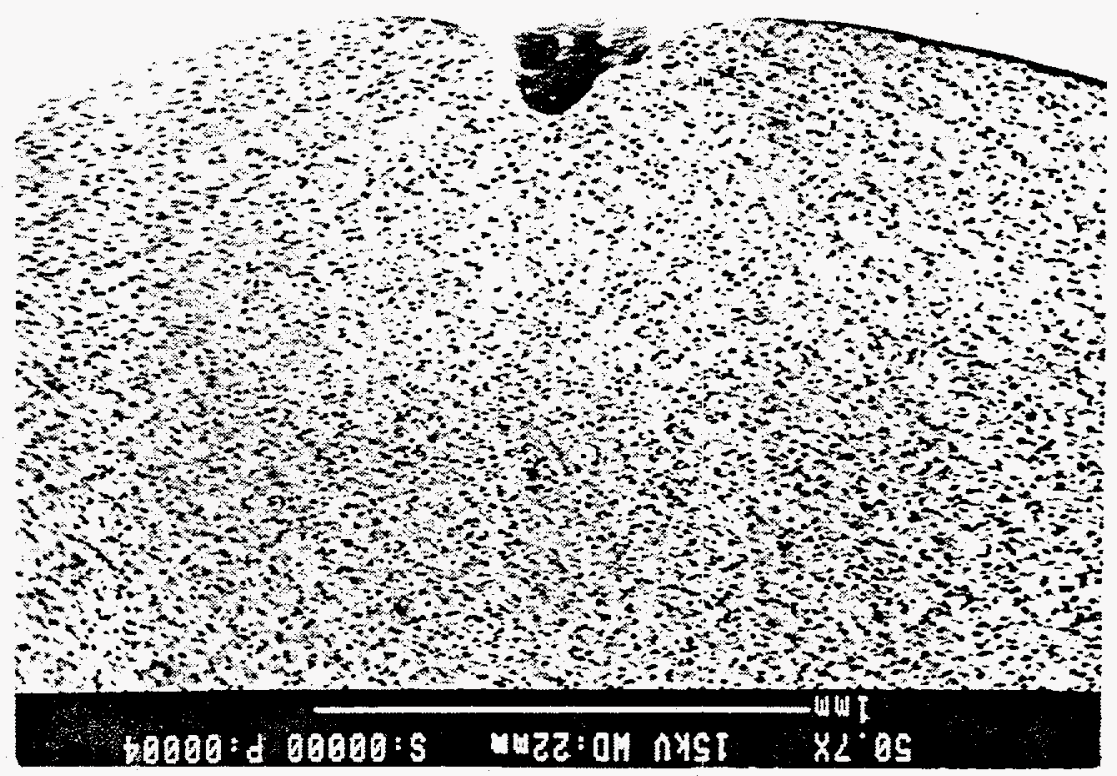




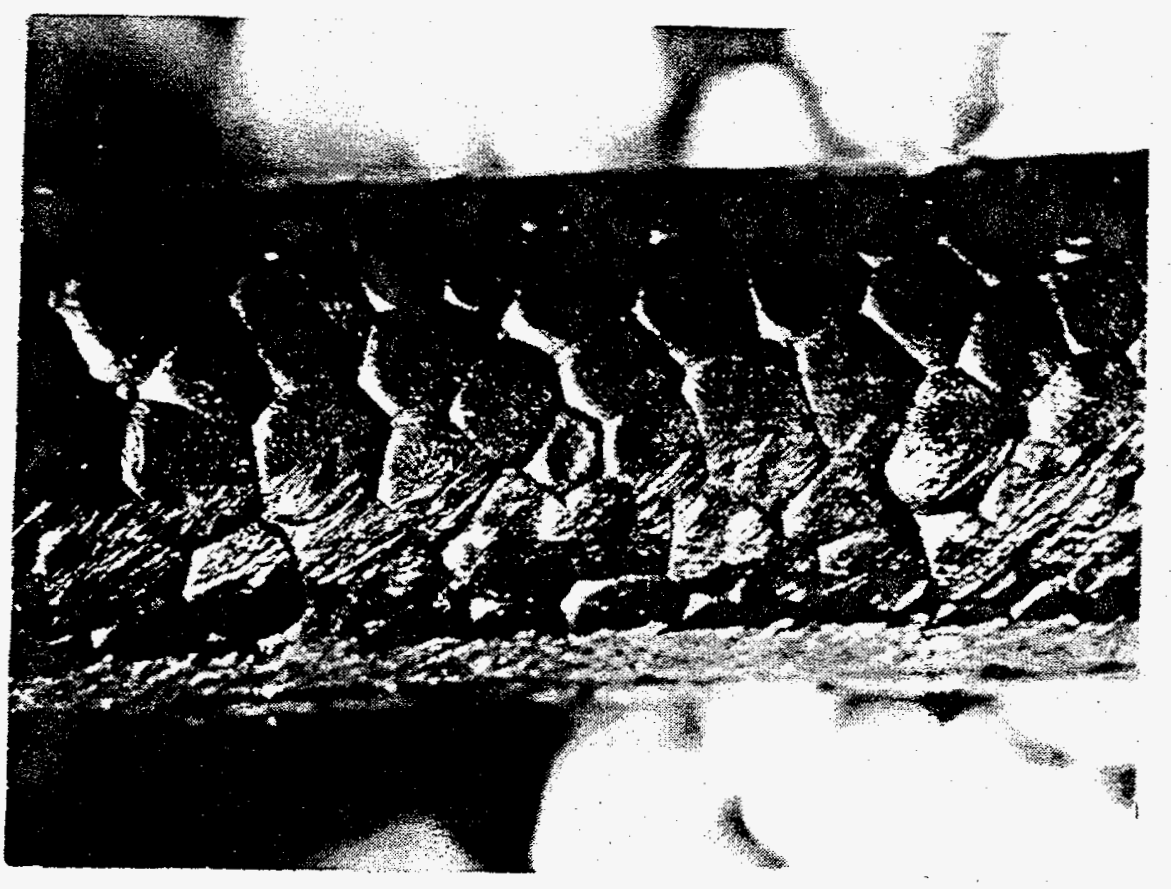

(A)

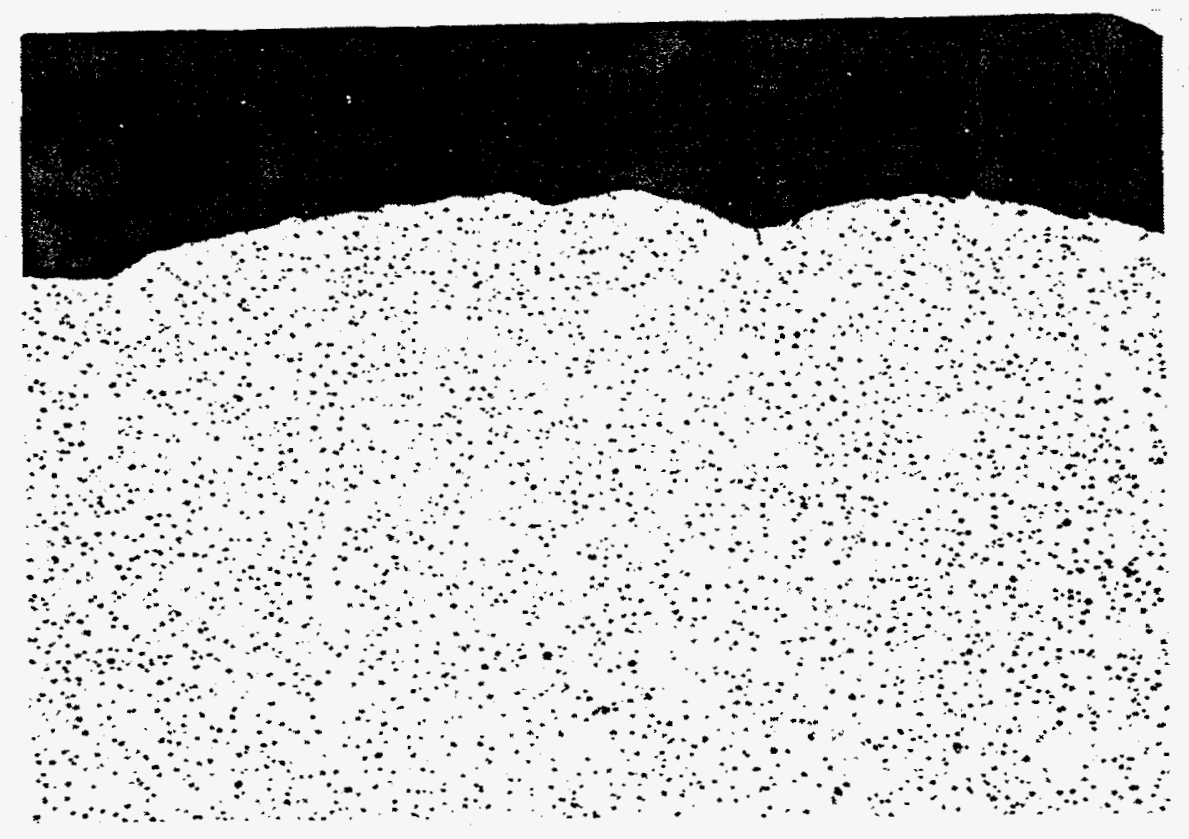

(B)

Figure 5.18. (A) Typical EPC Specimen Gauge Section Surface Finish. 10X

(B) Surface Depression From Bead Intersection on EPC Specimen. 50X 


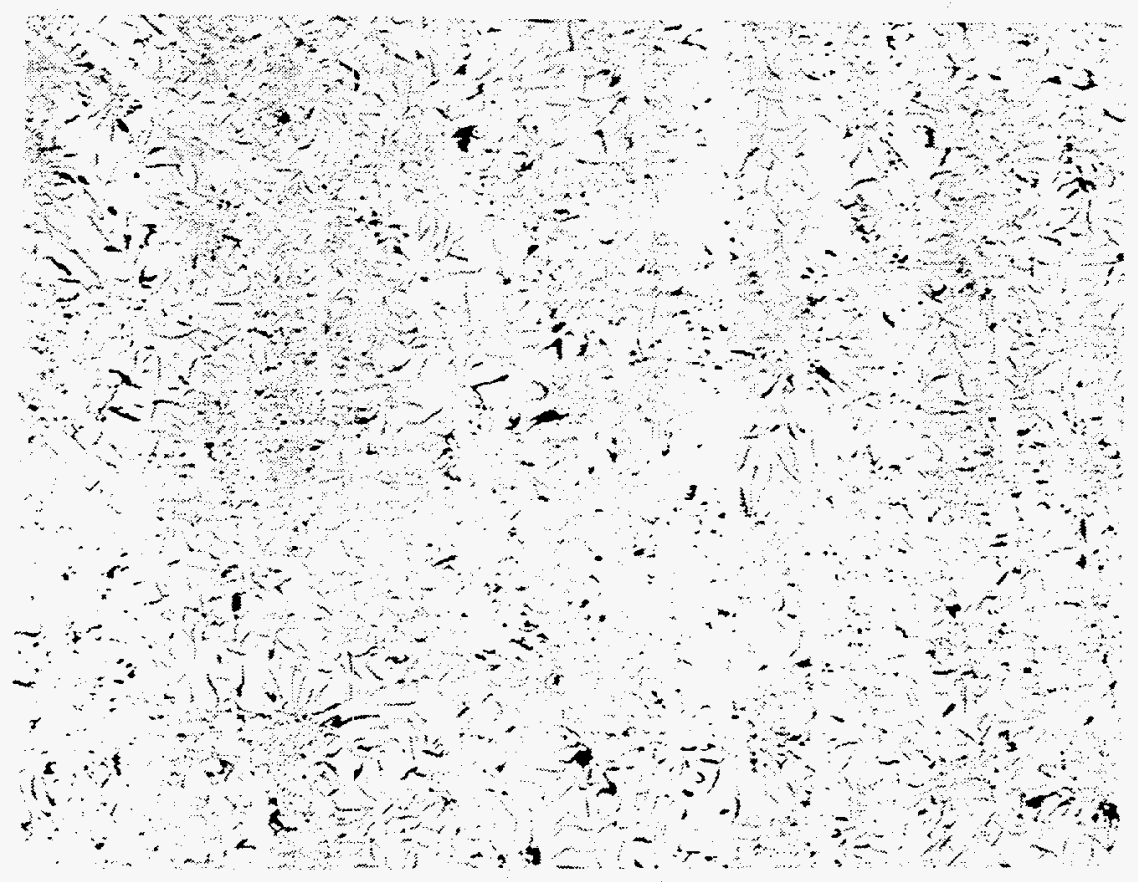

(A)

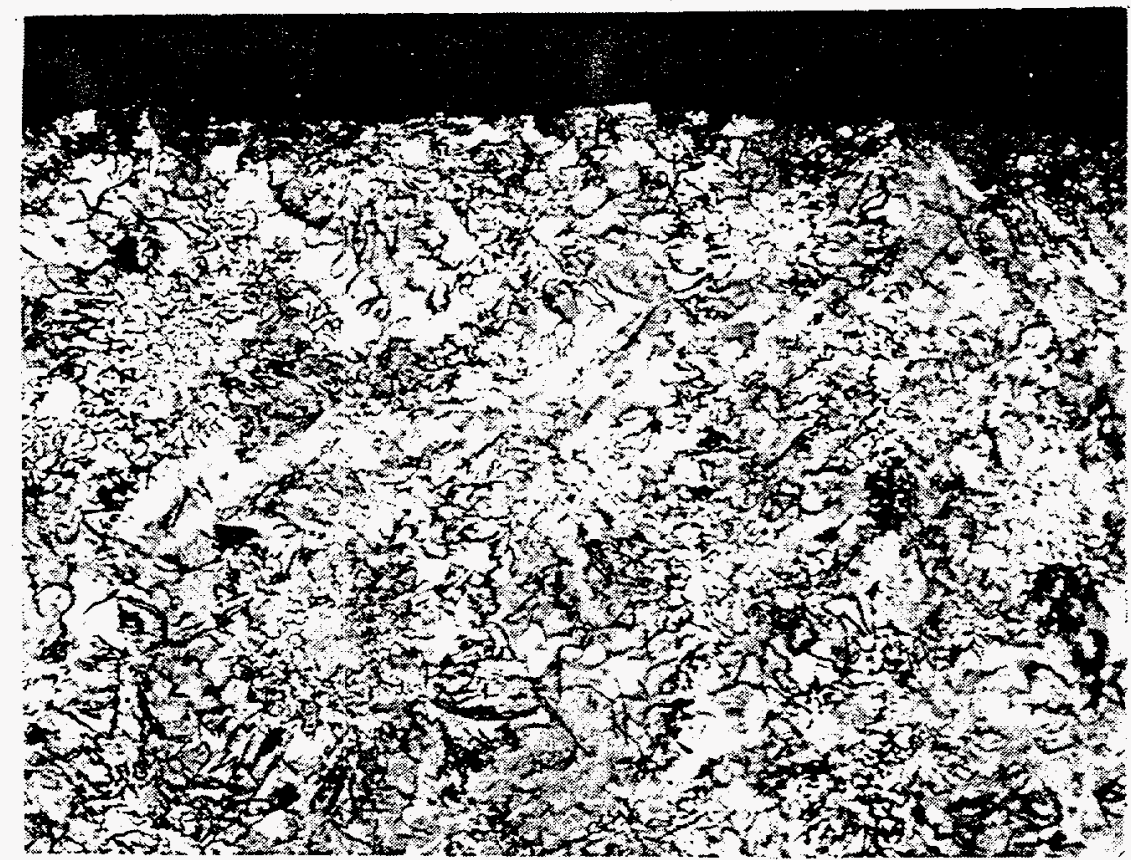

(B)

Figure 5.19. (A) Graphite Structure in an As-cast EPC Gray Iron Specimen. 100X

(B) Matrix Microstructure in an As-cast EPC Gray Iron Specimen. 200X $2 \%$ Nital Etch. 


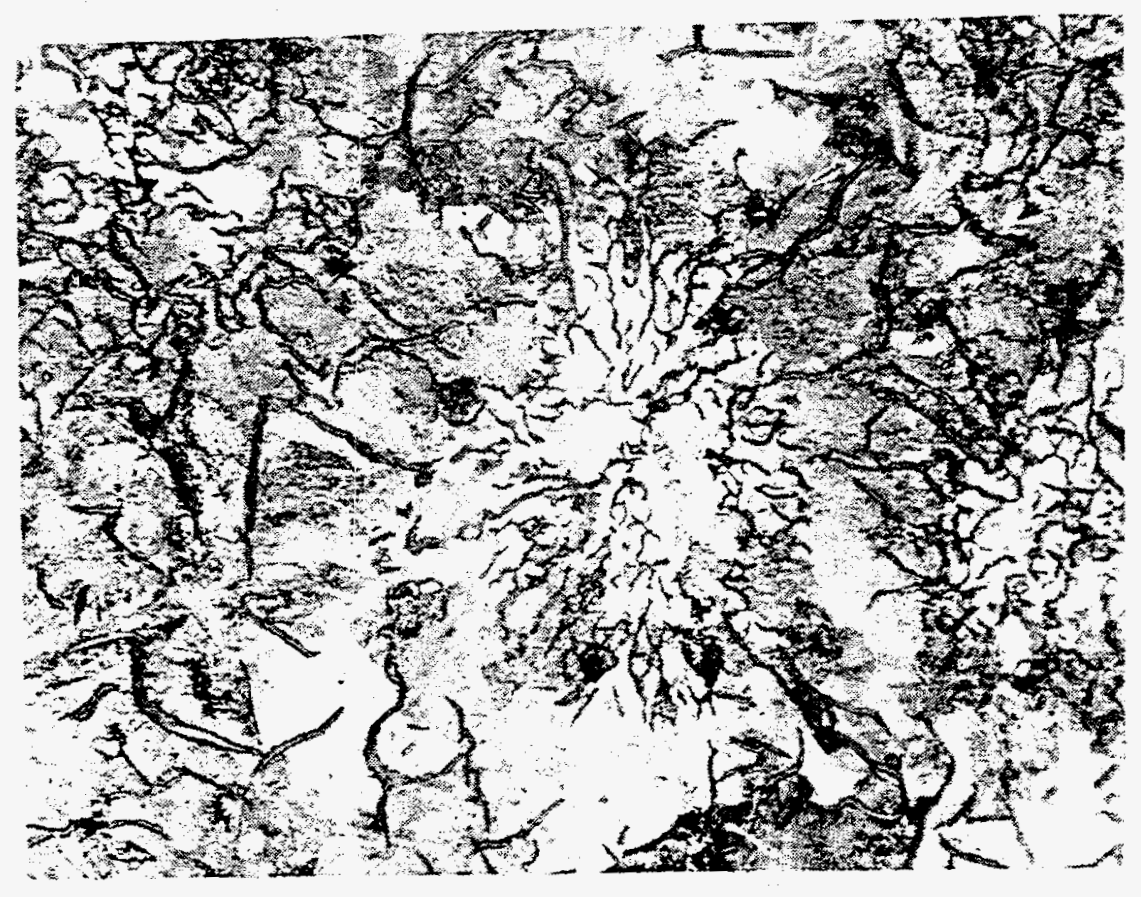

(A)

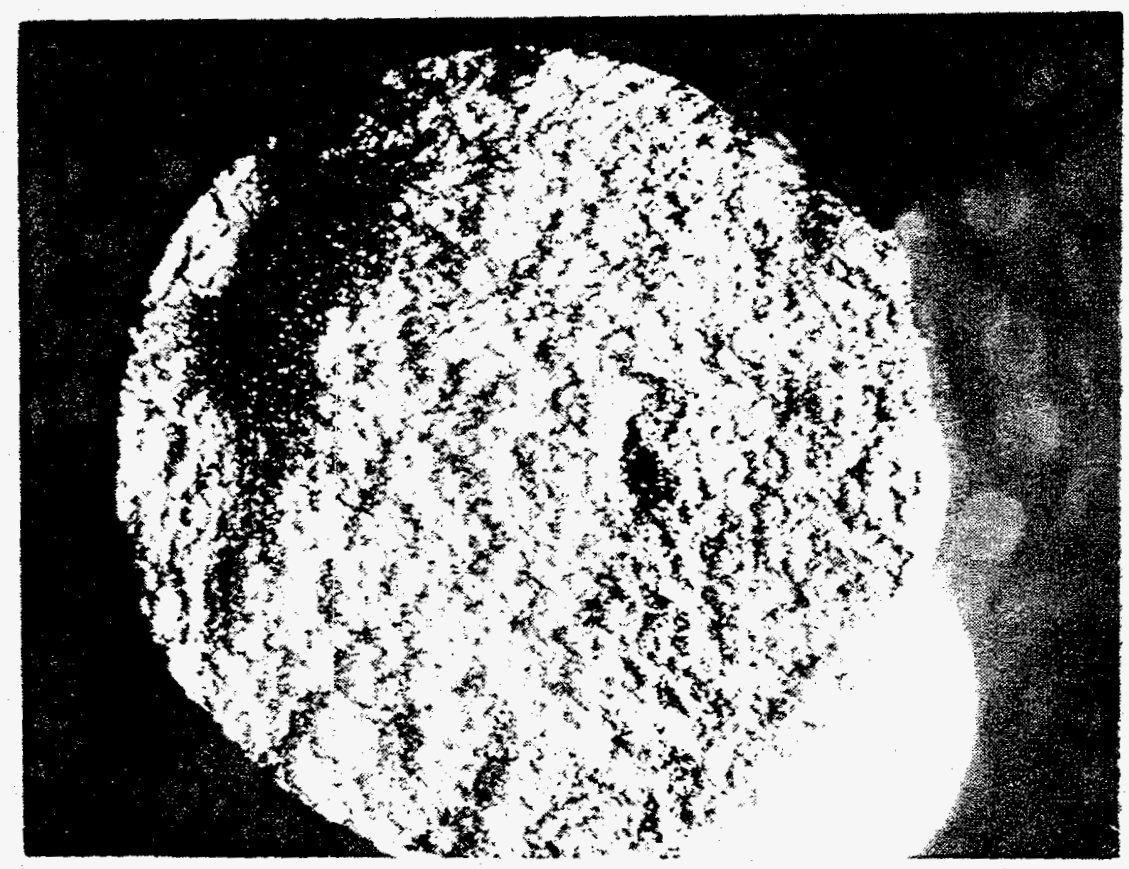

(B)

Figure 5.20. (A) Matrix Microstructure (Fig. 15.37 (B) enlarged). 500X

(B) Typical Fracture Face on As-cast EPC Gray Iron Specimens. 15X 

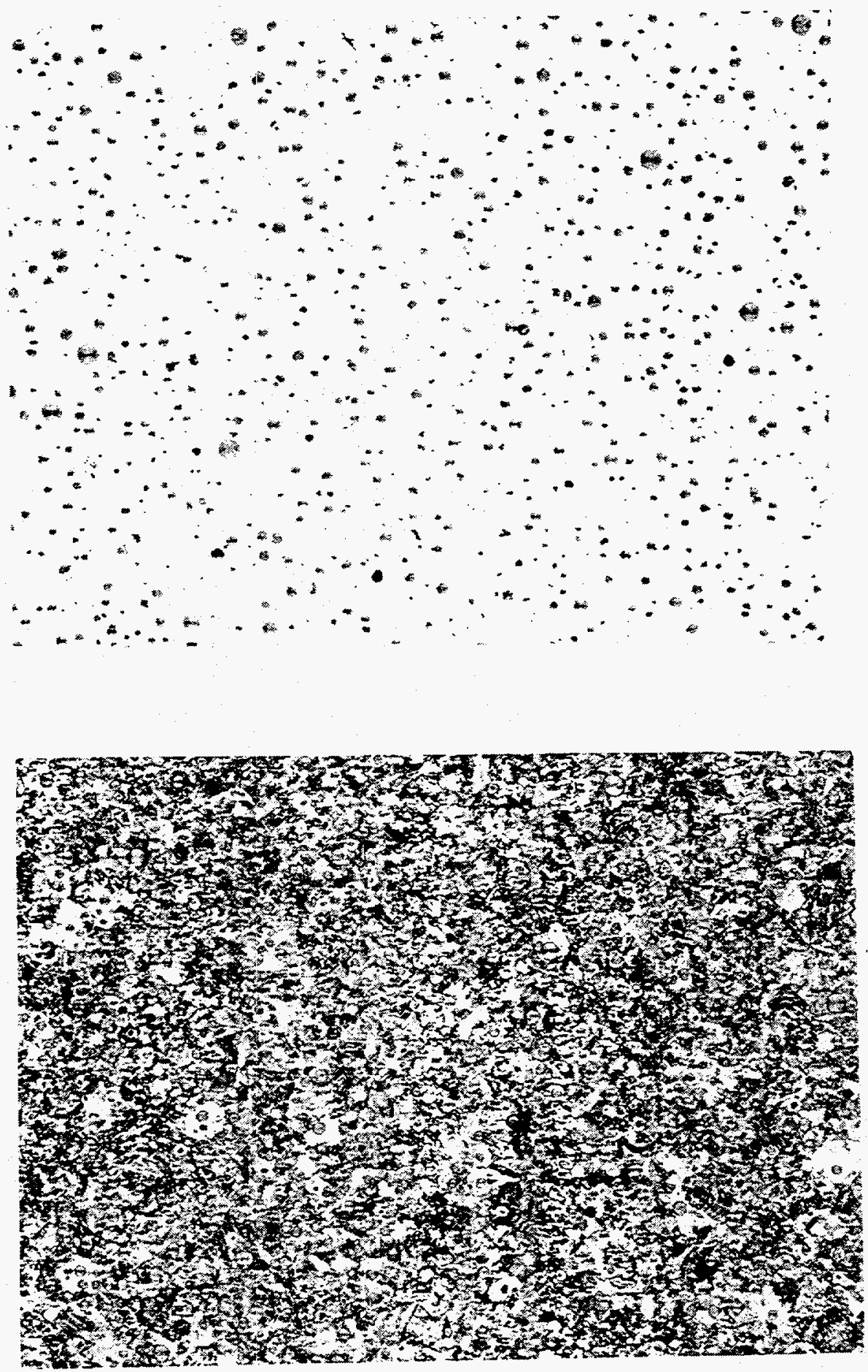

(B)

Figure 5.21. (A) Graphite Structure in an As-cast EPC Ductile Iron Specimen. 100X

(B) Matrix Microstructure in an As-cast EPC Ductile Iron Specimen. 100X 


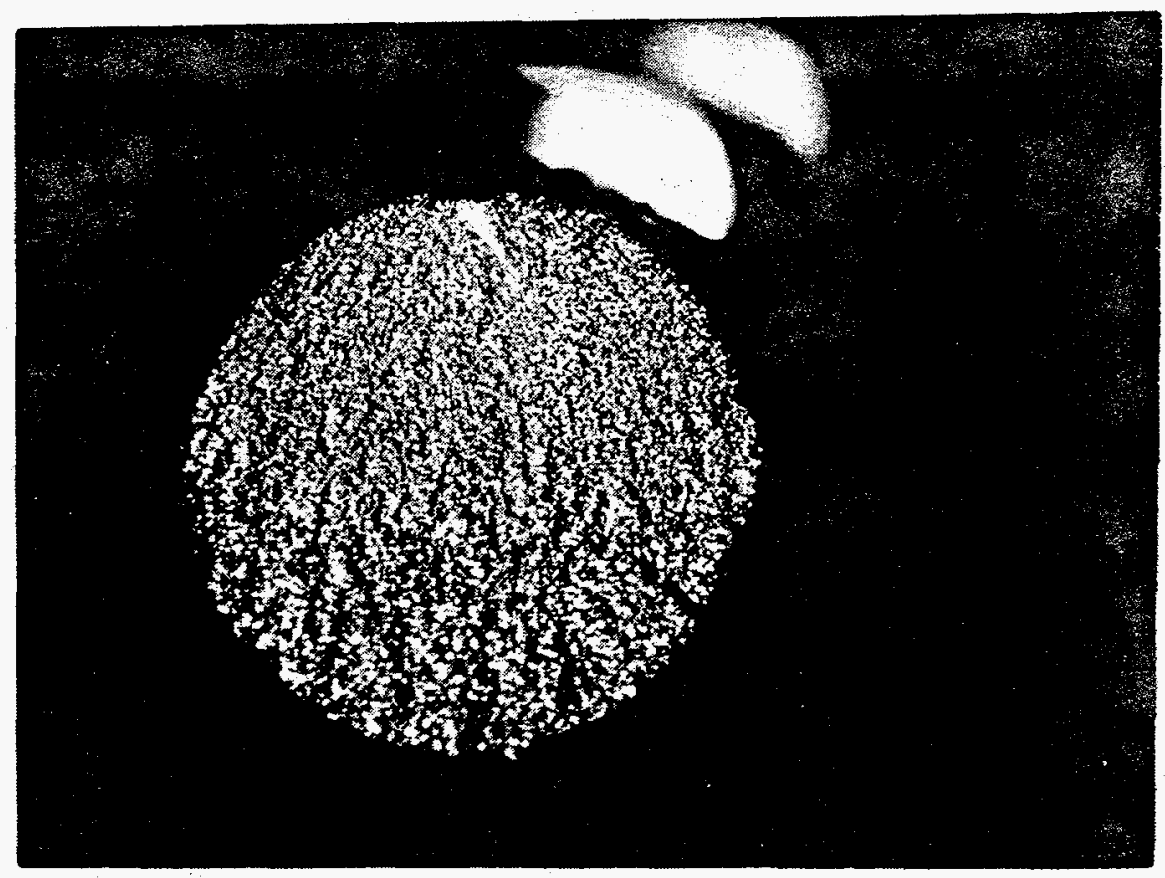

(A)

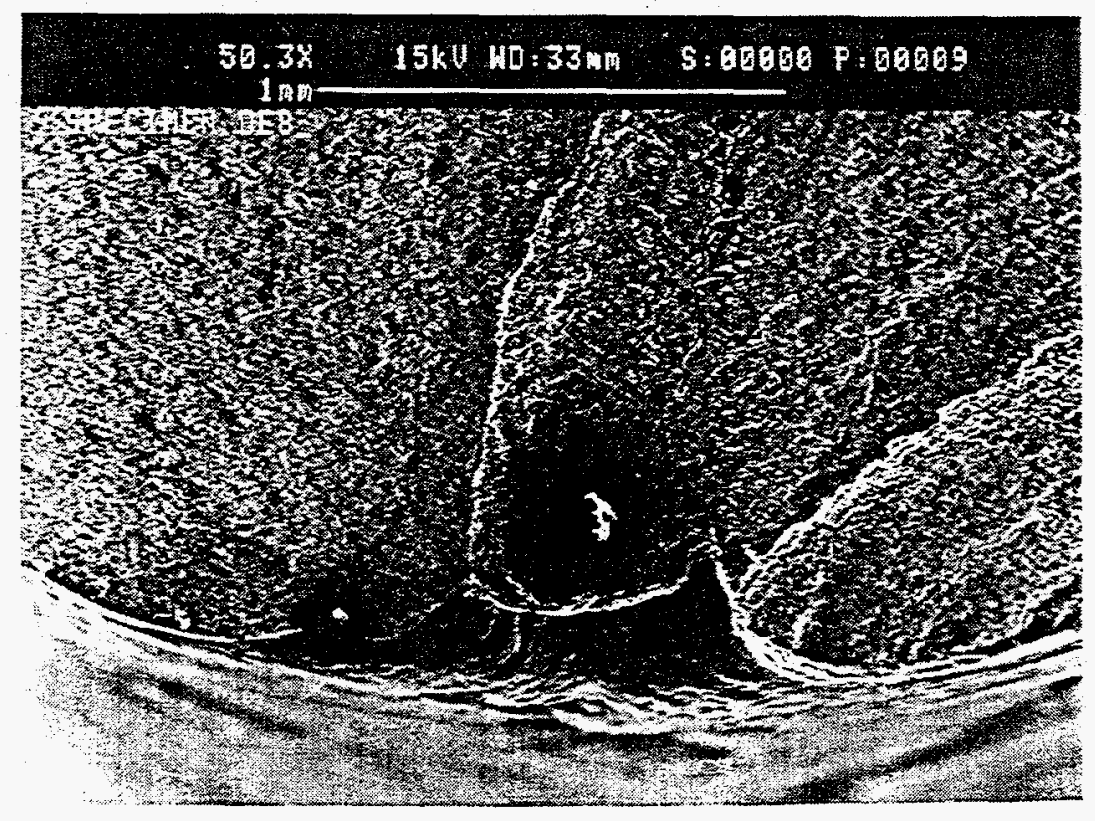

(B)

Figure 5.22. (A) Typical fracture Face of As-cast EPC Ductile Iron Specimen. 10X

(B) SEM Micrograph Showing Bead Intersection Notch on As-cast EPC Ductile Iron Specimen. 50.3X 
5.5.3. Lost Foam Cast and Machined Specimens. Typical microstructures of machined gray iron fatigue specimens are illustrated in Figure 5.23. The graphite configuration, illustrated in Figure 5.23(A), was mainly ASTM A247 Type A with traces of D and E. Graphite flake size was 4. The matrix microstructure, illustrated in Figure 5.23(B), was mostly fine to very fine pearlite, generally unresolvable at $500 x$. There was virtually no ferrite in the microstructure. These specimens were found to be sound with no internal microshrinkage, and the microstructure was uniform throughout the section.

A typical gray iron specimen fracture face is illustrated in Figures 5.24(B). Specific fatigue origins were more difficult to locate on this set of specimens than on the other gray iron groups. Again, there appeared to be multiple origins around the specimen periphery where graphite flake orientation was favorable for crack propagation. An example of the intersection of the gray iron fatigue fracture face with the specimen gauge surface is shown in Figure $5.24(B)$.

A typical microstructure of a machined ductile iron fatigue specimen is illustrated in Figures 5.25. The graphite particles, illustrated in Figure 5.25(A), were mainly ASTM A247 Type I with nodularity greater than $90 \%$. The nodule size was 6 to 7 , and the nodule count was 200-250 per $\mathrm{mm}^{2}$. The matrix microstructure, illustrated in Figure 5.25(B), consisted of pearlite with less than 5\% ferrite. Steadite and free carbides were not seen.

Typical ductile iron specimen fracture faces are illustrated in Eigures 5.26(A) and (B). Failures initiated at the machined surface of the specimen at graphite particles and/or areas containing small amounts of microshrinkage.

The gray iron fatigue specimen material was fairly consistent. The major difference was graphite morphology with the machined specimens having primarily Type $A$ and the lost foam cast (Lost foam casting) specimens primarily Type $D$ and $E$ graphite. Matrix microstructure was pearlitic in both cases with a bit more ferrite in the Lost foam casting specimens than in the machined specimens. The difference in microstructure was due to the difference in cooling rate between the $7 \mathrm{~mm}(0.276$ in.) diameter Lost foam casting gage section and the $30.5 \mathrm{~mm}$ ( $1.2 \mathrm{in.})$ diameter Lost foam casting test bars from which the machined specimens were obtained.

The ductile iron fatigue specimen material was quite consistent. Matrix microstructures were pearlitic with only traces of ferrite adjacent to the graphite nodules. Steadite was never seen, and carbides were present only in a shallow layer at the surface of the sand cast test specimens. Nodule counts were high in the specimen gauge sections as a result of the small cross-section. As expected, 


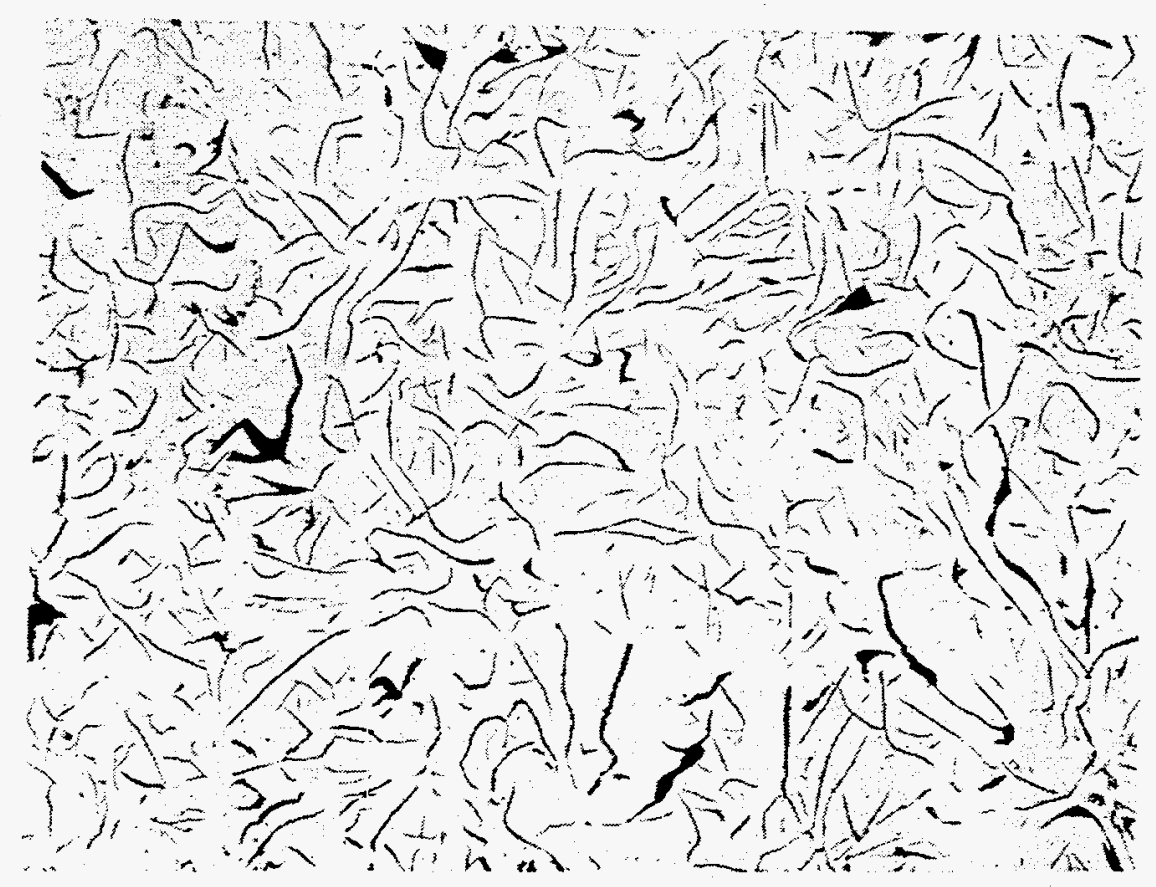

(A)

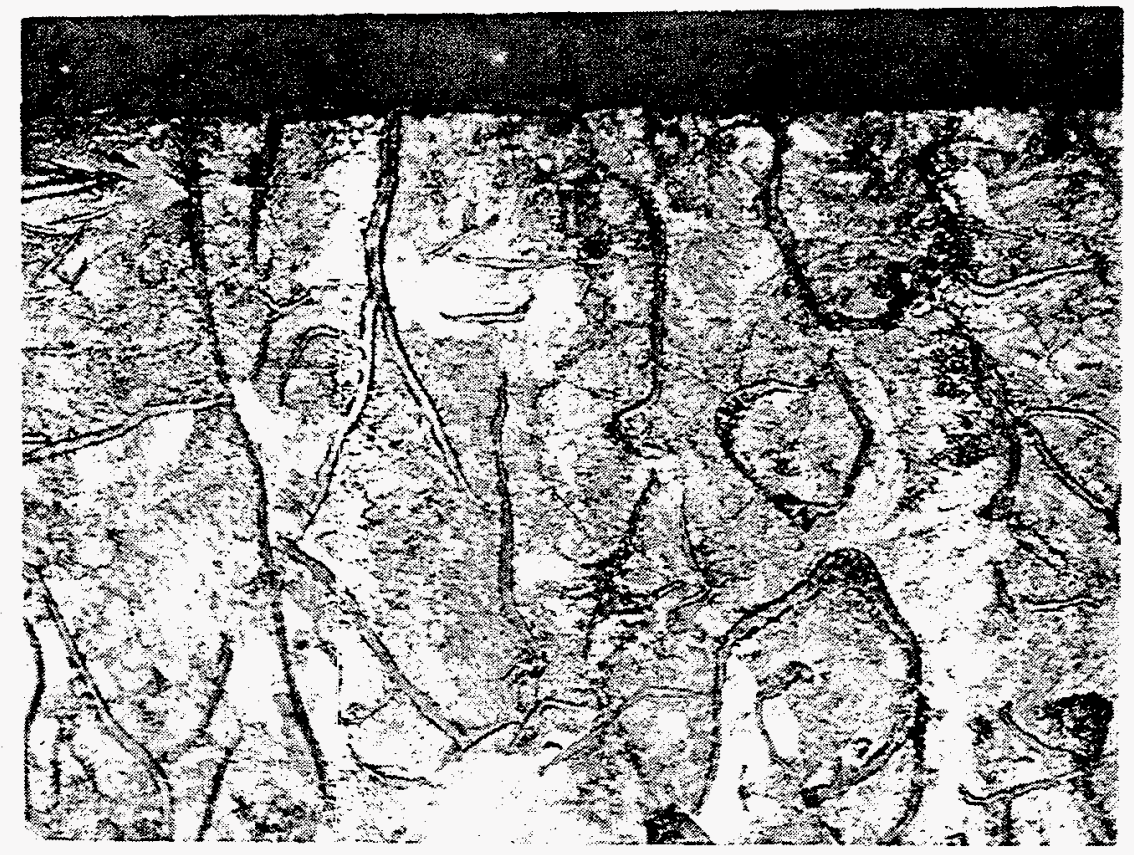

(B)

Figure 5.23. (A) Graphite Structure in a Machined Gray Iron Specimen. 100X

(B) Matrix Microstructure in a Machined Gray Iron Specimen. 375X $2 \%$ Nital Etch. 


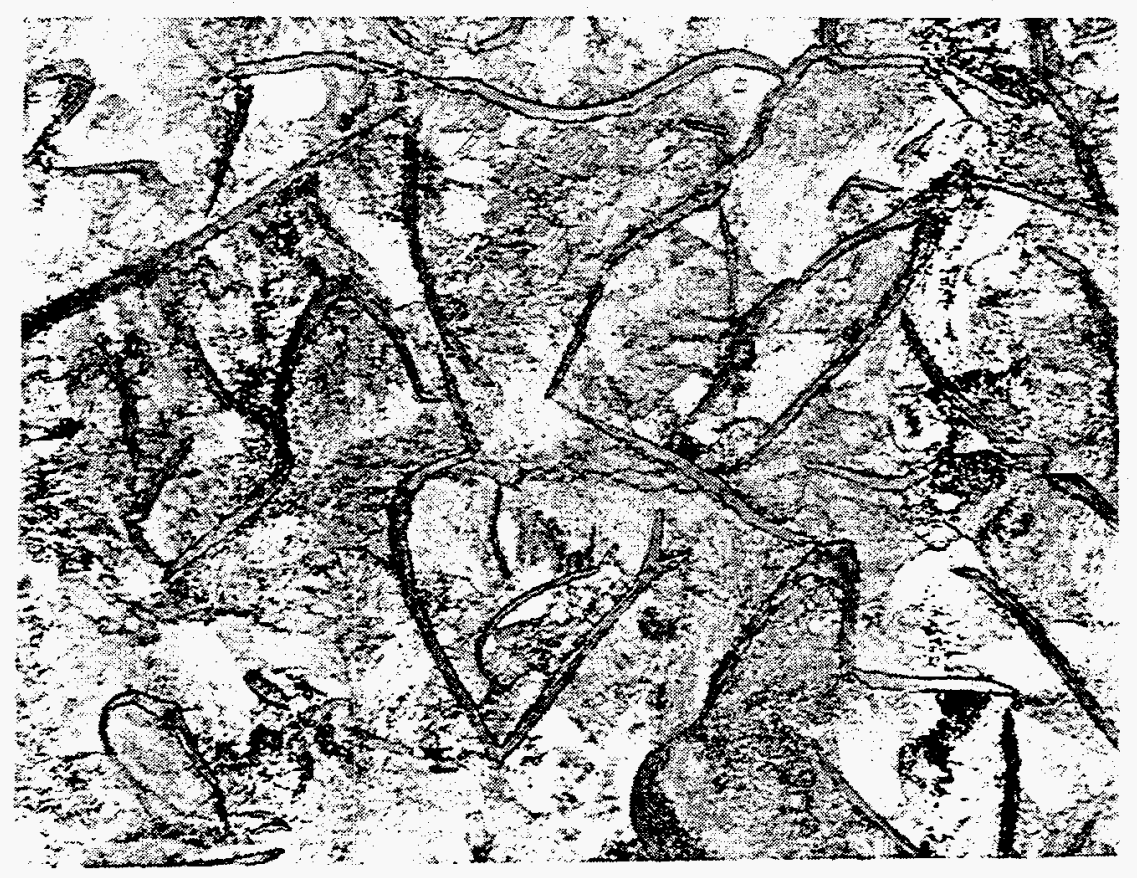

(A)

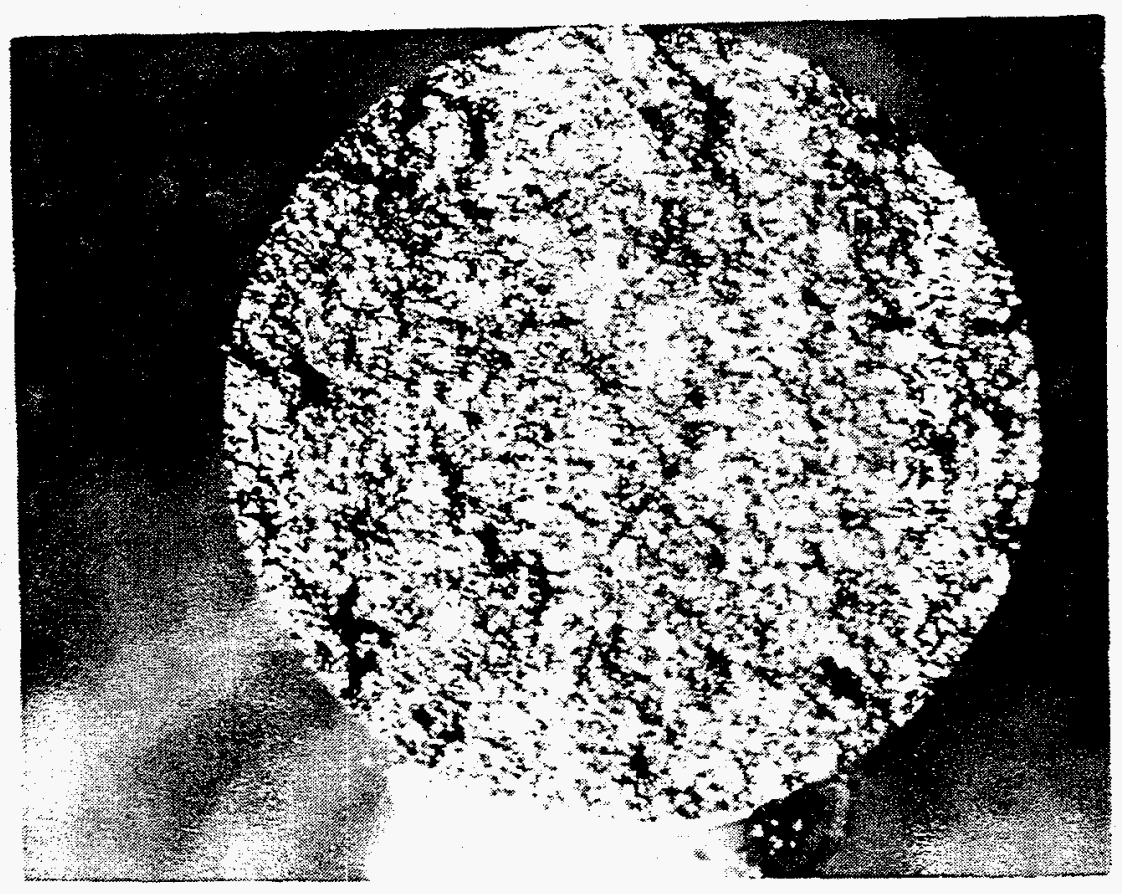

(B)

Eigure 5.24. (A) Matrix Microstructure (Fig. 15.42 (B) enlarged). 500X

(B) Typical Fracture Face on Machined Surface Gray Iron Specimens. 15X 

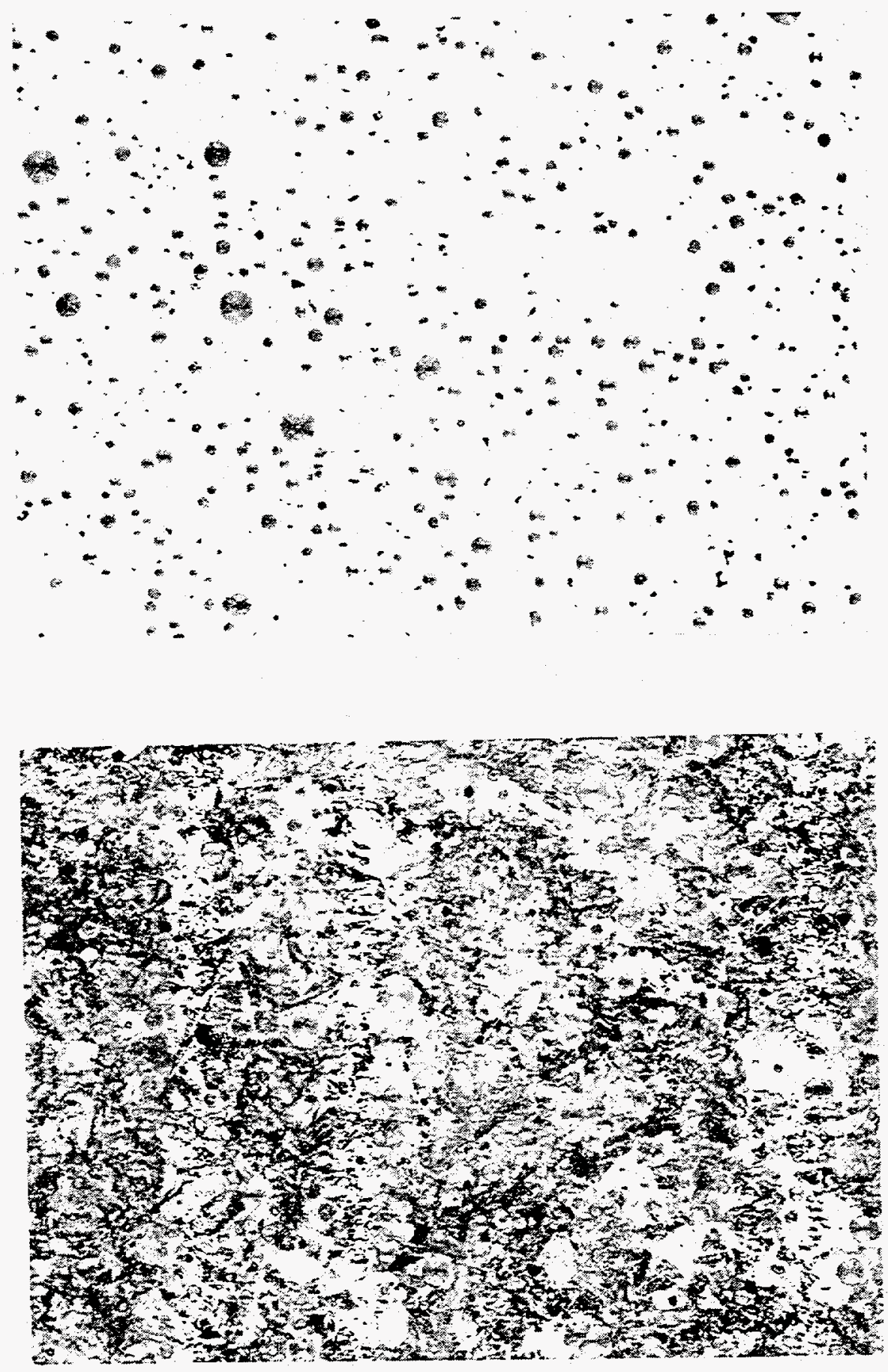

Eigure 5.25. (A) Graphite Structure in a Machined Surface Ductile Iron Specimen. 100X (B) Matrix Microstructure in a Machined Surface Ductile Iron Specimen. 100X 2\% Nital Etch. 


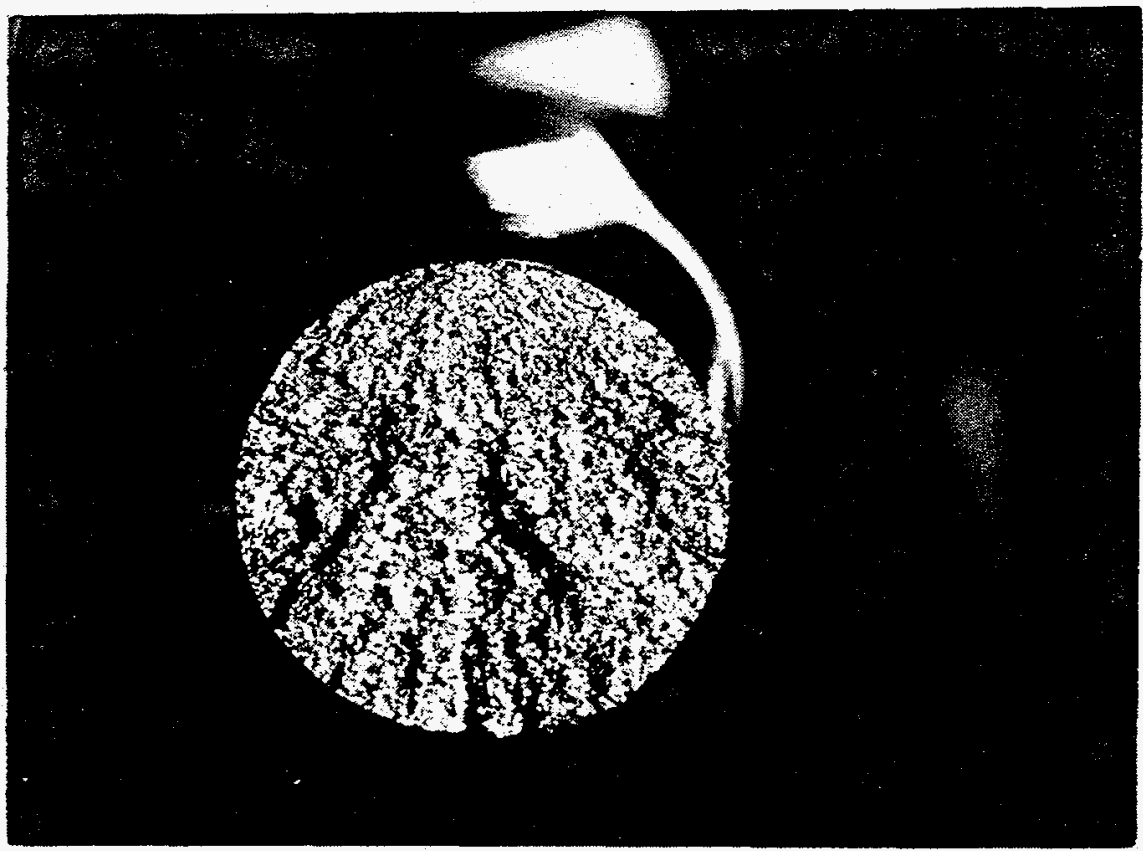

(A)

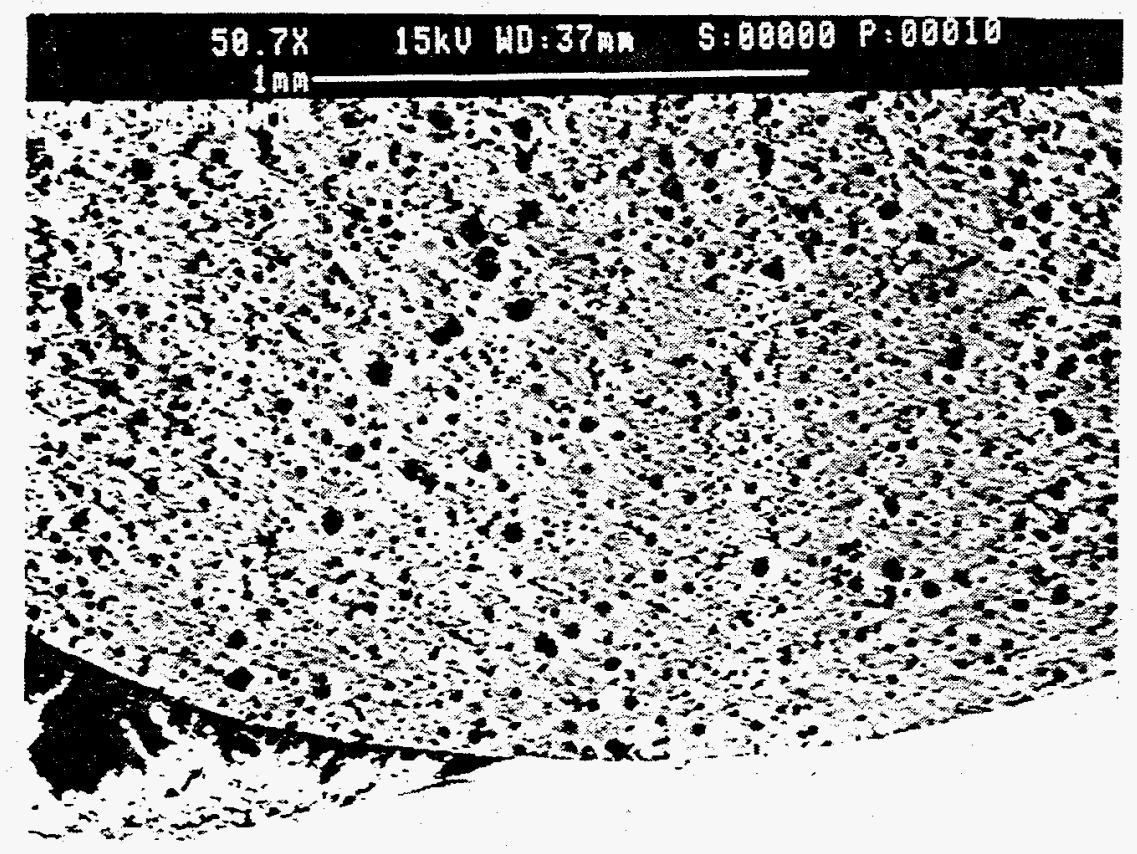

(B)

Figure 5.26. (A) Typical Fracture Face on a Machined Surface Specimen. $10 \mathrm{X}$

(B) SEM Micrograph Showing Typical Machined Surface Specimen Origin. $50.7 \mathrm{X}$ 
the machined surface test specimens had somewhat lower nodule count and slightly larger nodule size due to the heavier as-cast section.

\subsection{Tensile and Fatigue Test Results}

Tensile and fatigue test results for the test specimens are summarized in the Table 5.2. Stress-life, strain-life, and stress-strain results for the gray iron is illustrated in Figure 5.275.29 and similar data for ductile iron is illustrated in Figures 5.305.32 .

Normally, it is expected that at short cycle lives (high strain amplitudes), basic material properties including strength and toughness dominate fatigue properties so there should have been little difference between the three surface conditions. At high cycle lives (low strain amplitudes), fatigue properties become very sensitive to surface condition, soundness, inclusion shape, size and distribution, etc. For instance, ductile iron specimens with a sand cast surface showed a reduction in B50 stress amplitude of $29 \%$ at $2,000,000$ cycles while ductile iron specimens with the as-cast lost foam pattern surface showed a reduction of $42 \%$ compared to machined surfaces on lost foam castings.

Some degradation in fatigue properties was expected due to surface finish effects. The difference in runout between the sets of specimens should also not be overlooked. Lack of specimen straightness can result in higher than nominal load at the specimen surface due to bending moments and thus a shorter life than would be obtained if the specimen were completely straight. No attempt has been made to separate the effects, and both are probably operative.

5.6.1. Class 30 Gray Iron. All of the gray iron specimen groups conformed to SAE J431 Grade G3000 mechanical property requirements. The larger as-cast section size of the machined specimens resulted in slightly lower tensile strength and hardness compared to lost foam specimens having an as-cast surface. The sand cast specimen had substantially higher tensile strength than the other two groups.

The flawed nature of the gray iron microstructure (presence of graphite flakes) seemed to overcome any differences in fatigue strength between the Lost foam casting specimens that were cast and the Lost foam casting specimens tested with an as-cast surface machined and as-cast lost foam surface specimens - the tensile and fatigue results were similar. The higher strength of the no-bake specimens with the as-cast surface gave noticeably higher fatigue strength at short life (high strain) but no improvement over the other gray iron groups at long life. Overall, it appeared that gray iron was not much affected by surface finish. 
TABLE 5.2

SUMMARY OE TEINSILE AND FATIGUE TEST RESULTS

\section{TENSILE TEST RESULTS}

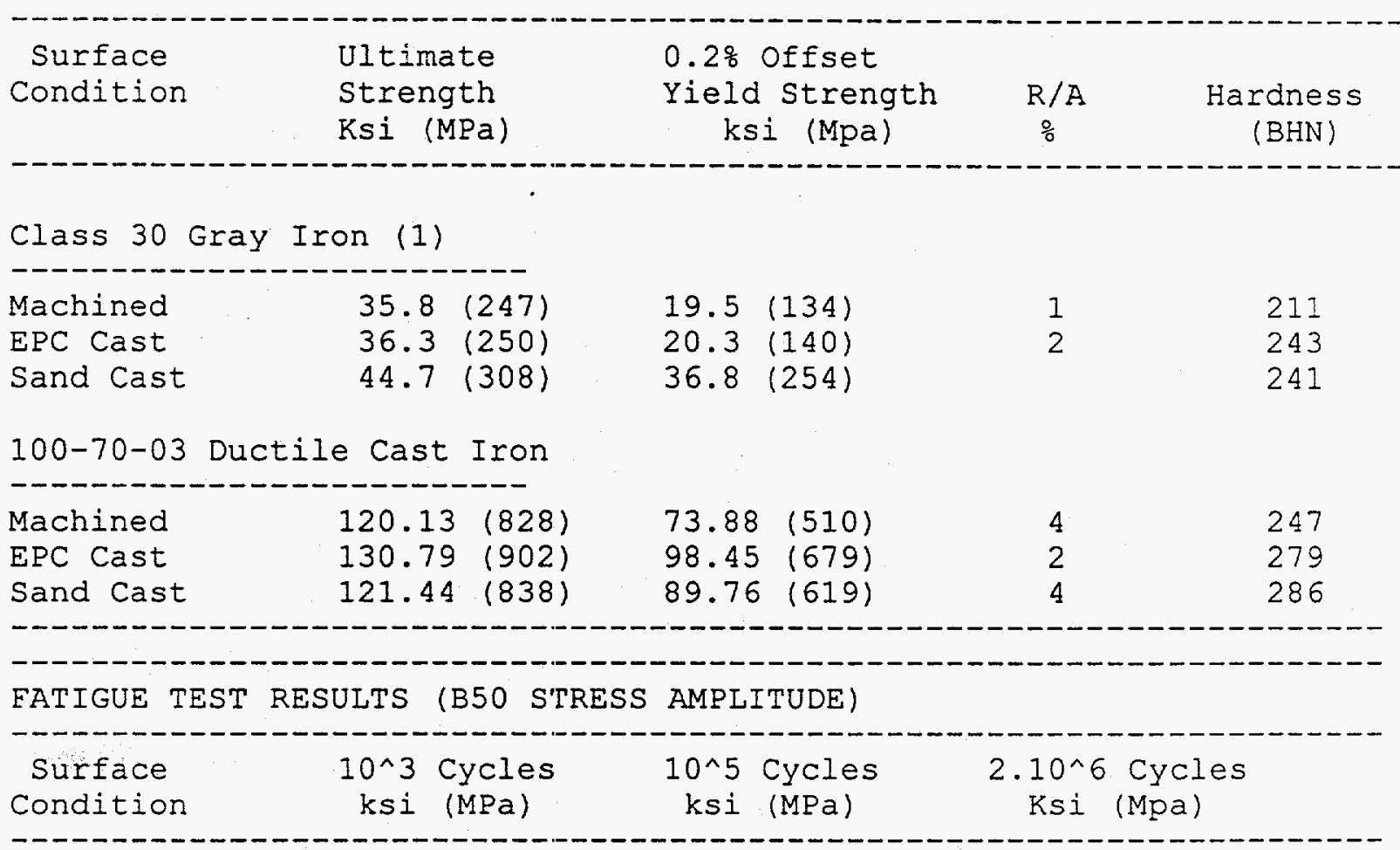

Class 30 Gray Iron

$\begin{array}{lrrrrr}\text { Machined } & 23.0 & (158) & 11.3(78) & 9.7 & (67) \\ \text { EPC Cast } & 22.8 & (157) & 9.9(68) & 8.2 & (57) \\ \text { Sand Cast } & 35.3 & (245) & 15.2(105) & 7.7 & (53)\end{array}$

100-70-03 Ductile Cast Iron

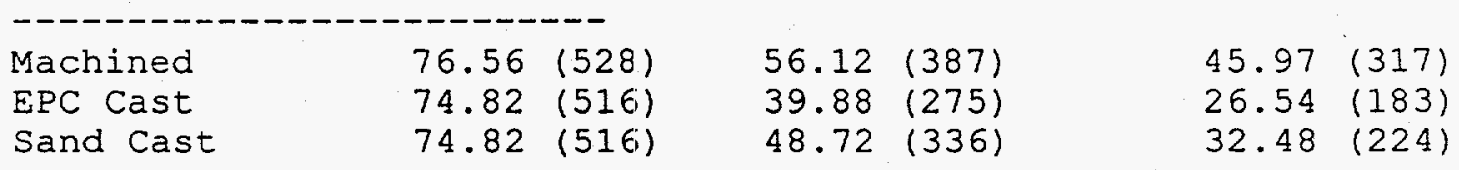

(1) Hardiness sconverted from Rockwell B

(2) For 356-T6 aluminum stress amplitude is at 4000, rather than 1000 cycles 


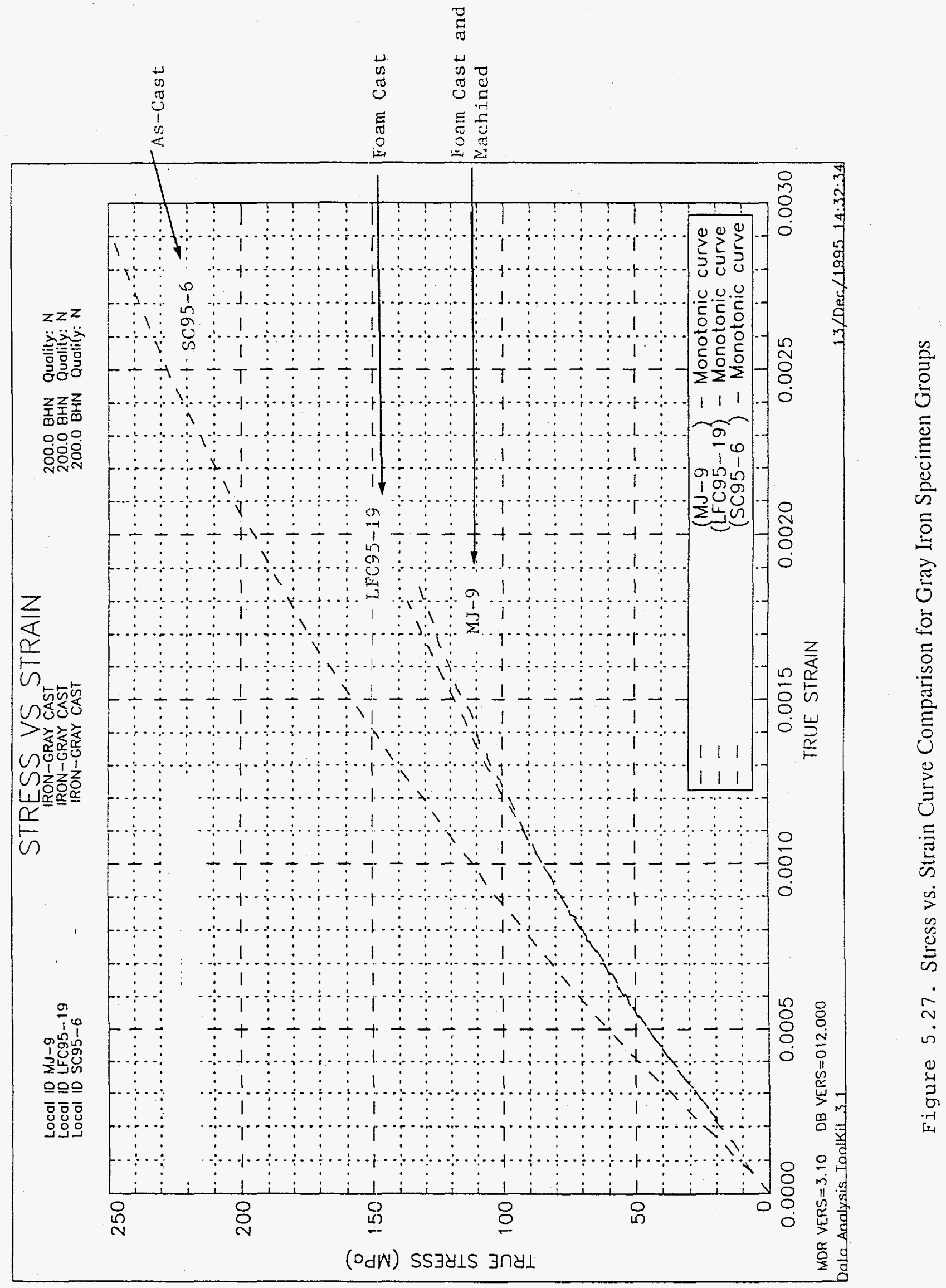




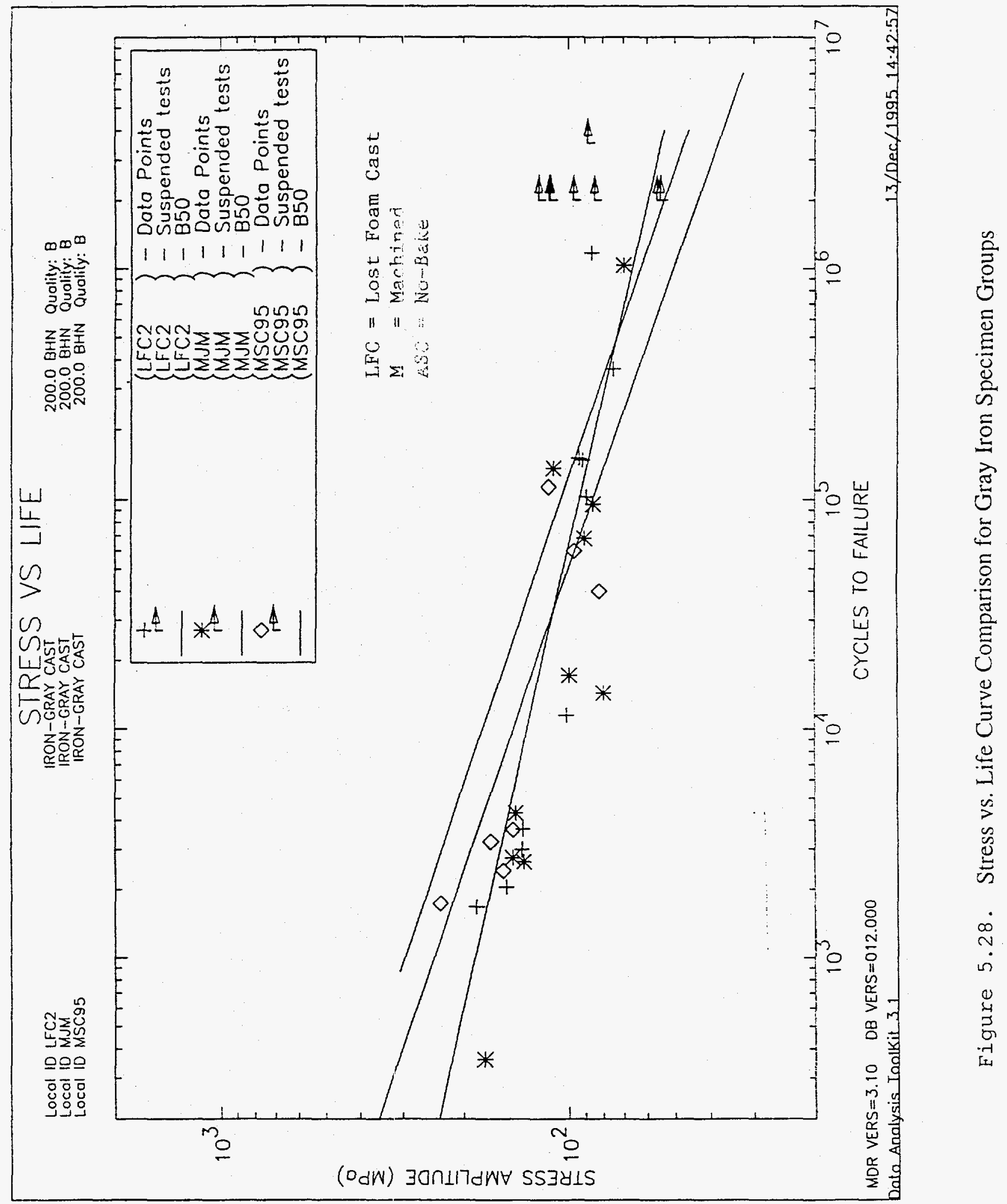




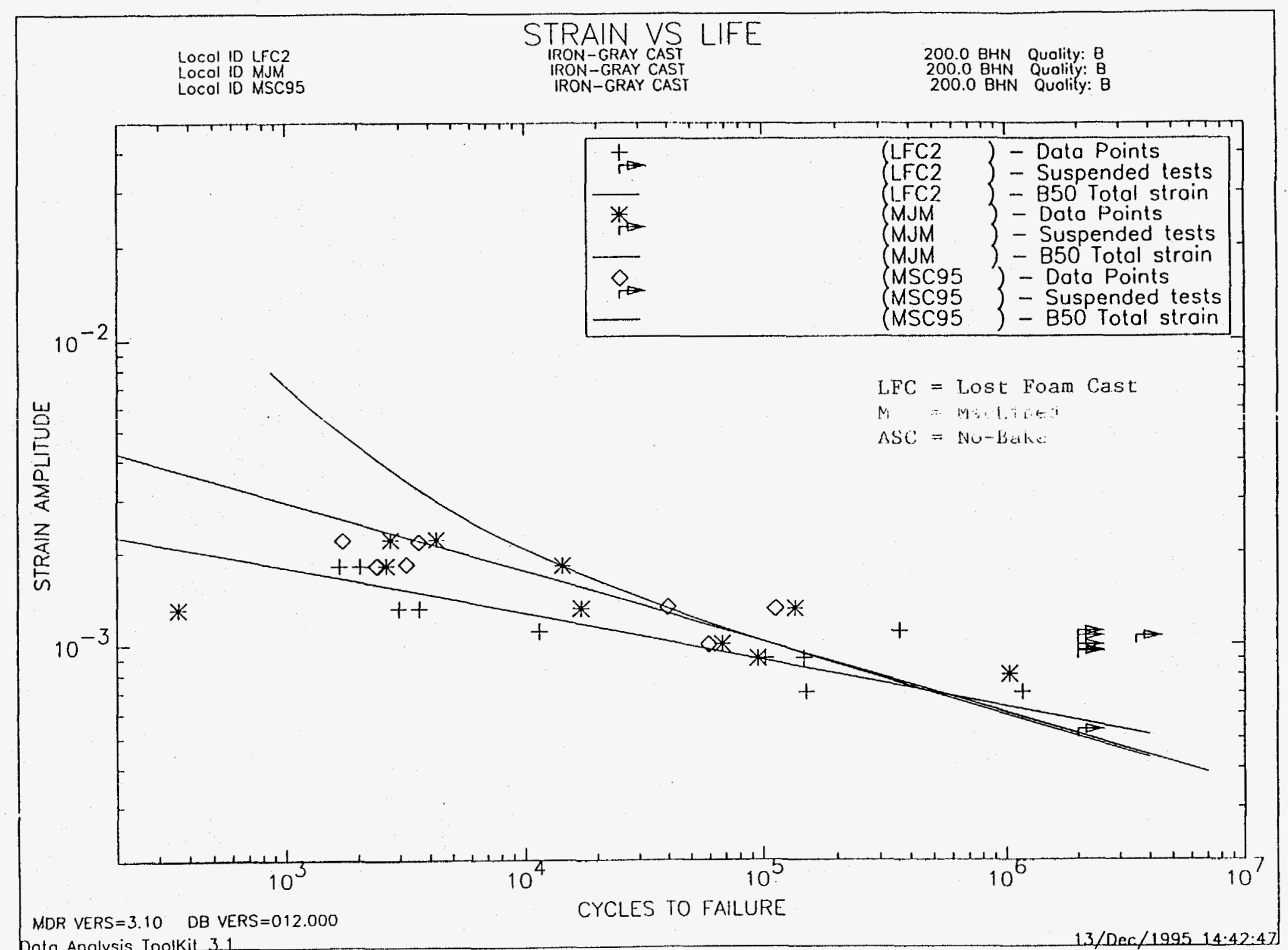

Figure 5.29. Strain vs. Life Curve Comparison for Gray Iron Specimen Groups 


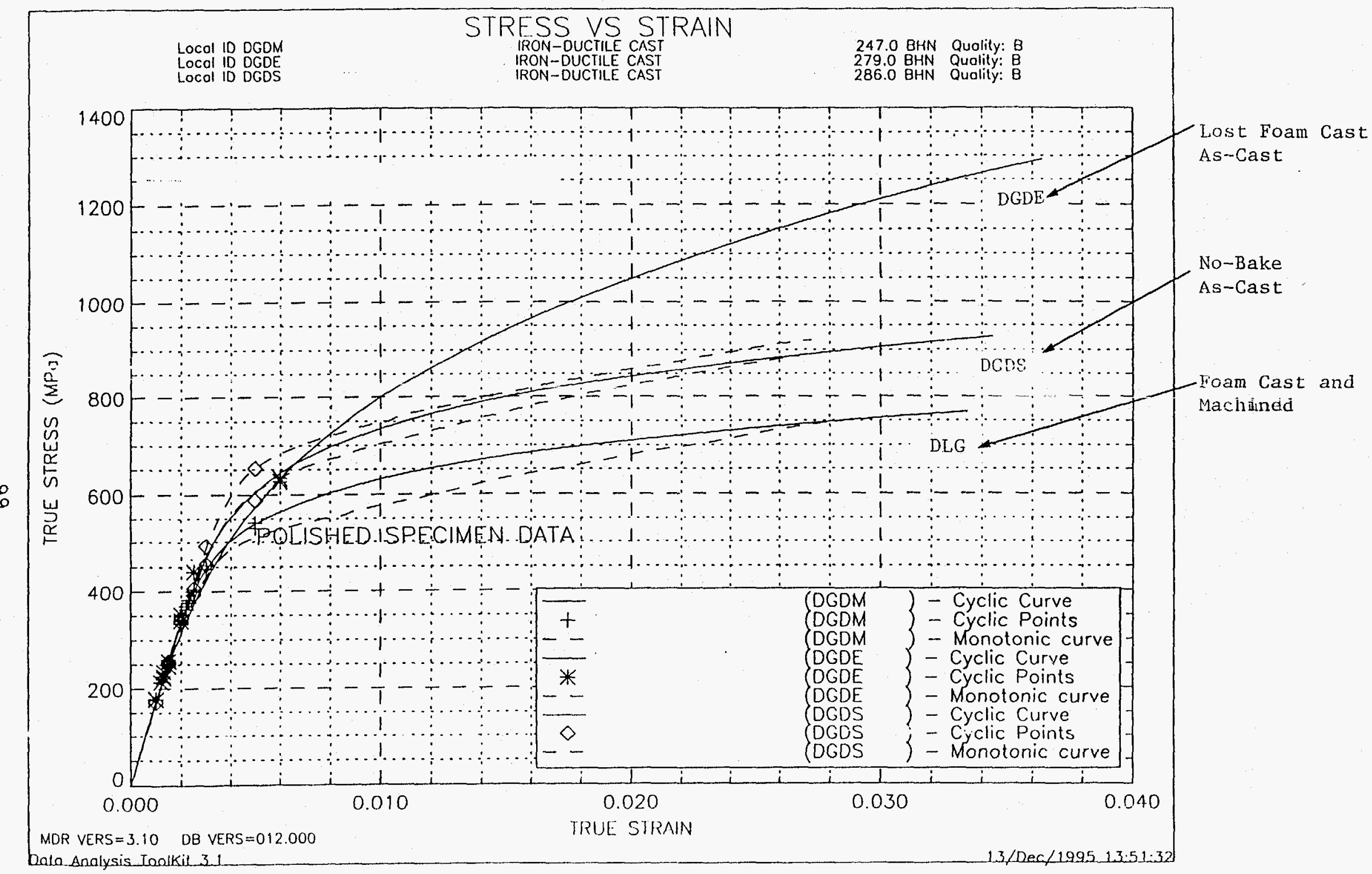

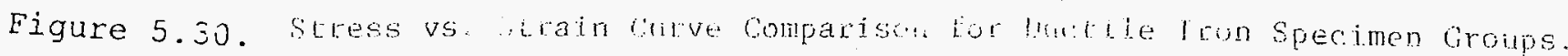




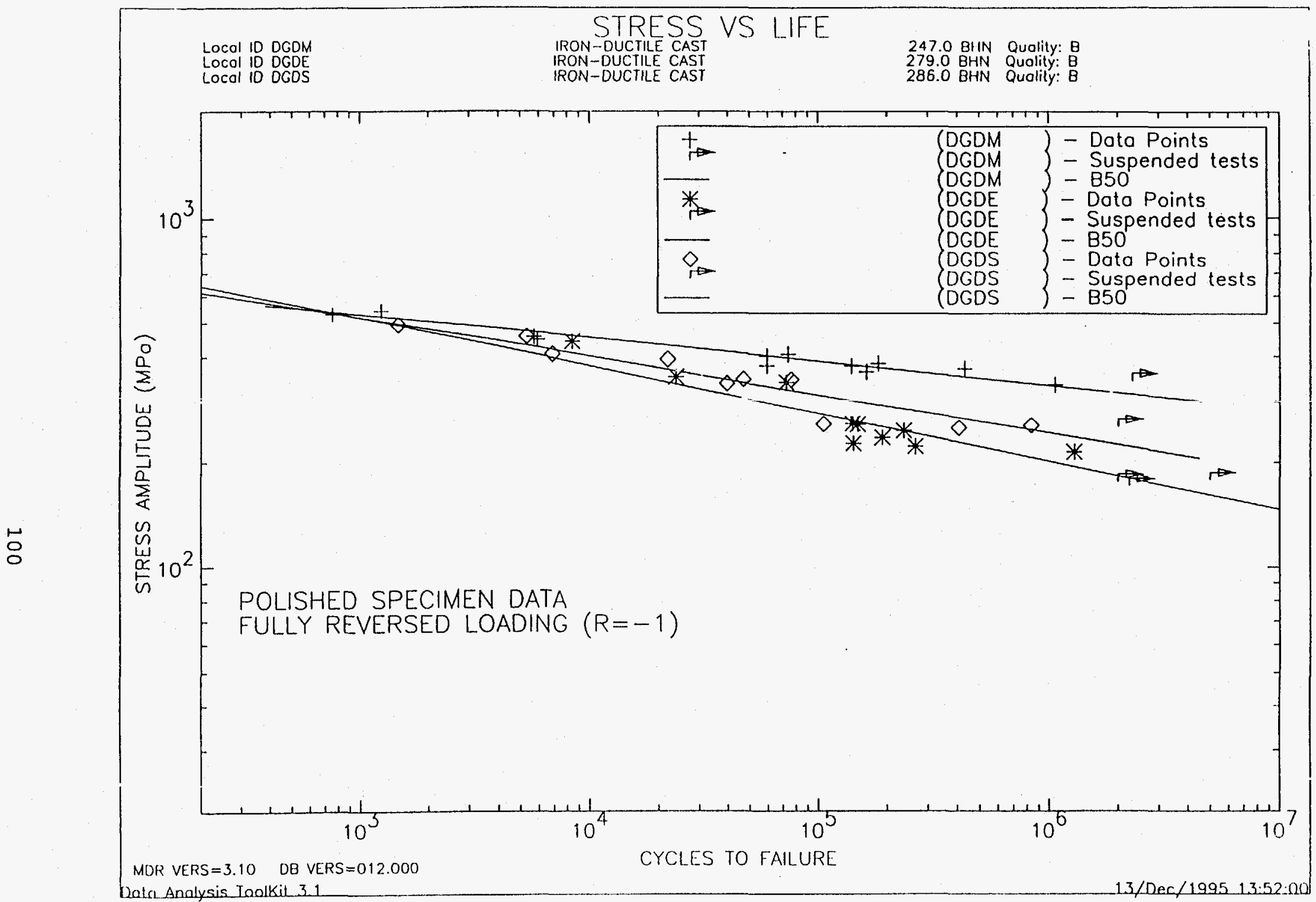

Figure 5.31. Stress vs. Life Curve Comparison for Ductile Iron Specimen Groups. 


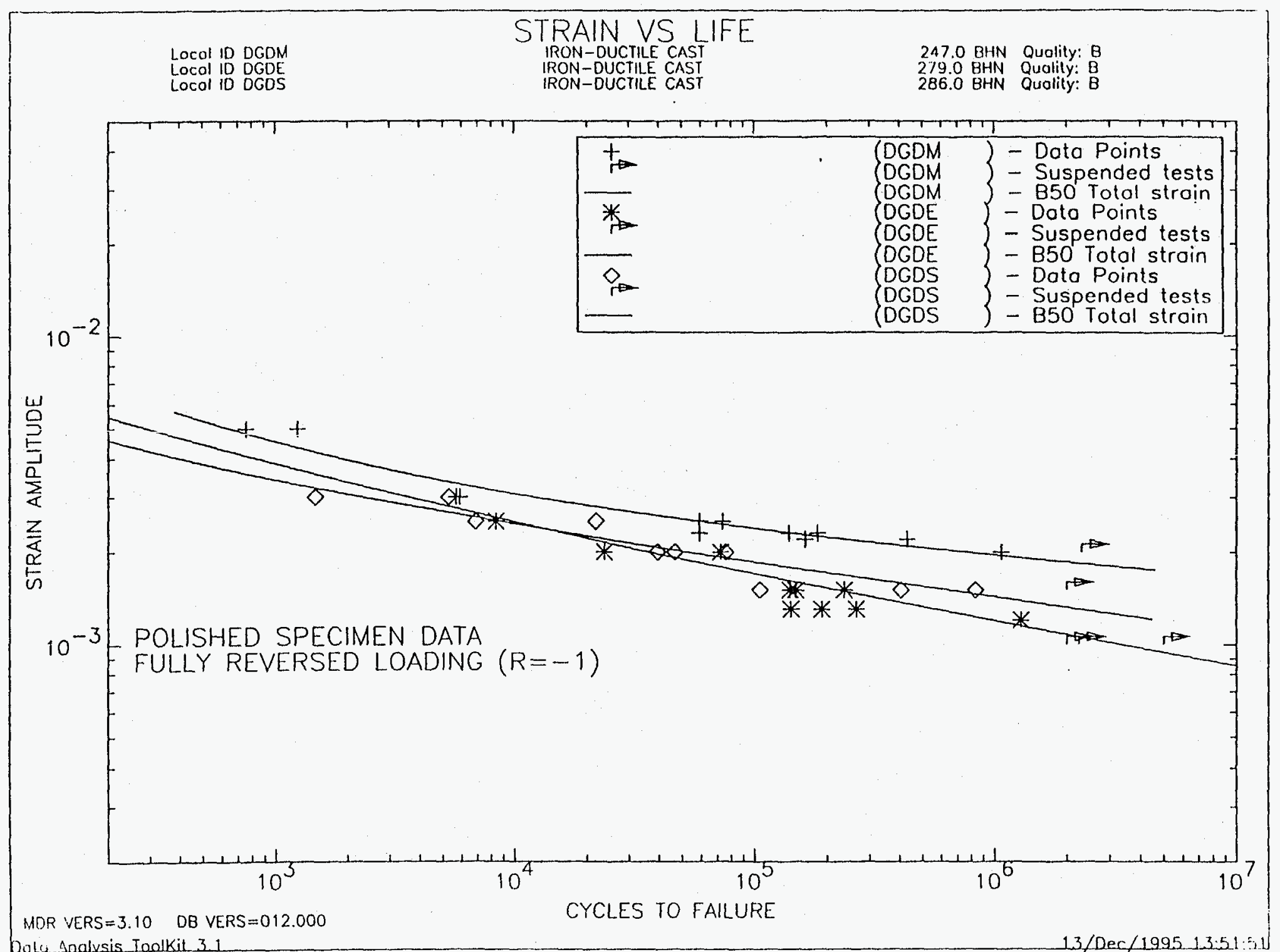

Figure 5.32. Strair ve. Lile Curve Compaison tor bucrile lron specimen Groups. 
Analysis of the gray iron fatigue test results was conducted differently than is typically done for axially loaded, strain controlled fatigue tests on materials such as steel or ductile iron.

The gray iron exhibited cyclic hardening and clearly behaved differently in compression than tension. As the specimens cycled in strain control, the load required to produce the specified tensile strain increased while the load required to produce the specified compressive strain decreased. The overall increase in the load caused the mean stresses recorded by the controller to be greater than zero. Therefore, the test was fully reversed in strain but not in stress. In addition, gray iron specimens exhibited a great deal of scatter. The same strain amplitude produced failures at lives that differed by two orders of magnitude.

The gray iron specimen mean stress values and data scatter made the use of the standard data analysis programs normally used for fully reversed cycling of steel impossible. Therefore, a simple power law curve fit was applied to the stress versus life and total strain versus life data to calculate the fatigue strength coefficient and the fatigue strength exponent. The near absence of plasticity made a power law fit to the total strain amplitude data acceptable. Also, because of the absence of plasticity, the values for the fatigue ductility coefficient and fatigue ductility exponent are theoretically infinite and were not calculated. The simple power law fit did not allow for the calculation of Weibull life values.

5.6.2. 100-70-03 Ductile Cast Iron. All of the ductile iron specimen groups conformed to ASTM A536 Grade 100-70-03 mechanical property requirements. The larger cast section size of the machined specimen group resulted in somewhat lower tensile strength and hardness compared with the lost foarn casting and sand cast specimens. However, the fatigue properties of the Lost foam casting cast and machined specimens were superior to those of specimens with as-cast surfaces.

It should not be inferred that lost foam casting cast surfaces have inherently lower fatigue strength compared to sand cast surfaces. Improvements in surface finish to reduce the size of the depressions at bead intersections will probably improve fatigue strength significantly since it appeared that the reduction was due to geometrical notch effects rather than degradation of the material microstructure.

\subsection{Summary and Conclusions-Gray and Ductile Iron Properties}

This section summarizes the tensile and fatigue property data obtained on lost foam cast Class 30 gray iron and 100-70-03 ductile iron. All of the tensile data were obtained from castings made as 
$30.5 \mathrm{~mm}$ (1.2 in.) diameter bars cast either in no-bake molds or from LF patterns. The following results were obtained:

1. The average yield strengths, ultimate strengths, and modulus values obtained from 1.2" (30.5 mm) diameter lost foam cast class 30 gray iron were comparable to values obtained from the same iron cast in oil bonded sand molds.

2. The hardness of $22.4 \mathrm{~g} / \mathrm{L}\left(1.4 \mathrm{lb} / \mathrm{ft}^{3}\right)$ EPS cast gray iron was somewhat lower than hardness values obtained from bars cast in oil bonded sand molds or $24.0 \mathrm{~g} / \mathrm{L}\left(1.5 \mathrm{lb} / \mathrm{ft}^{3}\right)$ EPMMA patterns.

The following conclusions were drawn from test data obtained from tensile and fatigue bars cast made as either no-bake or LF castings and tested with the as-cast surface intact or cast as $30.5 \mathrm{~mm}(1.2$ in.) diameter LFC castings and machined to produce the desired gauge shape.

3. The tensile properties of lost foam cast, sand cast, and machined Class 30 gray iron were similar and met SAE J431 G3000 mechanical property requirements.

4. Although no-bake cast gray iron specimens showed higher fatigue strength at short lives (high strain), the basically flawed nature of the gray iron microstructure (graphite flakes) resulted in similar fatigue strength at long life (low strain). Surface finish did not appear to have a great effect.

5. The tensile properties of lost foam cast, sand cast, and machined 100-70-03 ductile iron were similar and met the requirements of ASTM A536 Grade 100-70-03 mechanical properties.

6. Fully machined lost foam cast 100-70-03 fatigue specimens exhibited better fatigue life compared to lost foam and sand cast specimens tested with as-cast surfaces.

7. The as-cast surface (Lost Foam and sand) 100-70-03 ductile iron specimens produced fatigue strengths (B50 stress amplitude) 30-40\% lower compared to machined specimens. The reduced strengths were caused by a combination of increased total indicated runout (TIR) of the as-cast specimens and rougher gauge surface finish.

8. Failures on Lost Foam as-cast 100-70-03 ductile iron fatigue specimens began at bead triple points where coating penetrated to produce a pit on the cast surface. Smoother patterns are recuired to improve the fatigue properties of as-cast parts in lost foam castings. 


\subsection{CONCLUSIONS}

The following list presents the major conclusions drawn from this work. The conclusions are listed according to each topic area in which work was done.

\subsection{Pattern Dimensional Analysis}

1. For dimensional consistency, it is imperative that consistent and reproducible foams and blowing conditions be used.

2. Variations in blowing cycle can substantially alter pattern dimensions.

3. Demolding after short cooling cycle can produce

a. O.D. growth above tool dimensions

b. I.D. growth below tool dimensions

c. Both O:D. and I.D. growth.

4. Density variations were found to be a function of the tool temperature variations.

5. It is recommended that patterns from each batch be dimensionally analyzed using a calibrated coordinate measuring machine (CMM) or air gauging system to assure dimensional consistency. Only dimensional checks will assure that repeatable dimensions are being achieved.

6. A dimensionally accurate "HARD" standard is needed for each pattern to maintain air gauge calibration.

\subsection{Pattern Coating Control}

7. The coating permeability for gas, especially air, is the primary factor controlling the rate of pattern replacement by molten metal.

8. Air and gas removal from the mold cavity must occur prior to tho time that the liquid pyrolysis products wet the coating. Wetting by the liquid pyrolysis products occurs at about $250^{\circ} \mathrm{C}\left(480^{\circ} \mathrm{F}\right)$ and closes the coating pores so that no more gas can pass through the coating.

9. Room temperature permeability measurements of coatings are reasonably good measures of permeability during pouring. The pores are open until pyrolysis products soak into and close the pores. 
10. Liquid pyrolysis products must be removed at a rate equal to their rate of generation to prevent accumulation at the metal/pattern interface.

11. The flow rate of both air from the bead pores and gaseous pyrolysis products from the foam through the coating control the metal fill rate. Incomplete casting fill is almost always caused by low fill rates. Liquid pyrolysis product absorption largely controls carbonaceous residue and lap defects in castings. These factors dominate the coating performance and must be monitored and controlled in the foundry operation.

12. A correlation was found between coating properties and causes of casting scrap in one aluminum foundry.

Excessively high gas permeability was associated with short pour times and porosity in the aluminum castings. Low permeability was associated with long pouring times and laps and misruns in the castings.

13. Careful quality control to maintain consistency in the coating resulted in a scrap reduction in one aluminum. foundry from seven percent to under one percent.

\subsection{Sand Fill and Compaction Effects}

14. The flask serves as the energy transfer medium between the compactor table to the sand. Even though the drive table may have principally a horizontal or vertical direction of motion, other vibrational modes are introduced into the sand because of flask wall movement.

15. Flasks that are vibrated principally by vertical forces have both horizontal and vertical components introduced by flask wall movement. The ratio of horizontal to vertical accelerations depends on the ratio of vertical to horizontal flask stiffness, sand density, and the amount of off-axis loading.

16. Horizontally vibrated flasks similarly develop vertical vibrational components because of off-axis loading and flask movement.

17. Horizontal vibration moves sand into cavities more quickly than vertical vibration in flasks at equivalent vibrational amplitudes with accelerators above one $G$. 
18. Certain operaticnal features are required of both vertical and horizontal compactors employing either clamped or unclamped flasks. Sand densification in the flask and pattern cavities must progress in a systematic manner beginning towarc the bottom of the flask and moving toward the top. It is generally desirable to have a 50 to $75 \mathrm{~mm}$ (2 to 3 in.) thick layer of fluidized sand at the top sand surface with dersified sand below the fluidized layer. Cavity filling should occur from within the fluidized layer. Densification occurs below the fluidized layer as sand moves downward to reduce the sand fraction.

19. Achieving the proper pattern position and orientation can provide generous rewards in compaction time savings. Since each compactor/filask/sand combination is somewhat different, acceleration maps within representative flasks should be developed.

20. Procedures have been developed to map accelerations that cause sand flow in flasks. The mapping procedure provides options for pattern placement within flasks to maximize the fill rate of pattern cavities.

21. There are two basic modes of sand vibration within flasks. The first consists of sand fluidization accompanied by the formation of a ridge or mound of sand toward the center of the flask. The mound in cylindrical flasks is produced as sand flows upward along the centerline, outward on the free surface, and downward along the flask wall. In square flasks, the mounding occurs on a line across the flask perpendicular to the direction of forced vibration.

22. A second vibrational mode is associated with extremely rigid flasks and has significantly less sand fluidization associated with it. This condition has been found in both round and square flasks at vibrational forces equal to those in flasks where total fluidization occurred. Flasks with a low stiffness produced more fluidization at a given vibrational amplitude. Flasks with high stiffness produced more rapid sand densification.

23. Filling of pattern cavities and densification of sand within the cavities must occur simultaneously to prevent sand collapse defects at the top cavity surface during pouring. Sand collapse can be minimized or avoided by filling the flask slowly to allow complete sand migration and compaction before the depth of sand above the cavity becomes too great. 
24. The discovery of: casting distortion caused by sand expansion is significant. Sand expansion not only distorts castings but is thought to be the root cause of most metal penetration defects. Alternate low expansion materials are currently being evaluated for physical and thermal properties which will yield dimensionally accurate castings.

\subsection{Metal Flow and Gating}

25. There is little or no effect of gate size on pattern or fill time. However, the gate location (top versus side versus bottom) and number of gates (particularly when streams of metal are allowed to impinge) may influence fillability, fill time, and defect formation.

26. Fill times and metal velocities have been obtained from test castings poured using a wide range of alloys, pouring temperatures, and pattern thicknesses. Statistically designed experiments showed that the coating, the type of foam, the metal pressure head, and interactions between these parameters are most significant factors influencing metal fill velocity.

27. Pattern coating properties that resulted in excessively high metal fill rates produced internal defects, or voids, which were caused by entrapped foam decomposition products.

28. For aluminum poured using a high permeability coating, a critical gate area was found that permitted the gate, rather than the foam decomposition rate or coating permeability, to act as the choke. (The coating serves as a choke to metal flow when it has a low permeability and does not allow gaseous foam decomposition products to exit the mold cavity. If the gas cannot exit, the metal cannot enter. In worst case situations, the gas will expand as it is heated and blow metal back out the sprue.) However, efforts to use the ingate as a choke were not successful. The gate could not practically be made small enough to serve as the choke because it did not provide enough support to allow the foam to be handled and coated. The critical gate size for iron, poured using a high permeability coating, approached 0.5 in ${ }^{2}$.

29. Higher pouring temperatures and higher permeability coatings permitted decomposition products to rapidly pass through the coating into the sand. High loss on ignition values were found in low permeability coatings. 
30. Some information was obtained on the "kinetic zone" at the metal-foam interjace. The gap where the foam softens, melts, and decomposes is relatively independent of aluminum pouring temperature but is somewhat larger when low permeability coatings are used. The gap appears to be much larger for cast iron.

\subsection{Mechanical Properties of Castinas}

31. The average yield strengths, ultimate strengths, and modulus values obtained from 1.2" (30.5 mm) diameter Lost foam casting Class 30 gray iron were comparable to values obtained from the same iron cast in oil bonded sand molds.

32. The hardness of gray iron castings made using $22.5 \mathrm{~g} / 1$ ( 1.4 lb/ft ${ }^{3}$ ) expanded polystyrene patterns was somewhat lower than hardness values obtained from bars cast in oil bonded sand molds or obtained using $24.0 \mathrm{~g} / 1$ (1.5 lb/ft $\mathrm{f}^{3}$ ) EPMMA patterns.

33. The tensile properties of lost foam cast, sand cast, and machined Class 30 gray iron were similar and met SAE J431 G3000 mechanical property requirements.

34. Although gray iron specimens cast in no-bake molds showed a higher fatigue strength when evaluated under high strain conditions, the basically flawed nature of the gray iron microstructure caused by graphite flakes resulted in similar fatigue strengths when evaluated under low strain conditions. Surface finish did not appear to have a substantial effect.

35. The tensile properties of lost foam cast, sand cast, and machined 100-70-03 ductile iron were similar and met the requirements of ASTM A536 Grade 100-70-03 mechanical properties.

36. Fully machined lost foam cast 100-70-03 fatigue specimens exhibited better fatigue life compared to lost foam and sand cast specimens tested with as-cast surfaces.

37. Eailures on as-cast lost foam 100-70-03 ductile iron fatigue specimens began at bead triple points where coating penetrated to produce a pit on the cast surface. Smoother patterns are required to improve the fatigue properties of as-cast parts in lost foam castings. 


\subsection{FUTURE RESEARCH}

Future research will deal with optimizing mold compaction theory and practice. Much work has been done on developing and testing instruments for measuring insitu sand densification and pattern distortion and these techniques and instruments will be used to solve production floor problems in the next phase of work.

In addition, research will be extended to the production of bronze and steel castings. Coatings must be optimized and desirable properties determined for pouring bronze and steel castings.

The primary problem with producing steel castings using the lost foam process is carburization during pouring. Efforts will be made to minimize carburization with the use of a new foam material and with the application of a high vacuum to the mold during pouring.

Efforts will also be initiated to learn how to model metal flow into lost foam cavities. The lack of a suitable model still requires considerable time to test and regate castings in order to get them into production. A mathematical model of metal flow, fill, and solidification has been devised and experiments will be conducted to verify the fill and solidification models and study process interactions such as part thickness, geometry and type of coating on the fill process. 
8.0 REFERENCES

1. Barrentine, Larry $B$. Concepts for $R \& R$ Studies. Milwaukee: ASQC Quality Press, 1991, pp. xi-48.

2. Einal Report to the American Foundrymen's Society, Inc. Expendable Pattern Casting Research. Volume 2, Table 12.21, page 12.105 .

3. Final Report to the American Foundrymen's Society, Inc. Expendable Pattern Casting Research. Volume 2, page 12.121.

4. Final Report to the American Foundrymen's Society, Inc. Expendable Pattern Casting Research. Volume 2, page 12.121-184.

5. Monroe, Raymond $W$. Expendable Pattern Casting. Chicago: American Eoundrymen's Society, 1992. 